\title{
Review
}

Mehri Ghasemi, Mengmeng Hao, Mu Xiao, Peng Chen, Dongxu He, Yurou Zhang, Weijian Chen, Jiandong Fan, Jung H. Yun*, Baohua Jia* and Xiaoming Wen*

\section{Lead-free metal-halide double perovskites: from optoelectronic properties to applications}

https://doi.org/10.1515/nanoph-2020-0548

Received September 28, 2020; accepted November 30, 2020; published online December 16, 2020

\begin{abstract}
Lead $(\mathrm{Pb})$ halide perovskites have witnessed highly promising achievements for high-efficiency solar cells, light-emitting diodes (LEDs), and photo/radiation detectors due to their exceptional optoelectronic properties. However, compound stability and $\mathrm{Pb}$ toxicity are still two main obstacles towards the commercialization of halide perovskite-based devices. Therefore, it is of substantial interest to search for non-toxic candidates with comparable photophysical characteristics. Metal-halide double perovskites (MHDPs), $\mathrm{A}_{2} \mathrm{BB}^{\prime} \mathrm{X}_{6}$, are recently booming as promising alternatives for $\mathrm{Pb}$-based halide-perovskites for their non-toxicity and significantly enhanced chemical and thermodynamic stability. Moreover, this family exhibits rich combinatorial chemistry with tuneable optoelectronic properties and thus a great potential for a broad range of
\end{abstract}

\footnotetext{
*Corresponding authors: Jung H. Yun, Nanomaterials Centre, School of Chemical Engineering and Australian Institute for Bioengineering and Nanotechnology, The University of Queensland, St. Lucia, QLD, 4072, Australia, E-mail: j.yun1@uq.edu.au; Baohua Jia and Xiaoming Wen, Centre for Translational Atomaterials, Swinburne University of Technology, Hawthorn, VIC, 3122, Australia, E-mail: bjia@swin.edu.au (B. Jia), xwen@swin.edu.au (X. Wen). https://orcid.org/0000-00026703-477X (B. Jia), https://orcid.org/0000-0001-8298-483X (X. Wen) Mehri Ghasemi, Centre for Translational Atomaterials, Swinburne University of Technology, Hawthorn, VIC, 3122, Australia; and Nanomaterials Centre, School of Chemical Engineering and Australian Institute for Bioengineering and Nanotechnology, The University of Queensland, St. Lucia, QLD, 4072, Australia

Mengmeng Hao, Mu Xiao, Peng Chen, Dongxu He and Yurou Zhang, Nanomaterials Centre, School of Chemical Engineering and Australian Institute for Bioengineering and Nanotechnology, The University of Queensland, St. Lucia, QLD, 4072, Australia

Weijian Chen, Centre for Translational Atomaterials, Swinburne University of Technology, Hawthorn, VIC, 3122, Australia. https:// orcid.org/0000-0001-8394-2391

Jiandong Fan, Department of Electronic Engineering, Institute of New Energy Technology, College of Information Science and Technology, Jinan University, Guangzhou, 510632, China
}

optoelectronic/electronic applications. Herein, we present a comprehensive review of the MHDPs synthesized so far, and classified by their optical and electronic properties. We systematically generalize their electronic structure by both theoretical and experimental efforts to prospect the relevant optoelectronic properties required by different applications. The progress of the materials in various applications is explicated in view of the material structure-function relationship. Finally, a perspective outlook to improve the physical and optoelectronic properties of the materials is proposed aiming at fostering their future development and applications.

Keywords: lead-free; metal-halide double perovskites; optoelectronic properties; photovoltaics; stability.

\section{Introduction}

Organic-inorganic halide perovskite solar cells have witnessed remarkable progress in the past few years with a rapid surge in the power conversion efficiency (PCE) from $3.8 \%$ in 2009 to $25.2 \%$ in 2019 [1-5]. Pb-based halide perovskites with a generic formula of $\mathrm{ABX}_{3}$ exhibit great potential to pilot the next generation of photovoltaic technologies by approaching the record PCE for the highefficiency silicon solar cells. This potential is attributed to some striking features of this class of materials, including narrow direct bandgap, long carrier diffusion length, high absorption coefficient, small and balanced electron and hole effective masses, small exciton binding energy and high carrier mobility [6-10]. Besides photovoltaics, organic-inorganic halide perovskites have extended their application into other fields, such as light-emitting diodes (LEDs) [11-14], X-ray detectors [15], photodetectors [16, 17], lasers [18] and batteries [19]. Despite this extraordinary potential and rocketing PCE improvement, these emerging technologies still face some barriers regarding insufficient stability against the operational conditions (heat, illumination and moisture) and toxic $\mathrm{Pb}$ inclusion in the light-absorbing layer [20]. 
To improve the stability, some strategies have been adopted by regulating the crystal structure of the materials to enhance phase stability [3], defect passivation to suppress penetrating paths from the environment [21, 22], finding stable inorganic transporting layers [23], modulating dimensionality (D) of the halide perovskite absorbing layer from three-dimension (3D) to two-dimension (2D) [24, 25], and developing sophisticated encapsulation methods $[26,27]$. On the other hand, toxicity is another challenge to be overcome, because $\mathrm{Pb}$ causes serious health concerns as a carcinogen [28]. Accordingly, significant efforts have been devoted to designing other $\mathrm{Pb}$-free stable halide perovskites for different optoelectronic applications [29-31]. This demand has agitated substantial research efforts to explore potential elements of heavy $s$ - and $p$-blocks (e.g. Sn, Ge, Bi and $\mathrm{Sb}$ ) to fill the "B" position in the $\mathrm{ABX}_{3}$ structure [32-38]. $\mathrm{Sn}$ and Ge were considered to be suitable substitutions of $\mathrm{Pb}$. However, high-energy-lying $5 s$ orbitals of these elements cause a high tendency of cation oxidation into $\mathrm{Sn}^{4+}$ and $\mathrm{Ge}^{4+}$ states [30, 31]. $\mathrm{Bi}^{3+}$ and $\mathrm{Sb}^{3+}$ with the same isoelectronic structure as $\mathrm{Pb}^{2+}$ have been inserted into the lattice, which lead to low-dimensional structures (OD, 1D, 2D) with the basic formula of $\mathrm{A}_{3} \mathrm{~B}_{2} \mathrm{X}_{9}$ [37-41]. In this category, facesharing bioctahedral $\left[\mathrm{Bi}_{2} \mathrm{I}_{9}\right]^{3-}$ clusters are isolated by monovalent cations in the "A" position. This crystal structure leads to less impressive optical and electronic characteristics [22, 42], because the low dimensionality of Bi-based halide perovskite derivatives restricts efficient charge transport in the active layer, resulting in carrier localization in the isolated $\left[\mathrm{Bi}_{2} \mathrm{I}_{9}\right]^{3-}$ clusters [43-46]. Therefore, it is highly desirable to find metal-halide perovskites that can approximate the properties of the extensively studied $\mathrm{MAPbX}_{3}\left(\mathrm{MA}=\mathrm{CH}_{3} \mathrm{NH}_{3}\right)$ perovskites by using a non-toxic metal cation. Given the simple combinatory of ions charge in a perovskite structure of $\mathrm{A}^{+} \mathrm{B}^{2+} \mathrm{X}_{3}$, a limited number of nontoxic and stable elements with the electron configuration of $d^{10} s^{2}$ or $d^{10} s^{0}$ can be contemplated for the "B" position. This situation can be overcome if we extend the exploration from ternary $\mathrm{A}^{+} \mathrm{B}^{2+} \mathrm{X}_{3}$ perovskites to quaternary compositions.

$\mathrm{A}_{2} \mathrm{BB}^{\prime} \mathrm{X}_{6}$ double perovskites have been proposed as promising and stable substitutions for $\mathrm{Pb}$-based halide perovskites, in which a vast number of $1^{+}$and $3^{+}$metal cations with appropriate electron configurations (e.g. $\mathrm{Bi}^{3+}, \mathrm{Sb}^{3+}$, $\mathrm{In}^{3+}, \mathrm{Cu}^{+}$and $\mathrm{Ag}^{+}$) can be accommodated in their lattice [47-50]. In fact, their oxide counterparts $\left(\mathrm{A}_{2} \mathrm{BB}^{\prime} \mathrm{O}_{6}\right)$ have been intensively investigated previously with abundant material properties including ferromagnetic, ferroelectric, colossal magnetoresistance and multiferroic characteristics, and their application as scintillators in radiation detectors was also reported [51-53]. Additionally, there are some reports on the exploration of double perovskites to tune the bandgap of oxide perovskites [54, 55]. Recently, $\mathrm{Cs}_{2} \mathrm{AgBiBr}_{6}$ has been proposed as a promising all-inorganic alternative for Pb-based perovskites, due to its remarkable stability [56], long carrier recombination lifetimes [48] and low carrier effective masses [50]. Early work has demonstrated a promising photovoltaic performance by incorporation of $\mathrm{Cs}_{2} \mathrm{AgBiBr}_{6}$ for solar cell application [57-62]. Although the maximum PCE reported so far for MHDPs is still far inferior to that of $\mathrm{Pb}$ halide perovskites [57-61], they have exhibited unique properties that extend their potential to other applications, such as sensors [63], photodetectors [64], radiation detectors $[65,66]$ and photocatalysis $[67,68]$ with encouraging initial results. However, concerning commercialization of these technologies using $\mathrm{Pb}$ halide perovskites is still on the way. In recent years, a few reviews have been published mainly focusing on the synthesis and crystal structure of MHDPs [69-72]. Relatively, an important aspect, the optoelectronic properties and the applications of these materials have rarely reviewed. Inspired by the extensive attention to these materials, we systematically review the electronic structures and photophysical properties of MHDPs in the electronic structure viewpoint of their bandgaps in this work. Following these sections, we discuss layer-structured MHDPs. Then we provide a perspective on the applications of materials through recognizing the required optoelectronic properties. Understanding the band structure of the materials is of paramount importance due to its intensive influence on the ultimate electronic structure, structural anti-site disorder, magnetic and electric properties [73, 74]. Therefore, identifying these aspects is essential to design new compounds with desired properties.

\section{Indirect bandgap MHDPs}

In addition to their intrinsically high stability, some optoelectronic properties of MHDPs such as carrier mobility and band structure extensively determine their potential applications with achievable performance. In $\mathrm{Pb}$-based halide perovskites $\left(\mathrm{APbX}_{3}\right.$ where "A" $=\mathrm{MA}^{+}, \mathrm{FA}^{+}=\mathrm{CH}\left(\mathrm{NH}_{2}\right)_{2}{ }^{+}$or $\mathrm{Cs}^{+}$; " $\mathrm{X}$ " $=\mathrm{I}^{-}, \mathrm{Br}^{-}$or $\mathrm{Cl}^{-}$) the valence band and conduction band are principally contributed by $\mathrm{X}-5 p$ and $\mathrm{Pb}-6 p$ orbitals that stimulate the direct bandgap nature of these materials. Besides, the band structures can be moderately modified since the size of " $A$ "-cation affects the halide frame tolerance against distortion/tilting [75]. A typical crystal structure of double perovskites with the afore-mentioned formula of $\mathrm{A}_{2} \mathrm{BB}^{\prime} \mathrm{X}_{6}$ contains corner-sharing octahedral where " $\mathrm{A}$ " cation is in the middle of the cuboctahedral cavity, similar to their $\mathrm{MAPbX}_{3}$ analogues [49]. The difference is that in 
double perovskites the centres of the octahedra are alternatively occupied by either monovalent $\left(\mathrm{B}^{+}\right)$or trivalent $\left(\mathrm{B}^{\prime 3+}\right)$ metal cations leading to a rock-salt configuration. To date, high-throughput computational investigations have explored the electronic properties of these compounds for optoelectronic application, while there are just a few reports on successful synthesis of MHDPs [50, 76].

\section{1 $\mathrm{A}_{2} \mathrm{BBiX}_{6}\left(\mathrm{~A}=\mathrm{MA}^{+}, \mathrm{Cs}^{+} ; \mathrm{B}=\mathrm{Ag}^{+}, \mathrm{K}^{+}\right.$; $\mathrm{X}=\mathrm{Cl}^{-}, \mathrm{Br}^{-}$and $\left.\mathrm{I}^{-}\right)$}

\subsection{1 $\mathrm{Cs}_{2} \mathrm{AgBiX}_{6}\left(\mathrm{X}=\mathrm{I}^{-}, \mathrm{Br}^{-}\right.$and $\left.\mathrm{Cl}^{-}\right)$}

In $\mathrm{Pb}$-based halide perovskites, the bandgap transition is associated with a ligand-to-metal charge transfer between the predominant halide $p$-orbitals at the valence band maximum (VBM) and $\mathrm{Pb} p$-orbitals at the conduction band minimum (CBM) [77]. Typical electronic configuration of $\mathrm{Pb}^{2+}\left(6 s^{2} 6 p^{0}\right)$ allows the contribution of filled $6 s$ orbitals alongside the halide $5 p$ orbitals into the valence band, while the conduction band is formed by the unoccupied $\mathrm{Pb}-6 p$ orbitals. This orbital contribution leads to a direct bandgap for this class of materials. Diverse theoretical and experimental studies have identified this specific composition of VBM and CBM as the main origin of some particular characteristics of $\mathrm{Pb}$-based perovskites such as long carrier lifetime and shallow defect states [78-80]. Besides, the rich $p$-orbital-based density of states in the vicinity of the band edges induces strong absorption of the material [80]. Given this, just three main groups of elements of $\mathrm{Tl}^{+}$, $\mathrm{Pb}^{2+}$ and $\mathrm{Bi}^{3+}$ show stable cations with an electronic configuration of $6 s^{2} 6 p^{0}$, among which only $\mathrm{Bi}^{3+}$ is rated as a low toxic element. In fact, for decades, $B$ has been applied as the nontoxic substitution for toxic $\mathrm{Pb}$ in different fields from organic synthesis to supply arms and ammunition [81]. Coordination anthologies of $\mathrm{Bi}$ are also frequently used in over-the-counter medications (e.g. Pepto-Bismol) [82]. In 2016, different research groups reported the first investigations of optical and structural properties of MHDPs by synthesizing $\mathrm{Cs}_{2} \mathrm{AgBiX}_{6}(\mathrm{X}=\mathrm{Br}, \mathrm{Cl})$ powder [47-50]. The compounds crystallized in a 3D elpasolite $\mathrm{K}_{2} \mathrm{NaAlF}_{6}$ architecture via either conventional solid-state reaction or solution-processing methods. The UV-Vis diffuse reflectance spectra of the samples showed striking similarities to those $\mathrm{Pb}$-based analogues (Figure $1 \mathrm{a}$ and $\mathrm{b}$ ). However, it was observed that the onset of the absorption spectrum is not as sharp as those for $\mathrm{Pb}$-based perovskites, which was attributed to the indirect nature of the materials' bandgap [49]. By transferring the reflectance data to the pseudo-absorption data using Kubelka-Munk equation
(Equation 1), the absorbance is defined as a function of reflectance [49].

$$
F(R)=\alpha=(1-R)^{2} / 2 R
$$

where $\alpha$ is the optical absorption coefficient and $R$ is the reflectance. Then applying the Tauc method on the transformed data, utilizing the equation of $[F(R) h v]^{1 / \gamma}$ versus $h v$ with $y=1 / 2$ for indirect transitions and $y=2$ for direct transitions (Figure 1c and d), the bandgap of the materials was determined. Adopting this approach indirect bandgaps of 2.77 and $2.19 \mathrm{eV}$ were calculated for $\mathrm{Cs}_{2} \mathrm{AgBiCl}_{6}$ and $\mathrm{Cs}_{2} \mathrm{AgBiBr}_{6}$, respectively. With the same strategy, Slavney et al. [48] measured the bandgap of the $\mathrm{Cs}_{2} \mathrm{AgBiBr}_{6}$ powder (Figure 1e). Regarding the indirect nature of the bandgap, the linear region of the plot was assumed as the expected photon-assisted transitions, in which a phonon is absorbed in $1.83 \mathrm{eV}$ and emitted at $2.07 \mathrm{eV}$ (Figure 1e, inset) [48]. Therefore, indirect bandgap energy of $1.95 \mathrm{eV}$ was estimated for the $\mathrm{Cs}_{2} \mathrm{AgBiBr}_{6}$ compound with assisting phonon energy of $0.12 \mathrm{eV}$.

At room temperature, $\mathrm{Cs}_{2} \mathrm{AgBiBr}_{6}$ displayed a weak photoluminescence (PL) peak at $1.87 \mathrm{eV}$ (Figure 1f) with a blue-shift to $1.98 \mathrm{eV}$ at a low temperature of $23 \mathrm{~K}$ (Figure 1f, inset) [48]. Time-resolved PL (TRPL) measurement could determine the dynamics of photogenerated carriers (Figure 1g) [48]. From TRPL curves, an initial fast drop accompanied by a slower decay was observed for $\mathrm{Cs}_{2} \mathrm{Ag}$ $\mathrm{BiBr}_{6}$. The PL decay trace could be well fitted by threeexponential functions, which suggested its three dynamic processes: $T_{1}$ as the short-lifetime process ( $\left.T_{1}<1 \mathrm{~ns}\right), T_{2}$ as the intermediate-lifetime ( $\left.T_{2}=50-150 \mathrm{~ns}\right)$ and $T_{3}$ as the long-lived part ( $\left.T_{3} \sim 660 \mathrm{~ns}\right)$. Full fitting parameters for single-crystal and powder samples are listed in Table 1 that shows the short and intermediate lifetimes of the powder are much shorter than those of single-crystals. Owing to much more surface states in powder, the short- and intermediate-lifetime components should be related to the surface-state emission. On the other hand, no significant difference of long PL decay time between the singlecrystals and powders could be recognized (ca. $660 \mathrm{~ns}$ ), which indicated this component may originate from the fundamental recombination of $\mathrm{Cs}_{2} \mathrm{AgBiBr}_{6}$.

Further investigation was also conducted to determine the materials' electronic structure by calculating their band structure (Figure 1i-1) [48, 49]. Regardless of many similarities between the band structure of $\mathrm{Cs}_{2} \mathrm{AgBiX}_{6}(\mathrm{X}=\mathrm{Br}$ and $\mathrm{Cl})$ double perovskites and $\mathrm{Pb}$-halide perovskites, there is a significant difference that confirms the indirect bandgap of $\mathrm{Cs}_{2} \mathrm{AgBiX}_{6}(\mathrm{X}=\mathrm{Br}$ and $\mathrm{Cl})$ double perovskites. This conclusion comes from the fact that in double perovskite compounds, the VBM shifts from $R$-point of the Brillouin zone in 
(a)

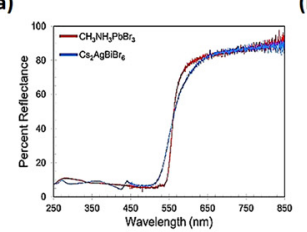

(f)

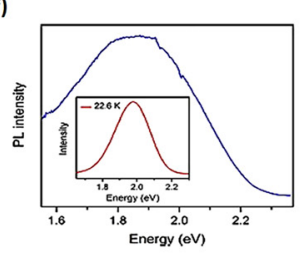

(b)

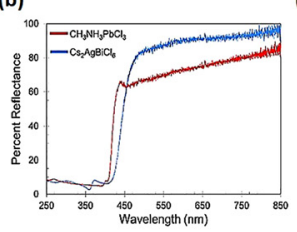

(c)

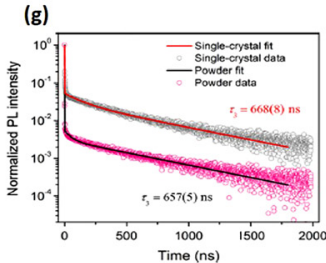

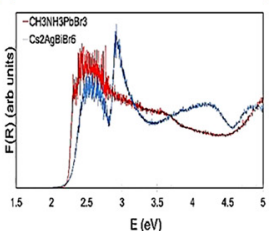

(d)

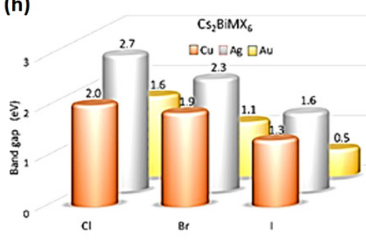

(e)

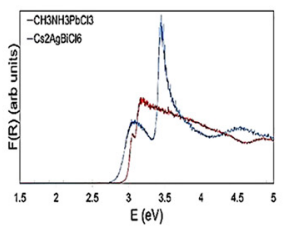

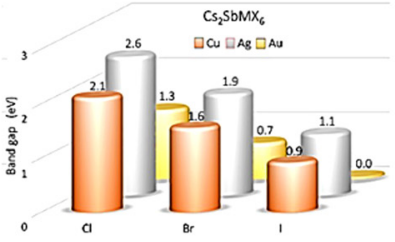

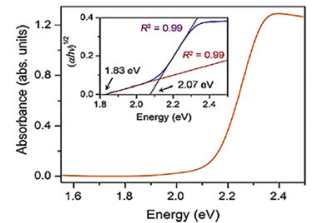

(i)

$\mathrm{Cs}_{2} \mathrm{AgBiBr}_{6} \quad$ (j) $\mathrm{Cs}_{2} \mathrm{AgBiCl}_{6}$

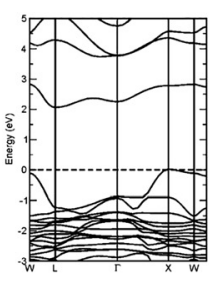

(k) $\quad \mathrm{CsPbBr}_{3}$

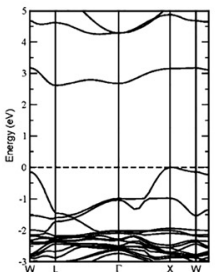

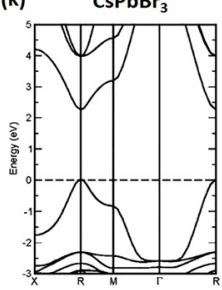

(I) $\mathrm{CsPbCl}_{3}$

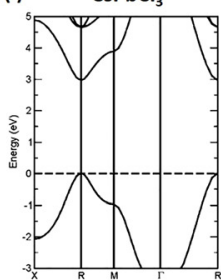

(m)

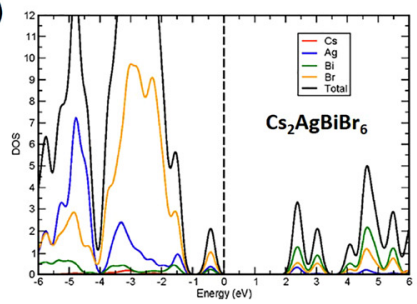

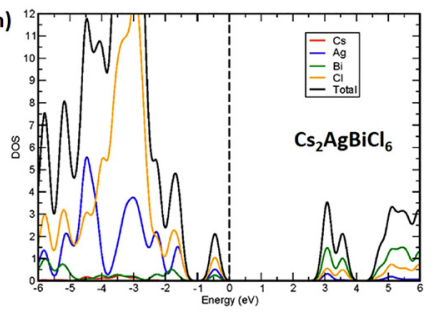

(q)

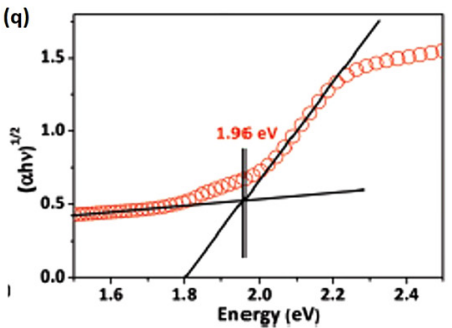

(o) $\quad \mathrm{Cs}_{2} \mathrm{AgBiCl}_{6} \quad \mathrm{Cs}_{2} \mathrm{AgBiBr}_{6}$
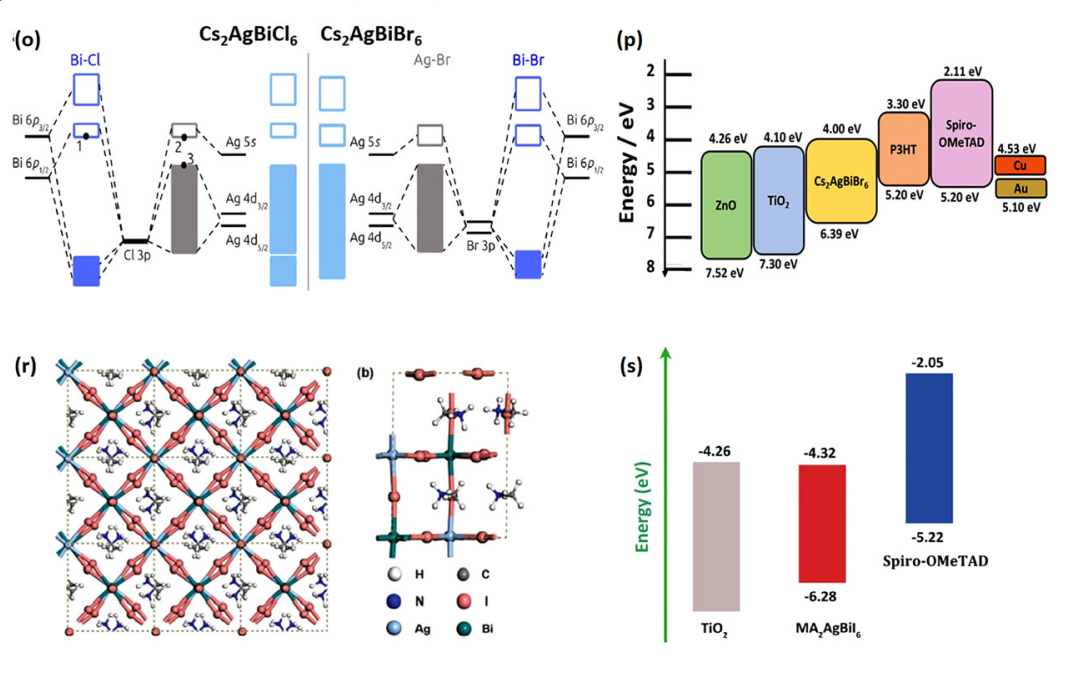

Figure 1: Diffuse reflectance spectra for (a) $\mathrm{Cs}_{2} \mathrm{AgBiBr}_{6}$ (blue) and $\mathrm{CH}_{3} \mathrm{NH}_{3} \mathrm{PbBr}_{3}$ (red) and (b) $\mathrm{Cs}_{2} \mathrm{AgBiCl}_{6}$ (blue) and $\mathrm{CH}_{3} \mathrm{NH}_{3} \mathrm{PbCl}_{3}$ (red) [49]. Copyright 2016, American Chemical Society. Kubleka-Munk plots for (c) $\mathrm{Cs}_{2} \mathrm{AgBiBr}_{6}$ (blue) and $\mathrm{CH}_{3} \mathrm{NH}_{3} \mathrm{PbBr}_{3}$ (red) and (d) $\mathrm{Cs}_{2} \mathrm{AgBiCl}_{6}$ (blue) and $\mathrm{CH}_{3} \mathrm{NH}_{3} \mathrm{PbCl}_{3}$ (red) [49]. Copyright 2016, American Chemical Society. (e) Absorbance spectrum of $\mathrm{Cs}_{2} \mathrm{AgBiBr}_{6}$ powder. Inset: Tauc plot of $\mathrm{Cs}_{2} \mathrm{AgBiBr}_{6}$ [48]. Copyright 2016, American Chemical Society. (f) Photoluminescence (PL) spectrum of $\mathrm{Cs}_{2} \mathrm{AgBiBr}_{6}$ powder. Inset: lowtemperature PL spectrum [48]. Copyright 2016, American Chemical Society. (g) Time-resolved room-temperature PL (TRPL) of $C s_{2} A g B i B r_{6}$ powder and single-crystals [48]. Copyright 2016, American Chemical Society. (h) Calculated electronic bandgaps for all compounds in the halide double perovskite family with ' $\mathrm{B}^{\prime 3+}$, sites of $\mathrm{Bi}^{3+}$ and $\mathrm{Sb}^{3+}[50]$. Copyright 2016, American Chemical Society. Band structure diagrams for (i) $\mathrm{Cs}_{2} \mathrm{AgBiBr}_{6}$, (j) $\mathrm{Cs}_{2} \mathrm{AgBiCl}_{6}$, (k) cubic $\mathrm{CsPbBr}_{3}$ and (l) cubic $\mathrm{CsPbCl}_{3}$ [49]. Copyright 2016, American Chemical Society. Atomic partial density of states (PDOS) plots for (m) $\mathrm{Cs}_{2} \mathrm{AgBiBr}_{6}$ and (n) $\mathrm{Cs}_{2} \mathrm{AgBiCl}_{6}$ [49]. Copyright 2016, American Chemical Society. (o) Comparison of the molecular orbital diagrams of $\mathrm{Cs}_{2} \mathrm{AgBiCl}_{6}$ (left) and $\mathrm{Cs}_{2} \mathrm{AgBiBr}_{6}$ (right) [47]. Copyright 2016, American Chemical Society. (p) Energy band levels of $\mathrm{Cs}_{2} \mathrm{AgBiBr}_{6}$ relative to other hole-/electron-transporting layers [62]. 2020 Wiley-VCH GmbH. (q) Kubleka-Munk plot for $\mathrm{MA}_{2} \mathrm{AgBi}_{6}$ [86]. Copyright 2015, Royal Society of Chemistry. (r) The optimized structure of $\mathrm{MA}_{2} \mathrm{AgBil}_{6}$ [86]. (s) Band energy diagram of $\mathrm{MA}_{2} \mathrm{AgBil} 6$ [86]. Copyright 2015, Royal Society of Chemistry.

a primitive cubic cell to $X$-point, while the CBM locates at $L$-point of the Brillouin zone [49, 83]. From the curvature of the bands, an estimation of the compounds' effective charge carrier masses was determined. This approach showed the effective masses of electron and hole were $0.53 \mathrm{~m}_{e}$ and $0.15 \mathrm{~m}_{e}$, respectively, for $\mathrm{Cs}_{2} \mathrm{AgBiCl}_{6}$, while the corresponding magnitudes for $\mathrm{Cs}_{2} \mathrm{AgBiBr}_{6}$ were $0.37 \mathrm{~m}_{e}$ and $0.14 \mathrm{~m}_{e}[49]$. This highlights smaller hole effective masses for 
Table 1: Full fit of the TRPL data for $\mathrm{Cs}_{2} \mathrm{AgBiBr}_{6}$ single-crystal and powder samples [48].

\begin{tabular}{lrrr}
\hline Compound & $T_{\mathbf{1}}$ (ns) & $T_{\mathbf{2}}$ (ns) & \multicolumn{1}{c}{$\boldsymbol{T}_{\mathbf{3}}$ (ns) } \\
\hline $\mathrm{Cs}_{2} \mathrm{AgBiBr}_{6}$ single-crystals & 0.54 & 145 & 668 \\
$\mathrm{CS}_{2} \mathrm{AgBiBr}_{6}$ powders & 0.204 & 54 & 657 \\
\hline
\end{tabular}

double perovskite compounds than those of $\mathrm{Pb}$-halide perovskites [50].

Partial density of state (PDOS) measurement showed a valence to conduction band transition in $\mathrm{Cs}_{2} \mathrm{AgBiX}_{6}(\mathrm{X}=\mathrm{Br}$ and $\mathrm{Cl}$ ) double perovskites from the filled $3 p / 4 p$ orbitals of halogens to $\mathrm{Bi}-6 p$ and $\mathrm{Ag}-5 s$ states (Figure $1 \mathrm{~m}$ and $\mathrm{n}$ ). Relatively flat bands due to extensive presence of Ag- $4 d$ orbitals in the valence band should be partially responsible for the indirect bandgap characteristic in these compounds [49]. Figure 10 illustrates the changes of electronic structure for different halogen atoms in which by moving from $\mathrm{Cl}$ to $\mathrm{Br}$, a reduction in the valence bandwidth and a slight rise in the VBM are observed. This ignites the bandgap shrinkage for the case of $\mathrm{Br}$ halogen, because the energy difference between the $\mathrm{Ag}-4 d$ and $\mathrm{Br}-4 p$ levels is smaller than that of Ag- $4 d$ and $\mathrm{Cl}-3 p$ states. Br- $4 p$ orbitals with higher energy cause a shift towards higher energy levels. Similarly, Volonakis et al. performed density functional theory (DFT) calculations on a range of MHDPs whose " $\mathrm{B}^{+ \text {", }}$ and " $\mathrm{B}^{\prime 3+}$ " sites are occupied by metal cations of $\mathrm{Cu}^{+}, \mathrm{Ag}^{+}$ and $\mathrm{Au}^{+}$and pnictogen cations of $\mathrm{Bi}^{3+}$ and $\mathrm{Sb}^{3+}$, respectively [50]. They discussed that by moving down the halogens in the periodic table column, a reduction in the bandgap value of the investigated double perovskite structures appeared [50]. Additionally, the investigation of the monovalent and trivalent metal cations at " $\mathrm{B}$ "” and " $\mathrm{B}^{\prime 3+}$ " sites showed that the bandgap magnitude was affected by the size of " $\mathrm{B}^{\prime 3+}$ " cation, while no monotonic shift concerning the size of the " $\mathrm{B}$ " " noble-metal cation could be seen (Figure $1 \mathrm{~h}$ ). This behaviour was contributed to the energy of the pnictogen- $p$ orbitals $\left(\mathrm{B}^{\prime 3+}=\mathrm{Bi}^{3+}, \mathrm{Sb}^{3+}\right)$, which decreased by increasing the atomic number in the periodic table column, hence lowering the energy of the CBM. The energy band alignments of the $\mathrm{Cs}_{2} \mathrm{AgBiBr}_{6}$ double perovskite thin-film indicated a valence band and conduction band levels of 6.39 and $4.00 \mathrm{eV}$, respectively, which are rather well-positioned relative to other frequently used hole- and electron-transporting layers in the solar cell application (Figure 1p) [62].

Although successful synthesis of $\mathrm{Cs}_{2} \mathrm{AgBiBr}_{6}$ through different approaches of solution processes and solid-state reaction, the iodide-based compound of $\mathrm{Cs}_{2} \mathrm{AgBiI}_{6}$ can be hardly form through these commonly used protocols. This barrier has been assigned to the negative decomposition enthalpy of this composition $\left(-47 \mathrm{meV}\right.$ atom $\left.^{-1}\right)$ through the following reaction of $\mathrm{Cs}_{2} \mathrm{AgBiI}_{6} \rightarrow 1 / 2 \mathrm{CsAg}_{2} \mathrm{I}_{3}+1 / 2 \mathrm{Cs}_{3} \mathrm{Bi}_{2} \mathrm{I}_{9}$ [84]. Nevertheless, Creutz et al. [85] reported the synthesis of colloidal nanocrystals of $\mathrm{Cs}_{2} \mathrm{AgBiI}_{6}$ by post-synthetic modification of $\mathrm{Cs}_{2} \mathrm{AgBiBr}_{6}$ nanocrystals through a novel anion-exchange method. A strong absorption over the visible region with an indirect bandgap of $1.75 \mathrm{eV}$ was obtained for the $\mathrm{Cs}_{2} \mathrm{AgBiI}_{6}$ product. Despite this achievement, the intrinsic thermodynamic instability of $\mathrm{Cs}_{2} \mathrm{AgBiI}_{6}$ is still a problem that causes the decomposition of the single-crystals after several days of storing in ambient conditions.

Combining theoretical and experimental studies, the synthesis of $\mathrm{MA}_{2} \mathrm{AgBiI}_{6}$ perovskite single-crystals also has been reported, however, with a larger bandgap of $1.96 \mathrm{eV}$ than that predicted one by calculations $(1.63 \mathrm{eV})$ (Figure 1q). Likewise, this compound showed indirect bandgap characteristics with an outstanding air stability of four-months storage in ambient condition and no trace of material decomposition, whereas the crystal structure was found to be in the orthorhombic crystal system (Figure 1r) [86]. The results show that $\mathrm{MA}_{2} \mathrm{AgBiI}_{6}$ is a suitable candidate for tandem solar cells. The band dispersion around the conduction band and valence band leads to an imbalanced electron effective mass and hole effective mass of $0.47 \mathrm{~m}_{e}$ and $0.70 m_{e}\left(m_{e}\right.$ is the electron static mass) calculated for the material, which indicates better electron-transport efficiency than holes. However, the energy band diagram implies that electron transfer from the $\mathrm{MA}_{2} \mathrm{AgBiI}_{6}$ perovskite well-known electron-collecting layers should be problematic and in some cases inhibited (Figure 1s). This emphasizes more the importance of the band-alignment engineering of the constituent layers to fully realize the potential of the material for photovoltaics.

\subsection{2 $\mathrm{MA}_{2} \mathrm{KBiCl}_{6}$}

Due to different optical properties of hybrid perovskites plus their feasible implementation into devices of a specific function [87], Wei et al. [88] investigated the formation of hybrid MHDPs. It was found that $\mathrm{MA}_{2} \mathrm{KBiCl}_{6}$ crystallizes in rhombohedral $R \overline{3} m$ symmetry to form a 3D network of alternatingly corner-sharing $\left(\mathrm{KCl}_{6}\right)^{5-}$ and $\left(\mathrm{BiCl}_{6}\right)^{3-}$ octahedra (Figure $2 \mathrm{a}-\mathrm{C}$ ). In this structure, organic cation of $\mathrm{MA}^{+}$occupied the cavity between the octahedra (Figure 2c) with a distortion into the lattice due to the different ionic radii of $\mathrm{K}^{+}\left(1.38 \mathrm{~A}^{\circ}\right)$ and $\mathrm{Bi}^{3+}\left(1.03 \mathrm{~A}^{\circ}\right)$. UV-Vis spectrometry measured the optical bandgap of $\mathrm{MA}_{2} \mathrm{KBiCl}_{6}$ with indirect semiconductor characteristics (Figure 2d). From the corresponding Tauc plot, two 
different values of 3.04 and $3.37 \mathrm{eV}$ were extracted for the apparent bandgaps of $\mathrm{MA}_{2} \mathrm{KBiCl}_{6}$ (Figure 2e). DFT calculations helped to interpret the band structure of the material (Figure $2 \mathrm{f}-\mathrm{g}$ ) that predicted indirect and direct bandgaps of 3.02 and $3.15 \mathrm{eV}$, respectively. The VBM and CBM band edges were found at $L$ - and $A$-points of the Brillouin zone that indicated the indirect characteristics of the bandgap of the material. PDOS measurements revealed VBM mainly composed of $\mathrm{Bi}-6 \mathrm{~s}$ and $\mathrm{Cl}-3 p$ antibonding states, while in CBM the main contribution came from the $\mathrm{Bi}-6 p, \mathrm{Cl}-3 p$ antibonding states with a small portion for $\mathrm{Cl}-3 \mathrm{~s}$ states (Figure $2 \mathrm{~h}$ ). Organic cation of $\mathrm{MA}^{+}$did not present in the states near VBM or CBM, previously seen in $\mathrm{MAPbI}_{3}$ [89]. Additionally, due to low-lying energy states of $\mathrm{K}^{+}$, the $\mathrm{K}-3 p$ states position at $\sim 13 \mathrm{eV}$ below the VBM, therefore, no trace of $\mathrm{K}^{+}$contribution in the material's VBM and CBM could be seen. This is totally different from the case of $\mathrm{Cs}_{2} \mathrm{AgBiBr}_{6}$ where $\mathrm{Ag}^{+}$indicated a clear contribution in the states near the VBM of the material.

\subsection{3 $\mathrm{MA}_{2} \mathrm{AgBiBr}_{6}$}

Wei et al. expanded the efforts to search for hybrid MHDPs by synthesizing a new environmentally friendly hybrid double perovskite of $\mathrm{MA}_{2} \mathrm{AgBiBr}_{6}$ [90]. Similar to its allinorganic analogue $\left(\mathrm{Cs}_{2} \mathrm{AgBiBr}_{6}\right)$, the presented material crystallized in $F m \overline{3} m$ space group with alternating $\left(\mathrm{BiBr}_{6}\right)^{3-}$ and $\left(\mathrm{AgBr}_{6}\right)^{5-}$ octahedra to form a 3D architecture (Figure 2i). From the material's absorption spectrum, a cutoff wavelength of $\sim 620 \mathrm{~nm}$ was extracted (Figure 2j). This generated an indirect bandgap of $2.02 \mathrm{eV}$ (Figure $2 \mathrm{k}$ ), which is smaller than those reported for $\mathrm{MAPbBr}_{3}(2.2-2.3 \mathrm{eV})$ [91]. Although this bandgap is assumed to be narrow enough to (a)

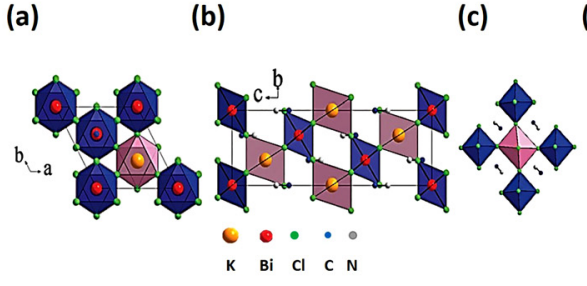

(g)

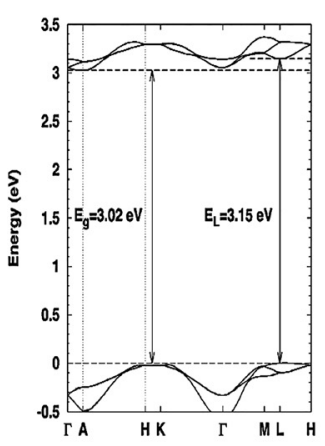

(h)

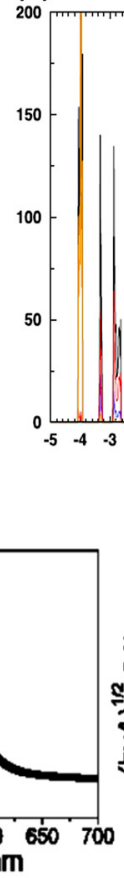

(c)

Energy (eV)

(j)

(k)

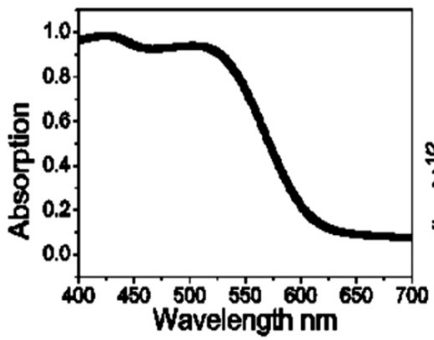

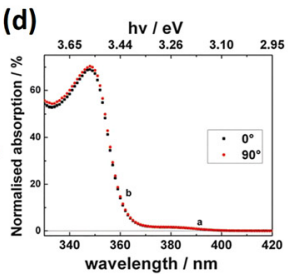

(e)
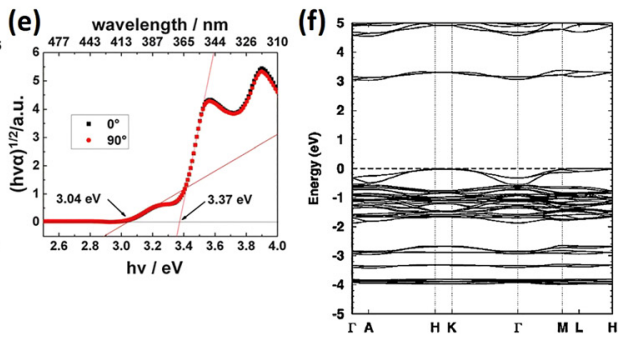

VBM
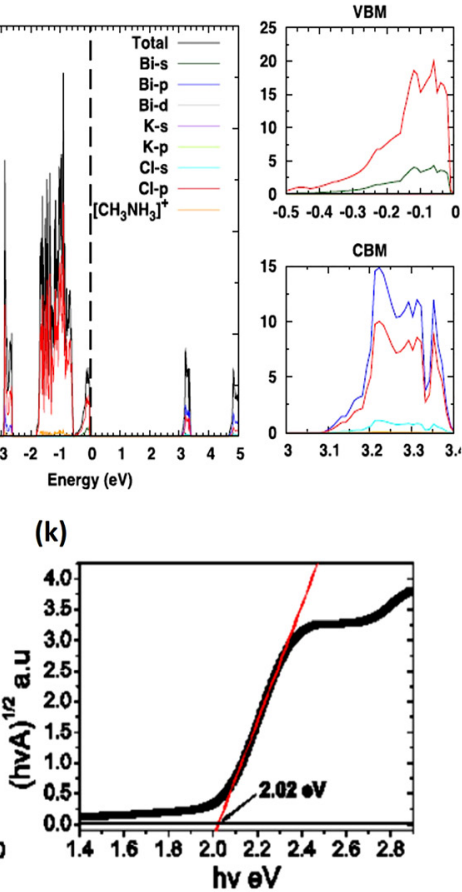

(i)
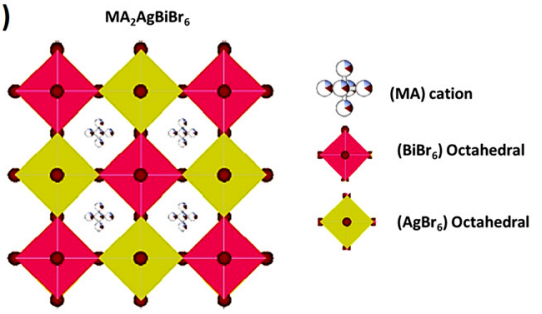

(I) 5

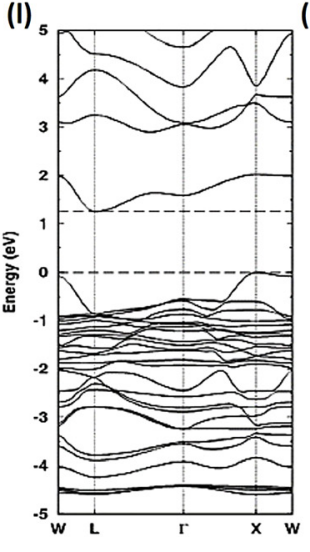

(m)

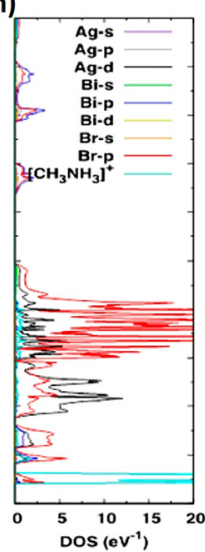

Figure 2: Crystal structure of $\mathrm{MA}_{2} \mathrm{KBiCl}_{6}$, along (a) the $c$-axis, (b) the $a$-axis and (c) tilted to show the MA location. (d) Absorption spectra and (e) the Tauc plot of $\mathrm{MA}_{2} \mathrm{KBiCl}_{6}$ [88]. Copyright 2015, Royal Society of Chemistry. (f) Calculated band structure of $\mathrm{MA}_{2} \mathrm{KBiCl}_{6}$ [88]. Copyright 2015, Royal Society of Chemistry. (g) Enlarged view of the band structure near the bandgap of $\mathrm{MA}_{2} \mathrm{KBiCl}_{6}$ [88]. Copyright 2015, Royal Society of Chemistry. (h) Calculated total and PDOS of $\mathrm{MA}_{2} \mathrm{KBiCl}_{6}$ [88]. Copyright 2015, Royal Society of Chemistry. (i) Crystal structure of $\mathrm{MA}_{2} \mathrm{AgBiBr}_{6}$ [90]. Copyright 2017, American Chemical Society. (j) Absorption spectrum and (k) Tauc plot of $\mathrm{MA}_{2} \mathrm{AgBiBr}_{6}$ [90]. Copyright 2017, American Chemical Society. (l) Calculated band structure and (m) PDOS of $\mathrm{MA}_{2} \mathrm{AgBiBr}_{6}$ [90]. Copyright 2017, American Chemical Society. 
observe semiconducting behaviour, a small ionic conductivity of $4.8 \times 10^{8} \Omega \mathrm{cm}$ could be measured for the proposed material. This suggested the electronic conductivity of $\mathrm{MA}_{2} \mathrm{AgBiBr}_{6}$ should be probably far smaller than that of $\mathrm{MAPbBr}_{3}$ due to a limited number of carriers with low mobility. DFT and PDOS calculations showed an indirect transition from $X$-point to the $L$-point of the Brillouin zone (Figure 2l). PDOS confirmed the main contributions of VBM originated from $\mathrm{Bi}-6 s, \mathrm{Ag}-4 d$ and $\mathrm{Br}-4 p$ states, whereas CBM mostly contained Ag-5s, Bi- $6 p$ and Br- $4 p$ states, similar to the case of $\mathrm{Cs}_{2} \mathrm{AgBiBr}_{6}$. No significant contribution of $\mathrm{MA}^{+}$cations in the band edges could be found, while the contribution of the Ag- $4 d$ states in the materials VBM led to the indirect transition at the band edges for $\mathrm{MA}_{2} \mathrm{Ag}$ $\mathrm{BiBr}_{6}$ (Figure 2m). Calculating the carrier effective masses of both compounds presented very similar values to $\mathrm{Cs}_{2} \mathrm{AgBiBr}_{6}$ that was due to their rather resembling band dispersion (Table 2).

\section{2 $\mathrm{Cs}_{2} \mathrm{BSbX}_{6}\left(\mathrm{~B}=\mathrm{Ag}^{+}, \mathrm{Cu}^{+} ; \mathrm{X}=\mathrm{Cl}^{-}\right.$and $\left.\mathrm{Br}^{-}\right)$}

\subsection{1 $\mathrm{Cs}_{2} \mathrm{AgSbCl}_{6}$}

To design a general strategy to tune the convergence of indirect and direct bandgap by chemical adjustment of the $s$-state and $p$-state characteristics of MHDPs, Tran et al. [92] successfully synthesized two types of halide double perovskites: $\mathrm{Cs}_{2} \mathrm{AgSbCl}_{6}$, with an indirect bandgap, and $\mathrm{Cs}_{2} \mathrm{AgInCl}_{6}$, with a direct bandgap. The viability of their strategy will be discussed in the following sections. Here, the optoelectronic properties of newly designed $\mathrm{Cs}_{2} \mathrm{AgSbCl}_{6}$ are particularity propounded. $\mathrm{Cs}_{2} \mathrm{AgSbCl}{ }_{6}$ is isostructural of $\mathrm{Cs}_{2} \mathrm{AgBiBr}_{6}$ and crystallizes in $F m \overline{3} m$ space group. The framework of the material likewise contains corner-sharing intermittent octahedra of $\left[\mathrm{SbCl}_{6}\right]^{3-}$ and $\left[\mathrm{AgCl}_{6}\right]^{5-}$ stacked to each other in a 3D skeleton, with $\mathrm{Cs}^{+}$cations located in the cavity in between the octahedra. The UV-Vis diffuse reflectance spectra measurement indicated a shallow absorption edge at around $2.54 \mathrm{eV}$ accompanied by a sharp increase in the absorption at $2.79 \mathrm{eV}$, which revealed the specific characteristics of an indirect bandgap semiconductor (Figure 3a). From the linear region of the material's Tauc plot, the phonon-assisted processes can be seen that indicated a phonon absorption and emission by transitions at 2.54 and $2.79 \mathrm{eV}$. To argue the electronic structure of the material, DFT calculations confirmed that $\mathrm{Cs}_{2} \mathrm{AgSbCl}_{6}$ owned an indirect bandgap with the VBM and CBM situated at the $W$-point and $X$-point of the Brillouin zone, severally (Figure 3b). PDOS measurements were exploited to create the band diagram for the proposed material (Figure 3c). The results showed that the material's VBM is predominantly constructed from antibonding Ag- $4 d / \mathrm{Cl}-3 p$ states, where a stronger $\mathrm{Cl}-3 p$ characteristic is conducted. On the other hand, Ag-s states were raised to the $\mathrm{CB}$ to have an interaction with the Sb- $p$ stats. Additionally, it was seen that the isolated conduction band mostly originated from the spin-orbit-effect, due to a split between the contributed Sb-5 $p_{1 / 2}$ and $S b-5 p_{3 / 2}$ states. Given this information, it is derived that antibonding $\mathrm{Sb}-p / \mathrm{Cl}-p$ states were the dominant orbitals at the CB of the $\mathrm{Cs}_{2} \mathrm{AgBiCl}_{6}$.

\subsection{2 $\mathrm{Cs}_{2} \mathrm{AgSbBr}_{6}$}

All the above-mentioned double perovskites possess widebandgap ranging from 1.9 to $3.37 \mathrm{eV}$, which arises some concerns on their capability as an efficient light harvester. One way to reduce the bandgap is replacing $\mathrm{Br}^{-}$with $\mathrm{I}^{-}$, in which owing to the interaction between the I-5p orbitals and metal cations, a drop in the CBM, as well as a rise in the VBM, and consequently a reduction in the material's bandgap occurs [93]. However, the synthesis of iodide-based double perovskites has been proven to be impossible experimentally, such that even a small amount of iodine deployment into the structure results in the material decomposition to lower-dimensional $\mathrm{A}_{3} \mathrm{Bi}_{2} \mathrm{I}_{9}$ phases. Another approach is to adopt a $\mathrm{B}^{\prime 3+}$ cation with an electron configuration of $5 s-5 p$ instead of the commonly used one with a $6 s-6 p$ electronic state (e.g. $\mathrm{Bi}^{3+}$ ). Regarding these, Wei et al. [94] focussed on the substitution of $\mathrm{Bi}^{3+}$ in the $\mathrm{Cs}_{2} \mathrm{AgBiBr}_{6}$ structure with $\mathrm{Sb}^{3+}$ to provide a new low bandgap MHDP. In common with most members of the double perovskite family, $\mathrm{Cs}_{2} \mathrm{AgSbBr}_{6}$ also crystallized in the cubic $F m \overline{3} m$ space group forming typical rock-salt architecture of double perovskites. One interesting fact related to this newly designed material was that upon heating at $480 \mathrm{~K}$ for $5 \mathrm{~min}$ in an inert atmosphere, a colour change from black to brown was observed that was found to be an irreversible transition. To uncover the origin of this phenomenon, X-ray photoelectron spectroscopy (XPS) measurements on both black and brown crystals showed the existence of $\mathrm{Sb}^{5+}$ in black crystals by detecting $\mathrm{Sb}-3 d_{5 / 2}$ corresponding peak at $540.5 \mathrm{eV}$. On the contrary, no trace of this peak could be found in the brown crystal. Hence, the reason for this colour change was hypothesized to be rooted in the charge transport between $\mathrm{Sb}^{3+}$ and $\mathrm{Sb}^{5+}$ in the black phase [94].

Similar to its Cl-based analogue, the Tauc plot of $\mathrm{Cs}_{2} \mathrm{AgSbBr}_{6}$ black crystals also showed a shallow absorption edge at $1.64 \mathrm{eV}$ with a sharp increase at $2.49 \mathrm{eV}$ (Figure 3d). Given these, an indirect bandgap of 1.64 was estimated for the material, which was considerably less than those reported for $\mathrm{Cs}_{2} \mathrm{AgBiBr}_{6}(\sim 1.95-2.19 \mathrm{eV})$ and also 


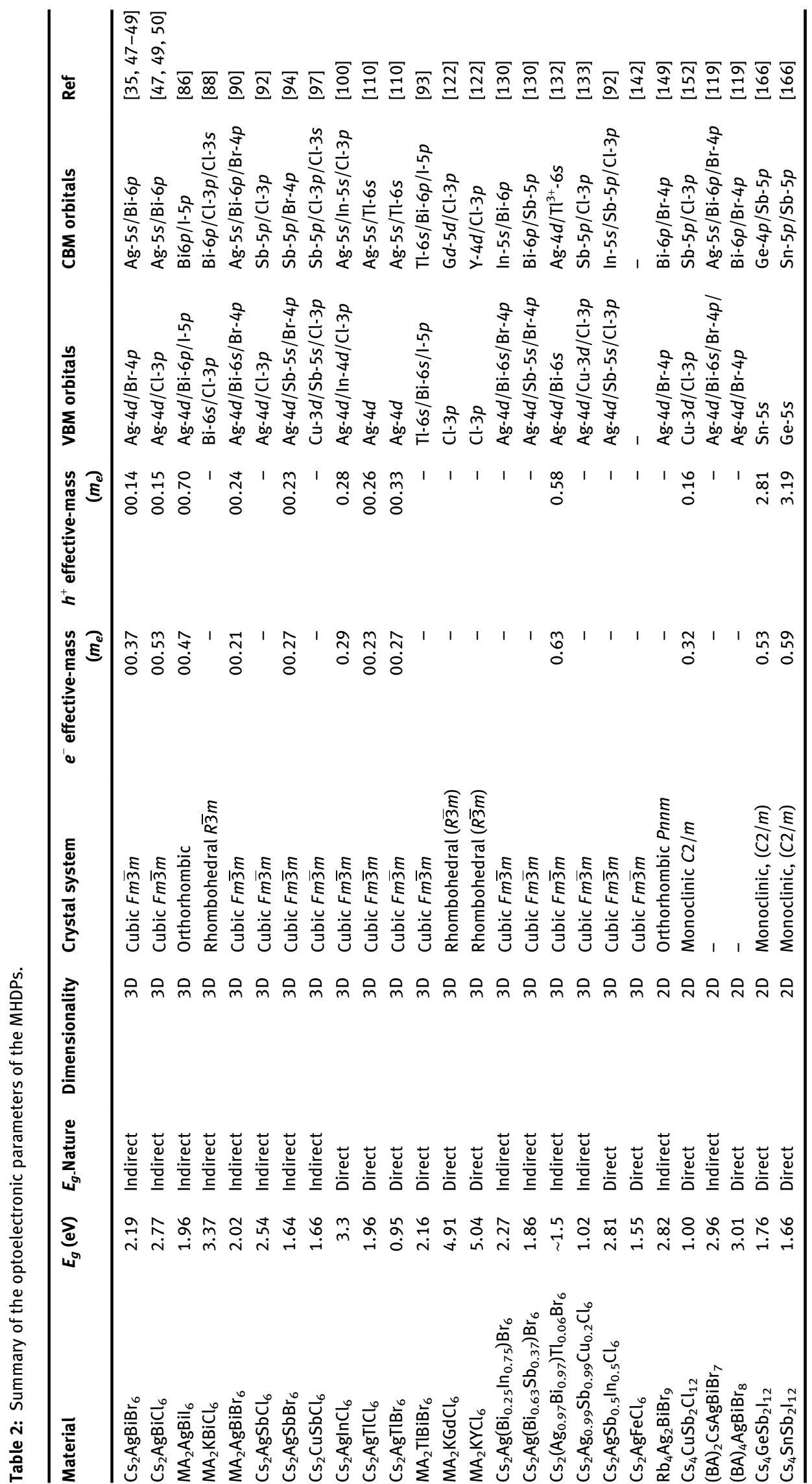


(a)

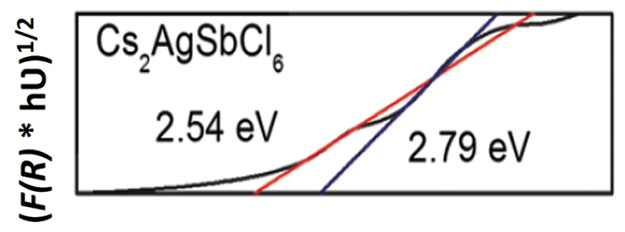

$\mathrm{hu} / \mathrm{eV}$

(b)

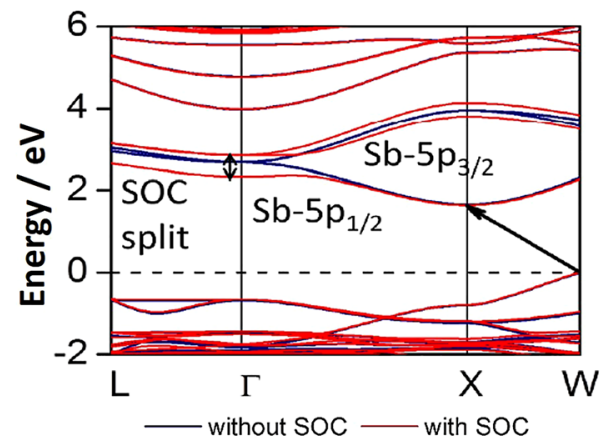

(d)

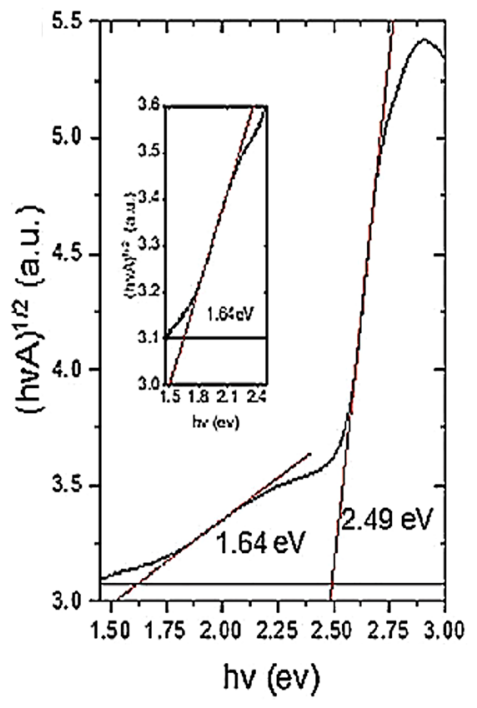

(e) (c)
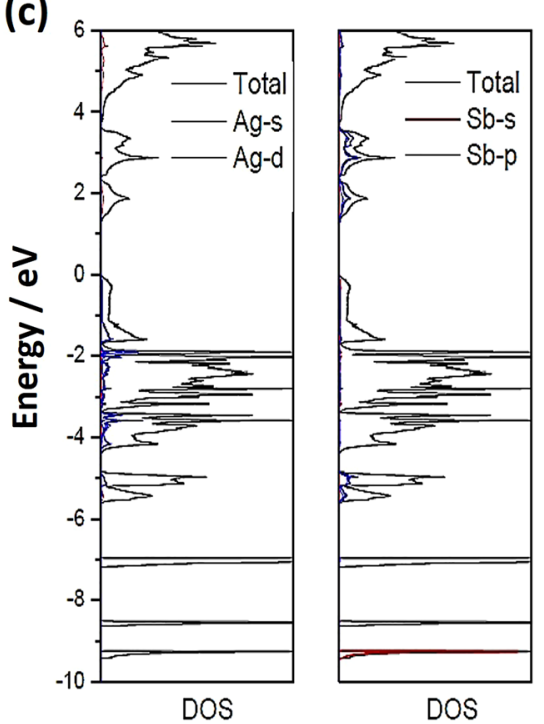

DOS

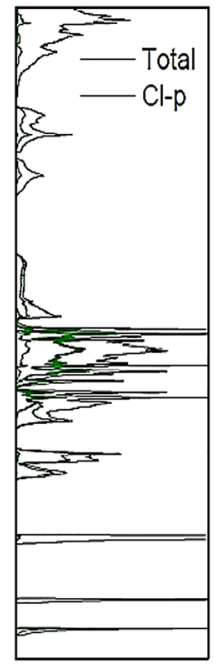

DOS
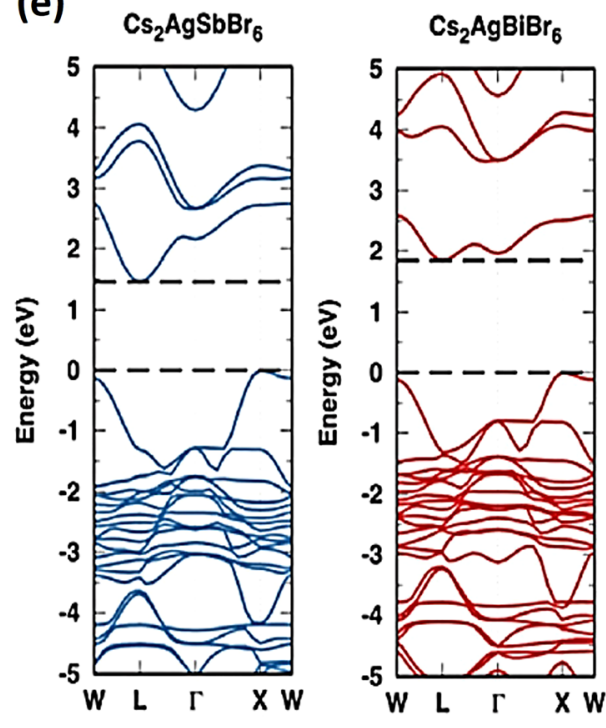

(f)
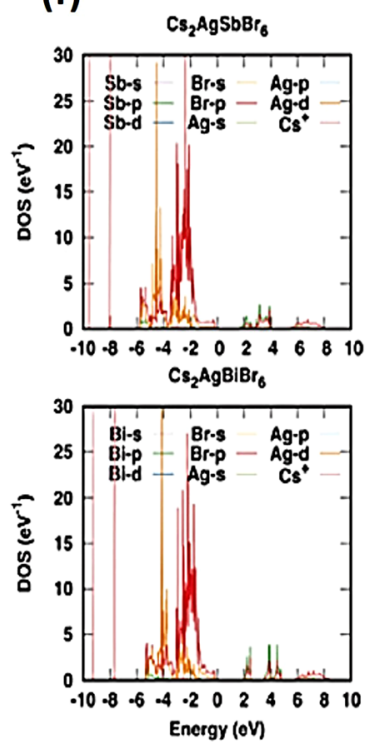

Figure 3: (a) Tauc plots for $\mathrm{Cs}_{2} \mathrm{AgSbCl}$ double perovskite [92]. Copyright 2015, Royal Society of Chemistry. (b) Band structure of $\mathrm{Cs}_{2} \mathrm{AgSbCl}_{6}$ double perovskite. (c) PDOS of $\mathrm{Cs}_{2} \mathrm{AgSbCl}_{6}$ double perovskite [92]. Copyright 2015, Royal Society of Chemistry. (d) Tauc plot of a black sample of $\mathrm{Cs}_{2} \mathrm{AgSbBr}_{6}$ powder [94]. Copyright 2015, Royal Society of Chemistry. The inset shows the indirect bandgap absorption edge. (e) Calculated electronic band structures of $\mathrm{Cs}_{2} \mathrm{AgSbBr}_{6}$ and $\mathrm{Cs}_{2} \mathrm{AgBiBr}_{6}$ double perovskites [94]. Copyright 2015, Royal Society of Chemistry. (f) PDOS of $\mathrm{Cs}_{2} \mathrm{AgSbBr}_{6}$ and $\mathrm{Cs}_{2} \mathrm{AgBiBr}_{6}$ double perovskites [94]. Copyright 2015, Royal Society of Chemistry.

$\mathrm{Cs}_{2} \mathrm{AgSbCl}_{6}$ (2.54 eV) [47, 48, 92]. To understand the band structure of $\mathrm{Cs}_{2} \mathrm{AgSbBr}_{6}$, the calculations were performed on both $\mathrm{Cs}_{2} \mathrm{AgBiBr}_{6}$ and $\mathrm{Cs}_{2} \mathrm{AgSbBr}_{6}$ powders. From Figure 3e, a significant similarity between the band structures of the two compounds can be seen. The VBM of $\mathrm{Cs}_{2} \mathrm{AgSbBr}_{6}$ locates at the $X$-point with a majority of Ag-4d/ $\mathrm{Br}-4 p$ antibonding states and a minima portion of Sb-5s orbitals (Figure 3f). However, the presiding states at the $\mathrm{CBM}$ of the materials are dependent on the $\mathrm{Sb}-5 p / \mathrm{Br}-4 p$ antibonding states. Sb-5p interaction yields a wide dispersion in the conduction band and lowering the band edge at the $L$-point, causing a much narrower calculated bandgap of $1.46 \mathrm{eV}$ compared with that of $\mathrm{Cs}_{2} \mathrm{AgBiBr}_{6}$ $(1.84 \mathrm{eV})$. Calculating electron and hole effective masses of both compounds from their band structure demonstrated relatively lower values for $\mathrm{Cs}_{2} \mathrm{AgSbBr}_{6}$ (Table 2). This is in consistent with the general trend that in large bandgap materials the valence band and conduction band are normally less dispersed, steering a decrease in the charge carrier mobility [95]. 


\subsection{3 $\mathrm{Cs}_{2} \mathrm{CuSbCl}_{6}$}

Theoretical calculations predicted that $\mathrm{Cu}^{+}$-based MHDPs may lead to a suitable bandgap for photovoltaic applications. Nevertheless, the synthesis of their bulk crystal is not yet feasible due to the problems of high formation energy and kinetic instability of the compounds. The reason of this has been shown to originate from the tendency of $\mathrm{Cu}^{+}$with electronic configuration of the $[\mathrm{Ar}] 3 d^{10} 4 s^{1}$ to form a fourfold coordination $\left[\mathrm{CuX}_{4}\right]$ tetrahedral in a non-perovskite structure rather than the sixfold $\left[\mathrm{CuX}_{6}\right]$ octahedral for double-perovskites configuration [96]. Zhou et al. [97] speculated that hot-injection method may overcome this obstacle and facilitate the crystallization of the material at the nanoscale. The reason for this hypothesis was the intense and rapid precursors' reaction through this approach. Therefore, they reported the successful colloidal synthesis of all-inorganic $\mathrm{Cu}^{+}$-based MHDP of $\mathrm{Cs}_{2} \mathrm{CuSbCl}_{6}$ nanocrystals. The material showed a highly symmetric face-centred cubic structure in a $F m \overline{3} m$ crystal system (Figure 4a). X-ray diffraction (XRD) characterization confirmed high crystallinity of nanocrystals with a single pure phase (Figure 4b). The nanocrystals showed the ability to absorb light from the entire visible region with a promising narrow optical bandgap of $1.66 \mathrm{eV}$ (Figure 4c). The relatively narrow bandgap of $\mathrm{Cs}_{2} \mathrm{CuSbCl}_{6}$ nanocrystals highlighted its great potential as light-absorbing material. Using nanosecond transient absorption (TA) spectroscopy, a fast decay component of $\tau_{1}=1.5-2$ ps related to the fast cooling of dark trapped states, an intermediate lifetime of $\tau_{2}=50-85 \mathrm{ps}$ attributed to the surface defect trap states, and long lifetime of $\tau_{3}=148 \mathrm{~ns}$ assigned to the dark trapped state were calculated for the material (Figure 4d). These results emphasized the importance of further understanding the non-radiative process of MHDPs and revealed the reason for the poor PL properties normally possessed by $\mathrm{Sb}$-based materials. To explain the electronic properties of $\mathrm{Cs}_{2} \mathrm{CuSbCl}_{6}$ nanocrystals, DFT calculations confirmed the indirect electronic bandgap of the material (Figure 4e). Because the VBM is positioned at the $X$-point, while CBM is located at the $L$-point. It was seen that in VBM the contribution of the $\mathrm{Cu}-3 d / \mathrm{Sb}-5 \mathrm{~s} / \mathrm{Cl}-3 p$ orbitals were dominant, whereas the CBM was significantly contributed by Sb-5p/ Cl-3p/Cl-3s states (Figure 4f).

\section{Direct bandgap MHDPs}

While the proposed MHDPs exhibit acceptable bandgap values in the visible range, one immediate challenge for these materials is their indirect bandgap that suppresses their potential for thin-film photovoltaic application. Generally, indirect bandgaps show weak oscillator abilities for either light absorption or radiative recombination, accordingly much thicker absorbing-layer is necessary for indirect bandgap semiconductors. On the other hand, if charge carrier mobility of the operating layer is not high enough, an optimum thickness applies. To circumvent this barrier, several works have been reported to develop new $\mathrm{Pb}$-free MHDPs with a direct bandgap that will be discussed in this section.

\section{$3.1 \mathrm{Cs}_{2} \mathrm{AgInCl}_{6}$}

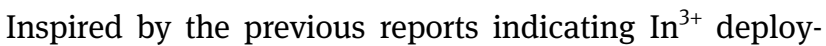
ment in an elpasolite structure of $\mathrm{Cs}_{2} \mathrm{NaB}^{\prime 3+} \mathrm{X}_{6}(\mathrm{X}=\mathrm{Cl}, \mathrm{Br}, \mathrm{I})$ $[98,99]$, Volonakis et al. [100] assessed the formation of hypothetical compounds of $\mathrm{Cs}_{2} \mathrm{AgInX}_{6}(\mathrm{X}=\mathrm{Cl}, \mathrm{Br}, \mathrm{I})$ with the predicted direct bandgap. As a result, they succeeded in synthesizing $\mathrm{Cs}_{2} \mathrm{AgInCl}_{6}$ with typical rock-salt ordering found in many double perovskites within a $F m \overline{3} m$ symmetry. Precise evaluation of the absorbance spectrum of the material revealed an absorption onset at $380 \mathrm{~nm}$ corresponding to the bandgap of $3.3 \mathrm{eV}$, with a further absorption feature located at $585 \mathrm{~nm}$ (bandgap of $2.1 \mathrm{eV}$ ) (Figure $4 \mathrm{~g}$ and $\mathrm{h}$ ). The interesting point is that a material with a bandgap of $2.1 \mathrm{eV}$ should be in orange, while the synthesized $\mathrm{Cs}_{2} \mathrm{AgInCl}_{6}$ powder was in white. Examining the material's reaction under photoexcitation revealed a colour change from white to orange under UV illumination. This phenomenon might be correlated with some structural changes or photoinduced electronic variations in the material $[101,102]$. One similar example is that the $\mathrm{AgCl}$ is a photosensitive compound with a shift in its oxidation state under light-illumination. This reversible photochromic behaviour can also be due to the extensive sensitivity of the $\mathrm{Cs}_{2} \mathrm{AgInCl}_{6}$ electronic structure to the marginal difference between the $\mathrm{In}-\mathrm{Cl}$ and $\mathrm{Ag}-\mathrm{Cl}$ bond lengths. Thus, it was presumed that the absorption onset at $2.1 \mathrm{eV}$ might arise from the photoinduced defect states upon lightillumination, while the actual onset was at $3.3 \mathrm{eV}$. Employing DFT calculations, a direct bandgap was found for $\mathrm{Cs}_{2} \mathrm{AgInCl}_{6}$, in which both $\mathrm{VBM}$ and CBM extrema rest in the middle of the Brillouin zone ( $\Gamma$-point) (Figure $4 i$ ). Square modulus of the electronic wave functions indicated that CBM was mostly derived from the In-5s/Ag-5s and Cl$3 p$ states, while the VBM comprised In- $4 d / \mathrm{Ag}-4 d$ and $\mathrm{Cl}-3 p$ states; non-occupied In- $5 s$ orbitals were also seen at these states (Figure 4j). This configuration strongly correlated with the direct characteristic of the compound's bandgap. Calculating the effective masses of the carriers for 


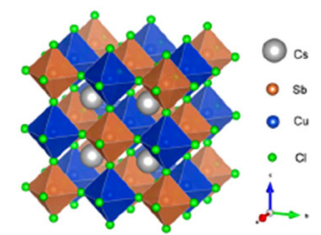

(e)

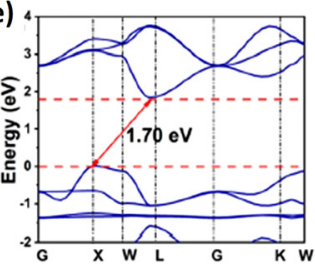

(i)

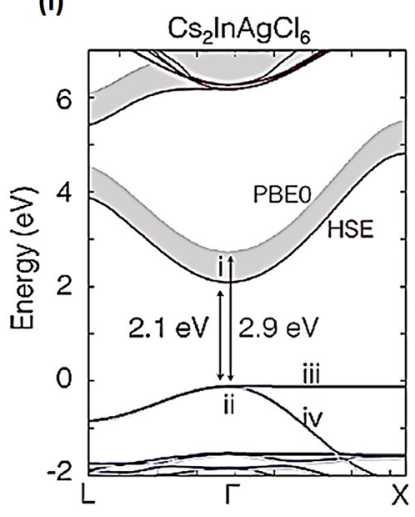

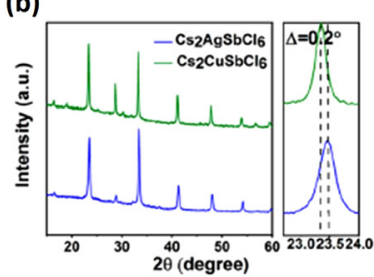

(c)
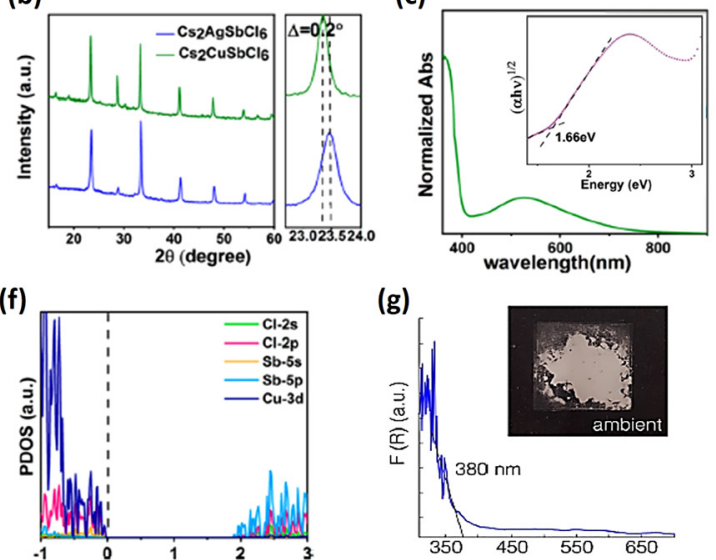

(j)

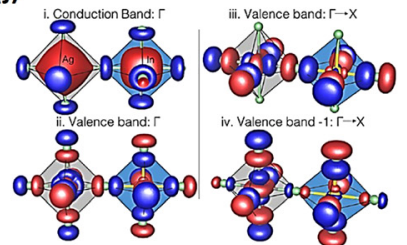

(k)

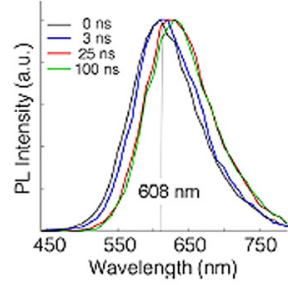

(g)

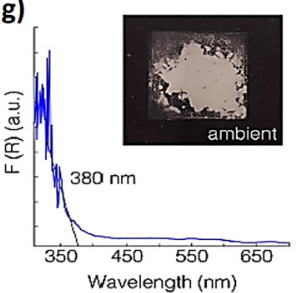

(I)

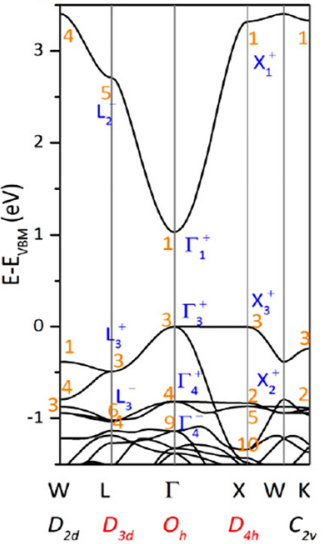

(h) (d)
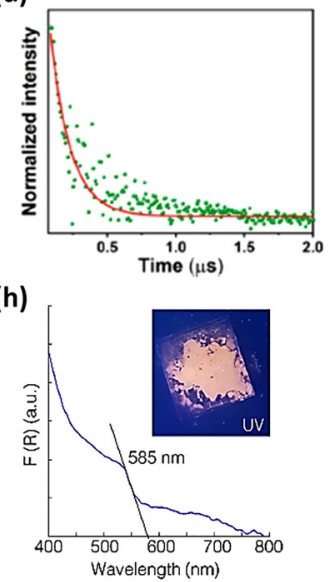

(m)

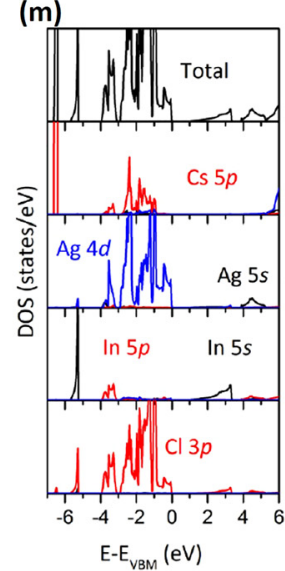

Figure 4: (a) Crystal structure of $\mathrm{Cs}_{2} \mathrm{CuSbCl}_{6}$ double perovskite [97]. Copyright 2020, American Chemical Society (b) XRD patterns of $\mathrm{Cs}_{2} \mathrm{CuSbCl}_{6}$ nanocrystals [97]. Copyright 2020, American Chemical Society (c) Absorption spectrum of $\mathrm{Cs}_{2} \mathrm{CuSbCl}_{6}$ nanocrystals [97]. Copyright 2020, American Chemical Society Inset: Corresponding Tauc plot of $\mathrm{Cs}_{2} \mathrm{CuSbCl}_{6}$ nanocrystals. (d) Nanosecond transient absorption (TA) signal of $\mathrm{Cs}_{2} \mathrm{CuSbCl}_{6}$ nanocrystals [97]. Copyright 2020, American Chemical Society (e) Electronic band structure of $\mathrm{Cs}_{2} \mathrm{CuSbCl}_{6}$. (f) PDOS of $\mathrm{Cs}_{2} \mathrm{CuSbCl}_{6}$ double perovskite [97]. Copyright 2020, American Chemical Society (g) UV-Vis absorbance of $\mathrm{Cs}_{2} \mathrm{AgInCl}_{6}$ in ambient and (h) under UV illumination (right) [100]. Copyright 2017, American Chemical Society. (i) Band structure of $\mathrm{Cs}_{2} \mathrm{AgInCl}_{6}$ double perovskite [100]. Copyright 2017, American Chemical Society. (j) Isosurface plots of $\mathrm{Cs}_{2} \mathrm{AgInCl}_{6}$ double perovskite [100]. Copyright 2017, American Chemical Society. (k) Normalized $\mathrm{Cs}_{2} \mathrm{AgInCl}_{6} \mathrm{PL}$ spectrum of $\mathrm{Cs}_{2} \mathrm{AgInCl}_{6}$ double perovskite as a function of time [100]. Copyright 2017, American Chemical Society. (l) Calculated band structure and (m) PDOS of $\mathrm{Cs}_{2} \mathrm{AgInCl}_{6}$ double perovskite [103]. Copyright 2017 American Chemical Society.

$\mathrm{Cs}_{2} \mathrm{AgInCl}_{6}$ disclosed an electron effective mass of $0.29 m_{e}$ and hole effective mass of $0.28 m_{e}$. Non-dispersive band between $\Gamma$ - and $X$-points (Figure $4 \mathrm{i}$ and $\mathrm{j}$ ) created a $2 \mathrm{D}$ confined wave function within the material. Most likely, this flat band would be a feasible state for deep defects formation that prevents efficient charge carrier transport in the material.

From the $\mathrm{PL}$ characterization on $\mathrm{Cs}_{2} \mathrm{AgInCl}_{6}$ powders, a well-defined peak at $608 \mathrm{~nm}(2.04 \mathrm{eV})$ was identified (Figure 4k), which experienced a red-shift over a $100 \mathrm{~ns}$ timescale. This trend suggested the sub-bandgaps filling as mentioned above. However, the magnitude of measured bandgap from the PL spectrum fell around $1.26 \mathrm{eV}$ lower than the one calculated from UV-Vis reflection. Understanding this discrepancy, Meng et al. [103] discussed that this mystery PL emission can be explained by a parityforbidden transition between the VBM and CBM at the $\Gamma$-point. The fountainhead of this feature rooted in the centrosymmetry of the material and contribution of the unoccupied In-5s orbitals in the CBM. Similar behaviour has been explored in other $\mathrm{Cs}_{2} \mathrm{~B}^{+} \mathrm{B}^{\prime 3+} \mathrm{X}_{6}$ double perovskites $\left(\mathrm{B}^{+}=\right.$group $I A$ or $I B, \mathrm{~B}^{3+}=\mathrm{In}^{3+}$ or $\left.\mathrm{Ga}^{3+}\right)[104,105]$. One point missing in the previous reports was considering the $\mathrm{O}_{h}{ }^{5}$ symmetry with an inversion centre in double perovskites with $F m \overline{3} m$ space group. The inversion centre could have critical effects on the optical transitions in the compound. 
Meng et al. [100] obtained a calculated bandgap of $2.1 \mathrm{eV}$, around $1.0 \mathrm{eV}$ smaller than that observed from UV-Vis spectroscopy. They found that VBM of the composition was as a result of $\mathrm{Ag}-4 \mathrm{~d} / \mathrm{Cl}-3 p$ antibonding states, while the CBM was dominantly composed of delocalized In-5s states (Figure 41 and $\mathrm{m}$ ). They thoroughly discussed that a combination of In-5s states and inversion symmetry $\left(\mathrm{O}_{h}\right)$ at the CMB gave a representation of $A_{1 g}\left(\Gamma_{1}^{+}\right)$to these states. On the other hand, at the VBM, Ag-4d orbitals had the highest energy, which determined the representation of $E_{g}\left(\Gamma_{3}^{+}\right)$for the VBM at the $\Gamma$-point. In the end, it was seen that in $\mathrm{Cs}_{2} \mathrm{AgInCl}_{6}$ both VBM and CBM contained even parity that caused a parity-forbidden transition between these bands at the $\Gamma$-point. This phenomenon has been also reported for other semiconductors with inversion symmetry (e.g. $\mathrm{CuM}^{\mathrm{III}} \mathrm{O}_{2}$ $\left(\mathrm{M}=\mathrm{Al}, \mathrm{Ga}\right.$, In) [106], $\mathrm{Tl}_{2} \mathrm{O}_{3}$ [107], $\mathrm{SnO}_{2}$ [108], $\mathrm{In}_{2} \mathrm{O}_{3}$ [109].

\section{2 $\mathrm{Cs}_{2} \mathrm{AgTlX}_{6}\left(\mathrm{X}=\mathrm{Cl}^{-}, \mathrm{Br}^{-}\right)$}

Unlike halide perovskites, in which the most explored method to tune the bandgap is the substitution of the halide in the structure, Slavney et al. demonstrated significant bandgap engineering in MHDPs. This was done through the energy alignment between the frontier orbitals of $\mathrm{B}^{+}$and $\mathrm{B}^{\prime 3+}$ cations of the nominal $\mathrm{A}_{2} \mathrm{BB}^{\prime} \mathrm{X}_{6}$ double perovskite structure [110]. This strategy allowed the formation of $\mathrm{Cs}_{2} \mathrm{AgTlX}_{6}$ $(\mathrm{X}=\mathrm{Cl}, \mathrm{Br})$ double perovskites with much smaller bandgaps than those of $\mathrm{Pb}$-based perovskites with the same halide anion [110]. $\mathrm{Cs}_{2} \mathrm{AgTlBr}_{6}$ owns the smallest bandgap since the discovery of the halide perovskite family from 1883 [111]. $\mathrm{XRD}$ characterization on the products of $\mathrm{Cs}_{2} \mathrm{AgTlX}_{6}(\mathrm{X}=\mathrm{Cl}$, $\mathrm{Br})$ confirmed cubic structure in $F m \overline{3} m$ space group, forming a 3D skeleton of alternating corner-sharing halide octahedra centred by $\mathrm{Ag}^{+}$and $\mathrm{Tl}^{3+}$ (Figure 5a). The optical absorption measurements revealed direct bandgaps of 1.96 and $0.95 \mathrm{eV}$ for $\mathrm{Cs}_{2} \mathrm{AgTlCl}_{6}$ and $\mathrm{Cs}_{2} \mathrm{AgTlBr}_{6}$, respectively (Figure $5 \mathrm{~b}$ and c). As compared to Cl-based $(2.5-3.3 \mathrm{eV}$ ) $[100,112]$ and Br-based $(1.8-2.3 \mathrm{eV})$ [113-115] halide perovskite counterparts, the obtained bandgap values for $\mathrm{Cs}_{2} \mathrm{AgTlCl}_{6}$ and $\mathrm{Cs}_{2} \mathrm{AgTlBr}_{6}$ were strongly red-shifted, such that $\mathrm{Cs}_{2} \mathrm{AgTlBr}_{6}$ bandgap was notably narrower than the typical I-based halide perovskites (1.2-1.6 eV) [116-118]. Despite the promising calculated bandgaps, similar to $\mathrm{Cs}_{2} \mathrm{AgInCl}_{6}$, no PL emission was observed for both compositions even at a low temperature of $20 \mathrm{~K}$. Determining the transition dipole matrix elements for $\mathrm{Cs}_{2} \mathrm{AgTlCl}_{6}$ indicated an identically zero dipole matrix elements at the $\Gamma$-point and along the $\Gamma-X$ direction. This represented a category of symmetry-forbidden transitions (Figure 5d), similar to the observed phenomenon in $\mathrm{Cs}_{2} \mathrm{AgInCl}_{6}$. However, going away from the $\Gamma$-point and along the $\Gamma-X$ direction and also along other lines in a reciprocal symmetry, the dipole matrix elements rapidly elevated. It meant that at energy levels higher than bandgap transitions were allowed. Therefore after excitation, charge carriers relaxed into the forbidden region. Since the energy-width of this region $(170 \mathrm{meV})$ (Figure 5e) was greater than the activation energy at room temperature $(26 \mathrm{meV})$, carriers were confined to the forbidden zone and cannot provide radiative recombination. This explained the lack of PL emission for the proposed compounds. These characteristics led to the long carrier recombination lifetimes in $\mu$ s scale (Figure $5 f$ ). DFT calculation (Figure $5 \mathrm{~g}$ ) revealed that the small bandgap of the compounds was contributed by two factors: (i) Wide dispersion in the conduction band due to an overlap between the Tl-6s/Ag-5s orbitals with the halide orbitals that led to the small electron effective mass in this region (Table 2). Highly dispersive bands drove the band spectra towards each other, which strongly narrowed the compounds' bandgap. (ii) Another reason should be inherited from the little intrinsic energy-gap between filled $\mathrm{Ag}$ - $4 d$ states at VBM and vacant Tl-6s states at CBM. In $\mathrm{Cs}_{2} \mathrm{AgTlX}_{6}(\mathrm{X}=\mathrm{Br}$, $\mathrm{Cl}$ ), the CBM mostly contained Tl-6s with a minor portion for Ag- $5 s$ orbitals, while the VBM was ruled by Ag- $4 d$ orbitals (Figure 5g). Hence, a metal-to-metal charge transfer (MMCT) could be considered for their bandgap transition, which was a predominant pattern for many MHDPs [119]. These results emphasize the role of energy-gap between the frontier orbitals of the monovalent and trivalent metal cations in determining the compound's bandgap. Considering $\mathrm{Cs}_{2} \mathrm{AgBiCl}_{6}[49,50]$ and $\mathrm{Cs}_{2} \mathrm{Tl}^{+} \mathrm{Tl}^{3+} \mathrm{Cl}_{6}$ [112] as the isostructures of the $\mathrm{Cs}_{2} \mathrm{AgTlCl}_{6}$, with bandgaps of 2.77 and $2.5 \mathrm{eV}$, respectively, they can give a better vision on this state. The greater bandgaps for these two compounds as compared to $1.96 \mathrm{eV}$ for $\mathrm{Cs}_{2} \mathrm{AgTlCl}_{6}$ demonstrated that the combination of the monovalent $\left(\mathrm{Ag}^{+}, \mathrm{Tl}^{+}\right)$and trivalent $\left(\mathrm{Bi}^{3+}\right.$ and $\mathrm{Tl}^{3+}$ ) metal cations widely defined the bandgap value of the final product (Figure $5 \mathrm{~h}$ ).

\section{3 $\mathrm{MA}_{2} \mathrm{TlBiBr}_{6}$}

The ionic characteristic of halide $\left(\mathrm{Cl}^{-}\right.$and $\left.\mathrm{Br}^{-}\right)$bonds sparks off the unfavourable electronic properties in MHDPs namely wide bandgap. One possible strategy to enhance this drawback is to use Pearson-softer anions and monovalent cations at $\mathrm{X}^{-}$and $\mathrm{B}^{+}$sites of the $\mathrm{A}_{2} \mathrm{BB}^{\prime} \mathrm{X}_{6}$ structure, respectively. Given this, Deng et al. in a deep computational work screened a series of hybrid MHDPs with the general formula of $\mathrm{MA}_{2} \mathrm{~B}^{+} \mathrm{BiX}$ where $\mathrm{B}^{+}=\mathrm{K}^{+}, \mathrm{Tl}^{+}, \mathrm{Cu}^{+}, \mathrm{Ag}^{+}$and $\mathrm{X}=\mathrm{Cl}^{-}, \mathrm{Br}^{-}$ and $\mathrm{I}^{-}$. This triggered the synthesis of $\mathrm{MA}_{2} \mathrm{TlBiBr}_{6}$ as a new 
member for the compositionally rich family of double perovskites [93]. Different from $\mathrm{MA}_{2} \mathrm{KBiCl}_{6}$, this new hybrid MHDP crystallized in the $F m \overline{3} m$ space group following the typical ordering of the double perovskites with a bandgap of $2.16 \mathrm{eV}$ (Figure 5i), which is proportional to that of $\mathrm{MAPbBr}_{3}$ $(2.2-2.35 \mathrm{eV})[120,121]$. Computed electronic band structures of the compound indicated curved band edges, in which VBM and CBM located at the $\Gamma$-point of the Brillouin zone given rise to the direct bandgap (Figure 5j). From PDOS calculations (Figure 5k), it was understood that the main contribution in the VBM belonged to Tl-6s/I-5p, Bi-6s/I- $5 p$ antibonding states. Whereas the conduction band edge mostly consisted of Tl-6s/I-5p bonding states and Bi- $6 p / \mathrm{I}-5 p$ antibonding states. Altogether of these orbital interactions, at the $\Gamma$-point conduction band showed the lowest energy level. Consequently, both CBM and VBM of the compound lay down at the $\Gamma$-point resulting in a direct bandgap characteristic.

\section{$3.4 \mathrm{MA}_{2} \mathrm{KBCl}_{6}(\mathrm{~B}=\mathrm{Gd}, \mathrm{Y})$}

To expand the family of hybrid MHDPs, Deng et al. demonstrated the first example of 3D rare-earth hybrid double perovskites of $\mathrm{MA}_{2} \mathrm{KGdCl}_{6}$ and $\mathrm{MA}_{2} \mathrm{KYCl}_{6}$, while previously the synthesis of some low-dimensional rare-earth hybrid perovskites have been reported [122, 123]. As found for $\mathrm{MA}_{2} \mathrm{KBiCl}_{6}$, these two compounds also crystallized in a rhombohedral $(R \overline{3} m)$ symmetry at room temperature, in which the inorganic framework is a lattice of intermittent corner-sharing $\left(\mathrm{BCl}_{6}\right)^{3-}(\mathrm{B}=\mathrm{Gd}, \mathrm{Y})$ and $\left(\mathrm{KCl}_{6}\right)^{5-}$ octahedra. The organic $\mathrm{MA}^{+}$cations were placed inside the inorganic cages (Figure 6a). The synthesis and characterization of these compounds were found to be effortful because both materials were deliquescent. However, their calculated positive decomposition enthalpies $\left(\Delta H_{d}=23.52\right.$ and $6.56 \mathrm{meV} /$ atom for $\mathrm{MA}_{2} \mathrm{KYCl}_{6}$ and $\left.\mathrm{MA}_{2} \mathrm{KGdCl}_{6}\right)$ and negative formation enthalpies $\left(\Delta H_{f}=-949.48\right.$ and $-634.81 \mathrm{meV} /$ atom for $\mathrm{MA}_{2} \mathrm{KYCl}_{6}$ and $\mathrm{MA}_{2} \mathrm{KGdCl}_{6}$ ) suggested that they were energetically favourable, similar to the inorganic rare-earth hybrid double perovskites [124]. A phase transition from the rhombohedral structure $(R \overline{3} \mathrm{~m})$ to the cubic structure $(F m \overline{3} m)$ was observed upon heating to $360-390 \mathrm{~K}$ for $\mathrm{MA}_{2} \mathrm{KGdCl}_{6}$ and $420-450 \mathrm{~K}$ for $\mathrm{MA}_{2} \mathrm{KYCl}_{6}$ (Figure 6b). Calculated electronic band structure of both rare-earth hybrid double perovskites gave large direct bandgaps of $4.91 \mathrm{eV}$ for $\mathrm{MA}_{2} \mathrm{KGdCl}_{6}$ and $5.04 \mathrm{eV}$ for $\mathrm{MA}_{2} \mathrm{KYCl}_{6}$ (Figure $6 \mathrm{c}$ ). These large bandgap values were attributed to the (a)

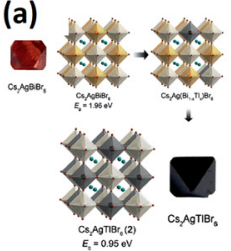

(b)

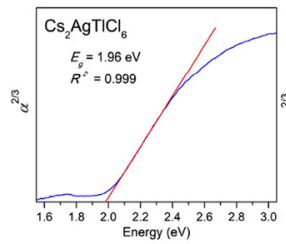

(c)

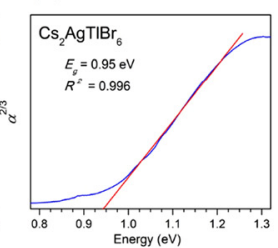

(g)
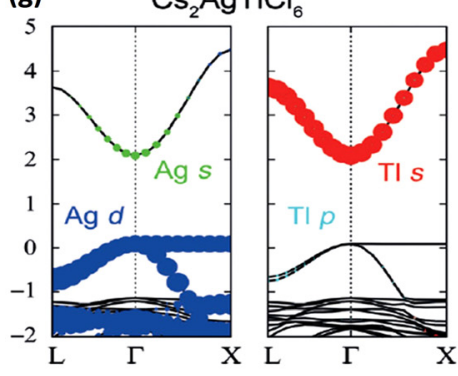

(h)

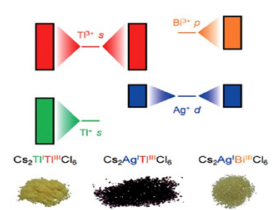

(i)
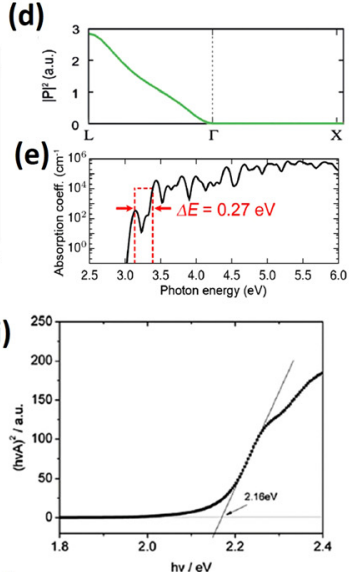

(k)

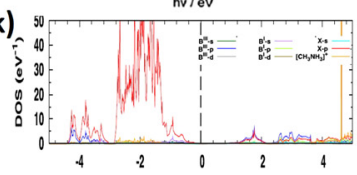

(f)

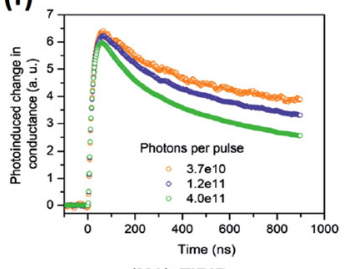

(MA) ${ }_{2} \mathrm{TIBIBr}_{6}$

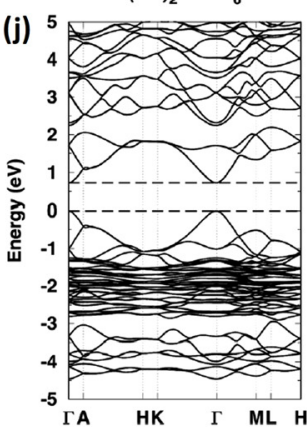

Figure 5: (a) Single-crystal structures of $\mathrm{Cs}_{2} \mathrm{AgBiBr}_{6}$ and $\mathrm{Cs}_{2} \mathrm{AgTlBr}_{6}$ double perovskites [110]. 2018 Wiley-VCH Verlag GmbH \& Co. KGaA, Weinheim. Tauc plot of (b) $\mathrm{Cs}_{2} \mathrm{AgTlCl}_{6}$ and (c) $\mathrm{Cs}_{2} \mathrm{AgTlBr}_{6}$ double perovskites [110]. 2018 Wiley-VCH Verlag GmbH \& Co. KGaA, Weinheim. (d) Transition dipole matrix elements $|P|^{2}$ along high-symmetry lines in reciprocal space. (e) Calculated absorption spectrum of $\mathrm{Cs}_{2} \mathrm{AgTICl}_{6}$

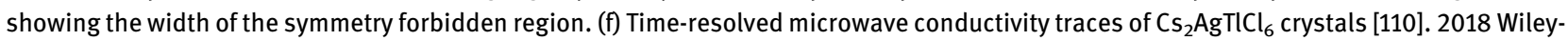
VCH Verlag GmbH \& Co. KGaA, Weinheim. (g) Calculated band structure of $\mathrm{Cs}_{2} \mathrm{AgTICl}_{6}$ [110]. 2018 Wiley-VCH Verlag GmbH \& Co. KGaA, Weinheim. (h) Schematic representation of the relative energies of the atomic orbitals (lines) and bands (rectangles) for closely related double perovskites [110]. 2018 Wiley-VCH Verlag GmbH \& Co. KGaA, Weinheim. (i) Corresponding Tauc plot of $\mathrm{MA}_{2} \mathrm{TlBiBr}_{6}$ hybrid double perovskite [93]. Copyright 2015, Royal Society of Chemistry. (j) Computed electronic band structure and (k) PDOS of $\mathrm{MA}_{2} \mathrm{TIBiBr}_{6}$ double perovskite [93]. Copyright 2015, Royal Society of Chemistry. 
attendance of $\mathrm{Cl}^{-}$with smaller ionic radius and higher electronegativity than bromine or iodine, and also the substantial ionic nature of the $\mathrm{K}^{+}$cation [93]. Assessing the contributed orbitals to the band-edges confirmed the dominant presence of the $\mathrm{Cl}-3 p$ nonbonding states at the VBM for both compounds, whereas the CBM was characterized by Gd$5 d / \mathrm{Cl}-3 p$ and Y-4d/Cl-3p bonding states for $\mathrm{MA}_{2} \mathrm{KGdCl}_{6}$ and $\mathrm{MA}_{2} \mathrm{KYCl}_{6}$, respectively (Figure $6 \mathrm{~d}$ ). On the other hand, $\mathrm{MA}^{+}$ and $\mathrm{K}^{+}$cations showed a localized energy state that energetically inactivated them to subscribe to the band edges, similar to $\mathrm{MA}_{2} \mathrm{KBiCl}_{6}$ [88]. Unlike other transition-hybrid MHDPs (e.g. $\mathrm{MA}_{2} \mathrm{TlBiBr}_{6}$ ) [110], whose direct bandgap was strongly dependent on the Tl-6s lone pairs, in rare-earth hybrid double perovskites of $\mathrm{MA}_{2} \mathrm{KBCl}_{6}(\mathrm{~B}=\mathrm{Gd}, \mathrm{Y})$ direct characteristic of the bandgap originated from the predominant role of $\mathrm{Cl}-3 p$ nonbonding states at the VBM. A direct bandgap is an important material characteristic to fulfil its potential for optoelectronic applications as it provides straightforward optical absorption and emission processes.
Although the calculated bandgaps for these proposed rareearth hybrid halide double perovskites were extensively wide and unsuitable for solar cells, it was believed that doping some other rare-elements such as $\mathrm{Tb}^{3+}, \mathrm{Ce}^{3+}$ or $\mathrm{Eu}^{3+}$ into the structure could further improve their potential as solid-state lighting [125].

\section{Bandgap engineering of MHDPs}

Although MHDPs have emerged as promising new alternatives for optoelectronic applications [48-50, 76, 88, 90, $100]$, in most cases, they have shown either large and indirect or direct forbidden bandgaps that practically are not satisfying for high-efficiency photovoltaics [103]. Though some computational works have predicted the potential solutions when both metal cations possess lone-pair frontier orbitals (e.g. $\mathrm{Cs}_{2} \mathrm{InBiCl}_{6}$ and $\mathrm{Cs}_{2} \mathrm{InSbCl}_{6}$ ) [126], experimental results confirmed their difficult formation at (a)

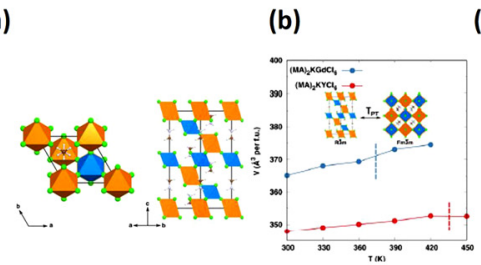

(g)

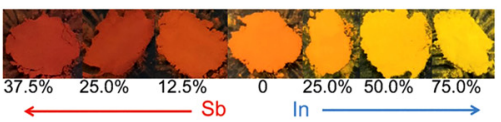

(h)

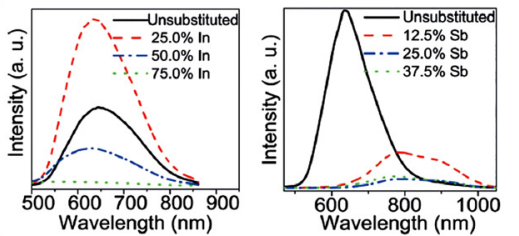

(k)

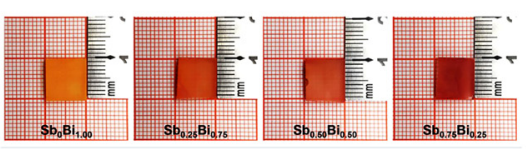

(c) $\mathrm{MA}_{2} \mathrm{KCdCl}_{6} \quad \mathrm{MA}_{2} \mathrm{KYCl}_{6} \quad$ (d)

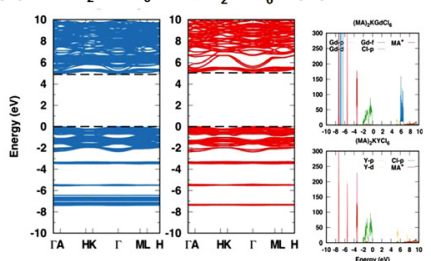

(i)
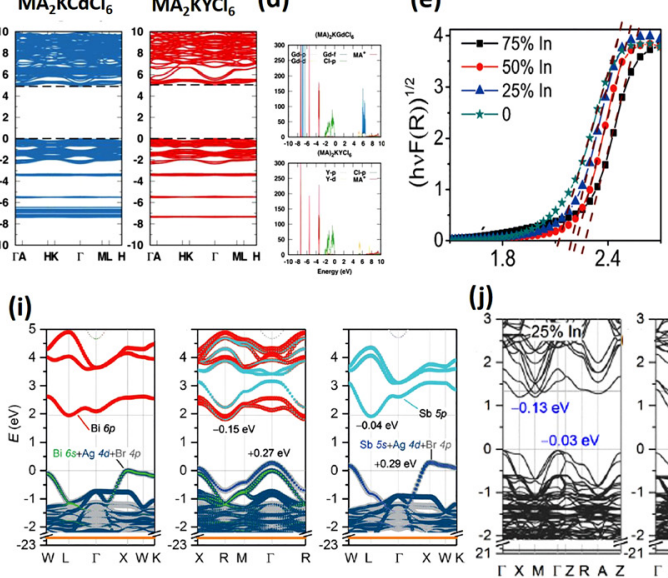

(f)

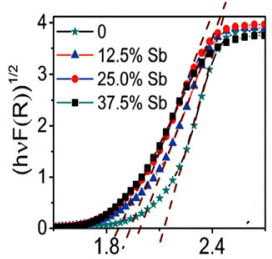

(j)
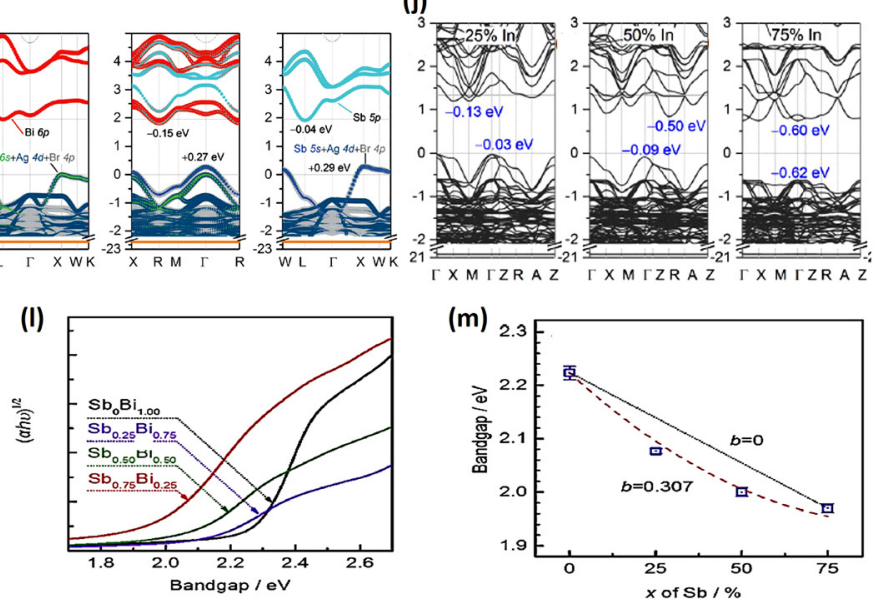

Figure 6: Conventional unit cells of rhombohedral $\mathrm{MA}_{2} \mathrm{KBCl}_{6}(B=\mathrm{Gd}$ and $\mathrm{Y})$ at room temperature viewed (a) along the $c$-axis and (b) parallel to the $a-b$ plane [122]. Copyright 2017 American Chemical Society. (c) Volumes per formula unit (f.u.) of $\mathrm{MA}_{2} \mathrm{KGdCl}_{6}$ and $\mathrm{MA}_{2} \mathrm{KYCl}_{6}$ upon heating [122]. Copyright 2017 American Chemical Society. (d) Calculated band structures and (e) PDOS for $\mathrm{MA}_{2} \mathrm{KGdCl}_{6}$ and $\mathrm{MA}_{2} \mathrm{KYCl}_{6}$ [122]. Copyright 2017 American Chemical Society. Indirect Tauc plots of (e) $\mathrm{Cs}_{2} \mathrm{Ag}\left(\mathrm{Bi}_{1-x} \mathrm{In}_{x}\right) \mathrm{Br}_{6}$ and (f) $\mathrm{Cs}_{2} \mathrm{Ag}\left(\mathrm{Bi}_{1-x} \mathrm{Sb}_{x}\right) \mathrm{Br}_{6}[130]$. $2017 \mathrm{Wiley}-\mathrm{VCH}$ Verlag GmbH \& Co. KGaA, Weinheim. (g) Photos of In- and Sb-alloyed $\mathrm{Cs}_{2} \mathrm{AgBiBr}_{6}$ samples. (h) PL spectra of In- and Sb-alloyed $\mathrm{Cs}_{2} \mathrm{AgBiBr}_{6}$ samples [130]. 2017 Wiley-VCH Verlag GmbH \& Co. KGaA, Weinheim. (i) Calculated band structure of $\mathrm{Cs}_{2} \mathrm{AgBiBr}_{6}, \mathrm{Cs}_{2} \mathrm{Ag}\left(\mathrm{Bi}_{0.75} \mathrm{Sb}_{0.25}\right) \mathrm{Br}_{6}$, and hypothetical $\mathrm{Cs}_{2} \mathrm{AgSbBr}_{6}$ [130]. 2017 Wiley-VCH Verlag GmbH \& Co. KGaA, Weinheim. (j) Calculated band structure of $\mathrm{Cs}_{2} A g\left(\mathrm{Bi}_{1-x} \mathrm{In}_{x}\right) \mathrm{Br}_{6}$ with $x=0.25,0.50$ and 0.75. (k) Optical images of $\mathrm{Cs}_{2} \mathrm{AgSb}_{x} \mathrm{Bi}_{1-x} \mathrm{Br}_{6}(0 \leq x \leq 0.75)$ thin-films [131]. 2019 Elsevier Ltd. All rights reserved. (l) Tauc plots of $\mathrm{Cs}_{2} \mathrm{AgSb}_{x} \mathrm{Bi}_{1-x} \mathrm{Br}_{6}(0 \leq x \leq 0.75)$ thin-films [131]. 2019 Elsevier Ltd. All rights reserved. (m) Averaged bandgap of $\mathrm{Cs}_{2} \mathrm{AgSb}_{x} \mathrm{Bi}_{1-x} \mathrm{Br}_{6}(0 \leq x \leq 0.75)$ thin-films [131]. 2019 Elsevier Ltd. All rights reserved. 
room temperature [127]. Therefore, if MHDPs are expected to find a deserved position in the future of optoelectronics, their bandgap engineering is of vital importance. Atomic substitution has been shown as an effective method for tuning the bandgaps of semiconductors $[128,129]$. In MHDPs with four various lattice sites in the $\mathrm{A}_{2} \mathrm{BB}^{\prime} \mathrm{X}_{6}$ structure, $\mathrm{B}^{\prime 3+}$ has the most diversity and freedom with more than 34 candidates to be placed at this site [76]. Given these, in this section, some reports on bandgap tuning of MHDPs are described.

\subsection{Alloying in $\mathrm{A}_{2} \mathrm{AgBiX}_{6}\left(\mathrm{~A}=\mathrm{MA}^{+}, \mathrm{Cs}^{+}\right.$; $\mathrm{X}=\mathrm{Cl}^{-}, \mathrm{Br}^{-}$and $\mathrm{I}^{-}$)}

\subsubsection{In- and $\mathrm{Sb}$-alloyed $\mathrm{Cs}_{2} \mathrm{AgBiBr}_{6}$}

Bandgap engineering of $\mathrm{Cs}_{2} \mathrm{AgBiBr}_{6}$ is one approach to improve the material properties for enhancing its photovoltaic performance. Du et al. have demonstrated $\operatorname{In}^{3+}$ and $\mathrm{Sb}^{3+}$ alloying with the hosting material's structure $\left(\mathrm{Cs}_{2} \mathrm{Ag}\right.$ $\left.\mathrm{BiBr}_{6}\right)$ using the typical formula of $\mathrm{Cs}_{2} \mathrm{Ag}\left(\mathrm{Bi}_{1-x} \mathrm{M}_{x}\right) \mathrm{Br}_{6}$ $(\mathrm{M}=\mathrm{In}, \mathrm{Sb})$ [130]. $\mathrm{In}^{3+}$ could be incorporated in the $\mathrm{Bi}^{3+}$ lattice site up to $75 \%$ before the formation of the secondary phases, whereas $\mathrm{Sb}^{3+}$ substitution with lower homogeneity was limited to $37 \%$. Diffuse reflection measurement revealed increment in the bandgap energy upon $\mathrm{In}^{3+}$ incorporation and decrement trend for $\mathrm{Sb}^{3+}$ adoption (Figure 6e and f). In particular, the bandgap of the hosting material enlarged from 2.12 to $2.27 \mathrm{eV}$ while the $\mathrm{In}^{3+}$ doping proportion $(x)$ increased from 0 to 0.75 . In opposite, a bandgap reduction from 2.12 to $1.86 \mathrm{eV}$ was observed for $\mathrm{Sb}^{3+}$ incorporation from 0 to 0.37 , in agreement with the sample colour (Figure 6g). Regarding the PL emission, the $\operatorname{In}^{3+}$-alloyed sample with $x=0.25$ yielded the strongest PL intensity, while $x=0.75$ showed the weakest (Figure 6h). Fitting the PL spectra indicated two Gaussian peaks at around 610-560 and $680 \mathrm{~nm}$. The former shifted with the $\mathrm{In}^{3+}$-alloying level and corresponded well with the band edge emission, whereas the latter with $1.8 \mathrm{eV}$ energy smaller than the bandgap value might correlate with the defects into the band structure. The PL intensity reduction following more $\mathrm{In}^{3+}$ substitution should be due to the formation of deeper defects or a symmetry-forbidden for the transition from VBM to the CBM due to the presence of In-5s states in the CBM (Figure 6h) [103]. For $\mathrm{Sb}^{3+}$-alloyed samples, a redshift in the PL spectrum compared to the pure $\mathrm{Cs}_{2} \mathrm{AgBiBr}_{6}$ compound was clear (Figure $6 \mathrm{~h}$ ). The two fitted peaks for $\mathrm{Sb}^{3+}$-substituted powders appeared to be at circa $775 \mathrm{~nm}$ $(1.6 \mathrm{eV})$ and $905 \mathrm{~nm}(1.4 \mathrm{eV})$, which considerably fall lower than the measured bandgap for $x=0.25$. This indicated the formation of substantially deep defect states that could be counted for the fast PL emission intensity suppression.

DFT calculations showed for $\mathrm{Sb}^{3+}$-alloyed samples with $x=0.25$, VBM derived from Sb-5s/Ag- $4 d / \mathrm{Br}-4 p$ orbitals (Figure 6i), while the CMB formed by Sb-5p/Bi-6p orbitals. These orbital interactions yielded a $0.15 \mathrm{eV}$ slip-down in the CBM and a $0.27 \mathrm{eV}$ shift-up in the VBM forming an indirect bandgap. More adoption of the $\mathrm{Sb}^{3+}$ into the structure mitigated the incorporation of the Bi- $6 p$ states into the CBM and broadened the VBM. For $\mathrm{In}^{3+}$-alloyed samples, the VBM originated from $\mathrm{Bi}-6 \mathrm{~s} / \mathrm{Ag}-4 \mathrm{~d} / \mathrm{Br}-4 p$ orbitals; and the CBM came from In-5s/Bi- $6 p$ with a $0.13 \mathrm{eV}$ drop in its energy level (Figure 6j). This fall came from the broadening of the In5s-dominated CBM. At the same time, an energy fall in the VBM revealed a competing trend between the simultaneous downshifts in CBM and VBM. The final bandgap value was influenced by the winner of this competition. If the second trend outweighs the first one, the bandgap will increase that corresponded to the case of the experimental observations in this work. Inspired by these observations, Liu et al. developed a facile solution-processed approach to synthesis high purity $\mathrm{Cs}_{2} \mathrm{AgSb}_{x} \mathrm{Bi}_{1-\chi} \mathrm{Br}_{6}(0 \leq x \leq 0.75)$ thin-films [131] with a maximum bandgap reduction of $0.25 \mathrm{eV}$ from 2.22 to $1.97 \mathrm{eV}$ for $x=0.75$ (Figure $6 \mathrm{k}-\mathrm{m}$ ).

\subsubsection{Tl-alloyed $\mathrm{Cs}_{2} \mathrm{AgBiBr}_{6}$}

To produce a material with competitive photophysical properties to those of $\mathrm{Pb}$-based halide perovskites $\left(\mathrm{MAPbI}_{3}\right)$, Slavney et al. demonstrated the dilute alloying of the $\mathrm{Cs}_{2} \mathrm{Ag}$ $\mathrm{BiBr}_{6}$ with $\mathrm{Tl}^{+}$. Introducing $\mathrm{TlBr}$ into the precursor solution allowed the tuning of $\mathrm{Tl}^{+}$across the structure following the formula of $\mathrm{Cs}_{2}\left(\mathrm{Ag}_{1-a} \mathrm{Bi}_{1-b}\right) \mathrm{Tl}_{x} \mathrm{Br}_{6}(0.003<x=a+b<0.075)$. The products showed a nearly identical crystal structure to the hosting $\mathrm{Cs}_{2} \mathrm{AgBiBr}_{6}$ composition [132]. Determining the $\mathrm{Tl}$ oxidation state, X-ray absorption near-edge structure (XANES) measurement showed three inflection points on the rising edge of the compound with the $\mathrm{Tl}^{3+}$ spectrum, while for $\mathrm{Tl}^{+}$it was only in one point (Figure 7a). In general, it was observed that $\mathrm{Tl}$ can be positioned at either $\mathrm{B}^{+}$or $\mathrm{B}^{3+}$ sites, where in the dilute alloying regime of $0.003<x<0.075$, the substitution in $\mathrm{B}^{3+}$ site is dominant. UV-Vis measurement showed a sharp drop in the bandgap energy from indirect $1.95 \mathrm{eV}$ for $x=0$ to direct $1.72 \mathrm{eV}$ or indirect $1.57 \mathrm{eV}$ for $x=0.010$ (Figure $7 \mathrm{~b}$ and $\mathrm{c}$ ). Further increasing $x$, a slower reduction was observed for the bandgap energy. At $x=0.075$ as the highest alloying level, the bandgap reached to indirect $1.40 \mathrm{eV}$ or direct $1.57 \mathrm{eV}$. Notably, this dilute alloying strategy brought the bandgap of $\mathrm{Cs}_{2} \mathrm{AgBiBr}_{6}$ within the acceptable range for single-junction photovoltaics. Time-resolved microwave photoconductivity (TRMC) measurements probed a 
(a)

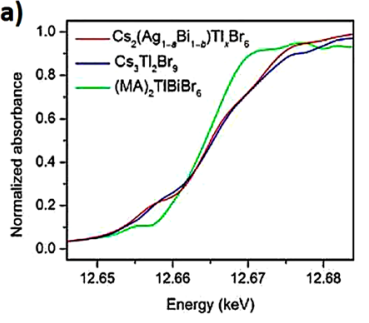

(e)

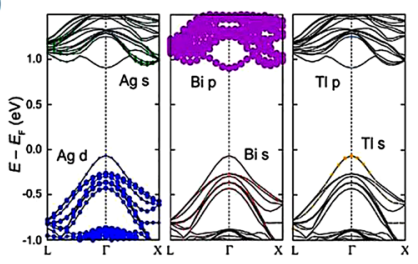

(i)

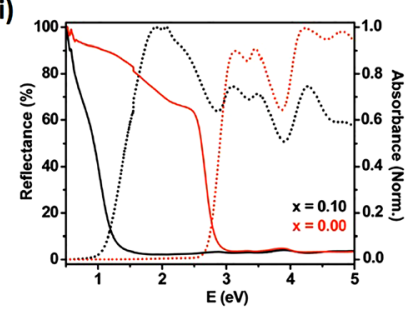

(b)

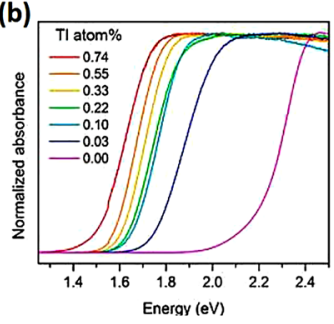

(f)

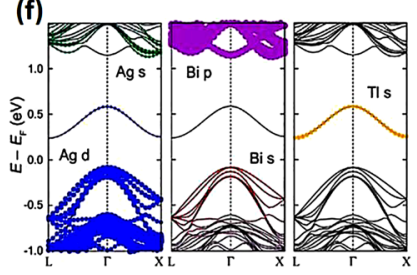

(j)

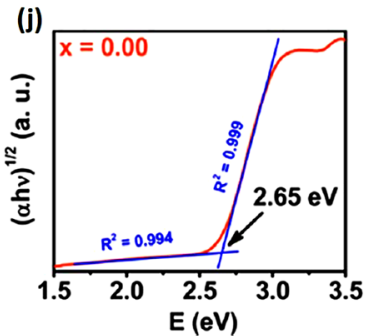

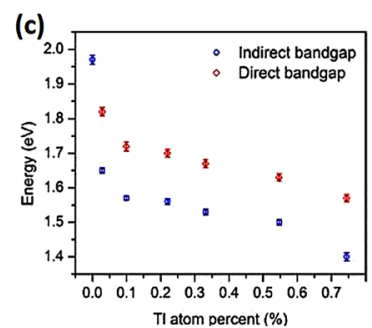

(I ato

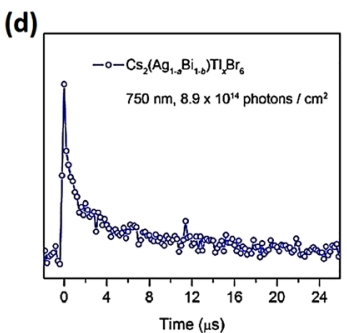

(h)

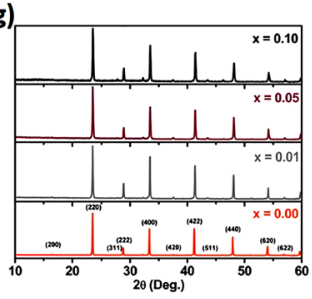

(k)

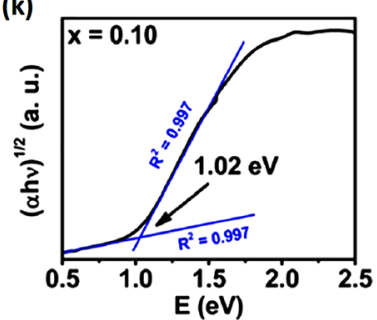

(h)

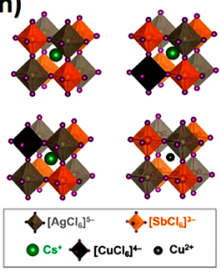

(I)

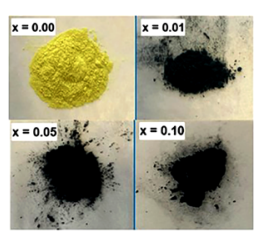

Figure 7: (a) X-ray near edge absorption structure (XANES) spectrum of $\mathrm{Cs}_{2}\left(\mathrm{Ag}_{1-a} \mathrm{Bi}_{1-b}\right) \mathrm{Tl}_{x} \mathrm{Br}_{6}(x=0.075), \mathrm{Tl}^{+}$and $\mathrm{Tl}^{3+}$ standards [132]. Copyright 2017, American Chemical Society. (b) Absorbance spectra of $\mathrm{Cs}_{2}\left(\mathrm{Ag}_{1-a} \mathrm{Bi}_{1-b}\right) \mathrm{Tl}_{x} \mathrm{Br}_{6}$ [132]. Copyright 2017, American Chemical Society. (c) Apparent bandgaps of $\mathrm{Cs}_{2}\left(\mathrm{Ag}_{1-a} \mathrm{Bi}_{1-b}\right) \mathrm{Tl}_{x} \mathrm{Br}_{6}$. (d) TRMC decay trace of $\mathrm{Cs}_{2}\left(\mathrm{Ag}_{1-a} \mathrm{Bi}_{1-b}\right) \mathrm{Tl}_{x} \mathrm{Br}_{6}$ (with $\left.x=0.075\right)$ single-crystals [132]. Copyright 2017, American Chemical Society. Band structures of $\mathrm{Cs}_{2}\left(\mathrm{Ag}_{1-a} \mathrm{Bi}_{1-b}\right) \mathrm{Tl}_{x} \mathrm{Br}_{6}(x=0.06)$ for (e) replacing $\mathrm{Ag}^{+}$with $\mathrm{Tl}^{+}$and (f) replacing $\mathrm{Bi}^{3+}$ with $\mathrm{Tl}^{3+}[132]$. Copyright 2017, American Chemical Society. (g) XRD patterns for $\mathrm{Cs}_{2} \mathrm{AgSbCl}_{6}(x=0.00)$ and for $\mathrm{Cu}^{2+}$-doped $\mathrm{Cs}_{2} \mathrm{AgSbCl}_{6}$ materials [133]. Copyright 2018, American Chemical Society. (h) Schematic representation of the $\mathrm{Cs}_{2} \mathrm{AgSbCl}_{6}$ double perovskite structure and of possible $\mathrm{Cu}^{2+}$. doped analogues [133]. Copyright 2018, American Chemical Society. (i) UV-Vis (solid lines) and normalized absorption (dotted lines) spectrum for $\mathrm{Cs}_{2} \mathrm{AgSbCl}_{6}$ parent $(x=0.00)$ and the maximum $\mathrm{Cu}^{2+}$-doped $(x=0.10)$ materials [133]. Copyright 2018, American Chemical Society. (j) The Tauc plots of $\mathrm{Cs}_{2} \mathrm{AgSbCl}_{6}(x=0.00)$ and $(\mathrm{k})$ for the maximum $\mathrm{Cu}^{2+}$-doped material $(x=0.10)$ [133]. (l) photographs of $\mathrm{Cs}_{2} \mathrm{AgSbCl}_{6}(x=0.00)$ and $\mathrm{Cu}^{2+}$-doped polycrystalline materials [133]. Copyright 2018, American Chemical Society.

decrease in the carrier lifetime in the alloyed compound, however still in the long-lived microsecond range (Figure 7d). This suggested that dopants did not form intensive recombination trap states, therefore carriers could expeditiously transfer in a solar cell structure.

DFT calculations helped to specify the electronic structure evolution of the compound after Tl-alloying. $\mathrm{Ag}^{+}$ replacement by $\mathrm{Tl}^{+}$, a direct bandgap with a reduction of ca. $0.1 \mathrm{eV}$ was observed (Figure 7e). Whereas considering $\mathrm{Tl}^{3+}$ substitution for $\mathrm{Bi}^{3+}$, much larger bandgap shrinkage of $0.8 \mathrm{eV}$ with an indirect transition was obtained (Figure 7f). A possible model to explain these different bandgap reductions can be that at low doping levels of $\mathrm{Tl}^{+}$, defect levels are extracted from $\mathrm{Tl}^{+}-6 \mathrm{~s}^{2}$ and $6 p^{0}$ orbitals, whereas substitution of $\mathrm{Tl}^{3+}$ introduces defect levels from $\mathrm{Tl}^{3+}-5 d^{10}$ and $6 s^{0}$ orbitals. By $\mathrm{Tl}^{3+}$ substitution, the average energy of the $\mathrm{Tl}^{3+}-6 s^{0}$ orbitals is below the CBM of pure $\mathrm{Cs}_{2} \mathrm{AgBiBr}_{6}$, which, therefore, results in a considerable bandgap reduction. This new band is dominated by $\mathrm{Tl}^{3+}-6 s^{0}$ and $\mathrm{Ag}$ $4 d$ orbitals that place the CBM at the $L$-point. On the other hand, $\mathrm{Tl}^{+}$substitution for $\mathrm{Ag}^{+}$, the average energy of the occupied $\mathrm{Tl}^{+}-6 \mathrm{~s}^{2}$ orbitals is above the hosting compound's VBM, which slightly narrows the bandgap. Equal substitution of $\mathrm{B}^{+}$and $\mathrm{B}^{\prime 3+}$ sites with $\mathrm{Tl}^{+}$and $\mathrm{Tl}^{3+}$, the CBM is dominantly derived from the lower-energy Tl-6s states, which ultimately maintains the indirect characteristic of the bandgap.

\subsection{Doping and alloying in $\mathrm{Cs}_{2} \mathrm{AgSbX}_{6}$ $\left(\mathrm{X}=\mathrm{Cl}^{-}\right.$and $\left.\mathrm{Br}^{-}\right)$}

\subsubsection{Cu-doped $\mathrm{Cs}_{2} \mathrm{AgSbCl}_{6}$}

To mitigate the poor alignment of the most double perovskites' absorption profile with the solar spectrum, 
Karmakar et al. [133] presented a dramatic red-shift in the bandgap energy of $\mathrm{Cs}_{2} \mathrm{AgSbCl}_{6}$ through $\mathrm{Cu}^{2+}$ doping. As discussed before, $\mathrm{Cs}_{2} \mathrm{AgSbCl}_{6}$ has an indirect bandgap transition, where the VBM and CBM mainly include Ag-4d/ $\mathrm{Cl}-3 p$ and Sb-5p/Cl-3p orbitals, respectively. A dilute incorporation of $3 d^{9}$ states around the compound's VBM may narrow the bandgap while the 3D structural framework maintained unaltered. Heterovalent $\mathrm{Cu}^{2+}$ doping can be a potential strategy to reach this goal. To this end, $\mathrm{Cu}^{2+}$ was doped into the polycrystalline $\mathrm{Cs}_{2} \mathrm{AgSbCl}_{6}$ through solvent synthesis to produce the product with nominal formula of $\mathrm{Cs}_{2} \mathrm{Ag}_{1-a} \mathrm{Sb}_{1-b} \mathrm{Cu}_{2 \mathrm{x}} \mathrm{Cl}_{6}(2 x=a+\mathrm{b}, x=0.00,0.01,0.05,0.10)$. $\mathrm{XRD}$ characterizations showed a nearly identical spectrum for samples before and after doping that confirmed the formation of a fairly single-phase crystalline solid (Figure 7g). However, closer examination indicated an increase in the $\mathrm{AgCl}$ concentration by incorporating more $\mathrm{Cu}^{2+}$ into the structure. Qualitatively, it was speculated that upon $\mathrm{Cu}^{2+}$-doping $\left[\mathrm{AgCl}_{6}\right]^{5-}$ octahedra in the lattice were substituted by $\left[\mathrm{CuCl}_{6}\right]^{4-}$ octahedra that yielded to the formation of vacancies to maintain charge neutrality. This caused some part of $\mathrm{AgCl}$ remained insoluble. In principle, $\mathrm{Cu}^{2+}$ can be incorporated into three sites of the hosting compound's crystal lattice: (i) Replacing the $\left[\mathrm{AgCl}_{6}\right]^{5-}$ octahedra or (ii) the $\left[\mathrm{SbCl}_{6}\right]^{3-}$ octahedra with $\left[\mathrm{CuCl}_{6}\right]^{4-}$ octahedra (Figure 7h). (iii) Occupying the centre of the cuboctahedra (A-site) of the lattice that induced the formation of a neighbouring vacancy (Figure $7 \mathrm{~h}$ ).

UV-Vis reflection measurement (Figure 7i) illustrated a drastic red-shift of the compound's optical band edge after $\mathrm{Cu}^{2+}$ doping with a bandgap shrinkage of $\mathrm{Cs}_{2} \mathrm{AgSbCl}_{6}$ from 2.65 to $1.02 \mathrm{eV}$ upon $1 \%(x=0.010) \mathrm{Cu}^{2+}$-doping (Figure 7j-k). This was consistent with the dramatic visual colour change from yellow to black upon inducing more $\mathrm{Cu}^{2+}$ into the structure (Figure 7l). A similar trend has been observed in Tl-alloyed $\mathrm{Cs}_{2} \mathrm{AgBiBr}_{6}$ [132], $\mathrm{Cu}^{2+}$-alloyed $\mathrm{Cs}_{4} \mathrm{Sb}_{2} \mathrm{MnCl}_{12}$ material [134] and $\mathrm{Pb}$-free $\mathrm{MA}_{2} \mathrm{CuCl}_{x} \mathrm{Br}_{4-x}$ hybrid perovskites [135]. A band tailing characteristic in the Tauc plot of the doped samples suggested the formation of defects in the structure. In low doping amounts, a localized state in the vicinity of the band edges formed corresponding to a localized transition. Whereas, higher doping concentration caused a reduction in the average $\mathrm{Cu}-\mathrm{Cu}$ distances between defect sites, therefore the localized impurity states converted to delocalized states, igniting more bandgap reduction by more $\mathrm{Cu}^{2+}$ doping.

\subsubsection{In-alloyed $\mathrm{Cs}_{2} \mathrm{AgSbCl}_{6}$}

Normally, it is not feasible to separately adjust the CBM and VBM, because they are practically antibonding and paired bonding. However, in double perovskites $\left(\mathrm{A}_{2} \mathrm{BB}^{\prime} \mathrm{X}_{6}\right)$, it is possible because in this structure $\mathrm{B}^{+}-d^{10}$ states establish the VBM, and $\mathrm{B}^{\prime 3+}-s / p$ states make up the CBM. To develop a systematic strategy for an indirect to direct bandgap convergence in MHDPs, Tran et al. [92] presented a rational design approach. The idea was based on regulating the electron configuration of the $\mathrm{B}^{\prime 3+}$ site in $\mathrm{A}_{2} \mathrm{BB}^{\prime} \mathrm{X}_{6}$ structure from $s^{0}$ to $s^{2}$ states. This strategy could adjust the main contributed states at CBM between $s$-orbitals and $p$-orbitals while the remainder of the band structure maintained intact. Studying optoelectronic properties of $\mathrm{Cs}_{2} \mathrm{AgSbCl}_{6}, \mathrm{Cs}_{2} \mathrm{~A}$ gInCl $\mathrm{I}_{6}$ and intermediate $\mathrm{Cs}_{2} \mathrm{AgSb}_{x} \mathrm{In}_{1-x} \mathrm{Cl}_{6}$ polycrystalline samples helped to understand the viability of this hypothesis. UV-Vis diffuse reflectance spectra characterization showed indirect bandgap of $2.54 \mathrm{eV}$ for $\mathrm{Cs}_{2} \mathrm{AgSbCl}_{6}$, as discussed thoroughly in the previous sections [92], and a direct bandgap of $3.53 \mathrm{eV}$ for $\mathrm{Cs}_{2} \mathrm{AgInCl}_{6}$. An indirect to direct transition was observed by replacing $60 \%$ of $\mathrm{Sb}^{3+}$ with $\mathrm{In}^{3+}$ $\left(\mathrm{Cs}_{2} \mathrm{AgSb}_{0.4} \mathrm{In}_{0.6} \mathrm{Cl}_{6}, x=0.4\right)$. From the corresponding Tau plot, it was seen that at $x=0.5$ the compound indicated a very platy absorption spectrum starting at the edge of $2.81 \mathrm{eV}$. A following sharper absorption at 3.12 approximated the bandgap of $2.81 \mathrm{eV}$ for this ratio of Sb:In (4:6) (Figure 8a). Further inducing $\mathrm{In}^{3+}$ in the structure, the characteristic of the direct bandgap appeared in their relevant spectrum. Figure $8 \mathrm{~b}$ depicts the phase-diagram of the bandgap of the $\mathrm{Cs}_{2} \mathrm{AgSb}_{x} \mathrm{In}_{1-x} \mathrm{Cl}_{6}(x=0,0.2,0.4,0.5,1)$ that clearly shows the bandgap transition from indirect to direct having more $\mathrm{In}^{3+}$ in the composition. The reason for this was attributed to an alternation in the characteristic of the CBM from $s$-orbital-derived feature to $p$-orbital-derived one. This observation confirmed the convergence of direct and indirect bandgaps in double perovskites through the adjustment of the CBM characteristics.

\subsection{Doping and alloying in $\mathrm{Cs}_{2} \mathrm{AgInCl}_{6}$}

\subsubsection{Mn-doped $\mathrm{Cs}_{2} \mathrm{AgInCl}_{6}$}

To tune the optical properties of MHDPs, Nandha et al. imparted the visible-light emission property in $\mathrm{Cs}_{2} \mathrm{AgInCl}_{6}$ through $\mathrm{Mn}^{2+}$ doping [136]. XRD characterization on samples with different amounts of $\mathrm{Mn}^{2+}$ in the precursor exhibited no new peak, inferring the formation of no impurity phase related to $\mathrm{Mn}$ (Figure 8c). Also, no additional peak of $\mathrm{AgCl}$ could be found that indicated the full reaction of $\mathrm{AgCl}$ in the precursor. Besides, the XRD spectra exhibited no discernible displacement of the peaks that confirmed the negligible impact on the crystal structure. UV-Vis measurement indicated the variation of absorption edge upon $\mathrm{Mn}^{+}$-doping 
(Figure 8d). This highlighted no significant change in the absorption of the parent material after Mn-doping, where the colour of the powders with 0 and $0.9 \% \mathrm{Mn}$ remained in the similar white (Figure 8d, inset). PL measurement on the Mn-doped $\mathrm{Cs}_{2} \mathrm{AgInCl}{ }_{6}$ powders showed weak PL spectra centred at $\sim 619 \mathrm{~nm}$. Interestingly, the PL intensity exhibited a significant increase upon Mn-doping, and the peak slightly shifted to $\sim 632 \mathrm{~nm}$ (Figure 8e). These results emphasized the influence of Mn-doping on PL emission efficiency. Previous reports discussed the de-excitation of a Mn- $d$-orbital electron from the ${ }^{4} \mathrm{~T}_{1}$ to ${ }^{6} \mathrm{~A}_{1}$ state as the origin of the enhanced PL intensity in Mn-doped semiconductors [137-139]. Since this transition for Mn- $d$ orbital electrons is spin-forbidden, a slow PL decay in the range of millisecond (ms) to sub-ms was expected for the doped samples, as shown in Figure 8f.
The long PL lifetimes of Mn-doped samples were obtained by a tri-exponential model, Figure 8f (inset). A PL enhancement of doped samples was ascribed to the weak interaction of ${ }^{4} \mathrm{~T}_{1}-{ }^{6} \mathrm{~A}_{1}$ inner core atomic like transition with non-radiative trap states in $\mathrm{Cs}_{2} \mathrm{AgInCl}_{6}$ lattice $[136,140]$. The PL emission intensity increased continuously up until $1 \%$ Mn doping; while further Mn content resulted in the reduction of PL intensity, possibly due to $\mathrm{Mn}-\mathrm{Cl}-\mathrm{Mn}$ exchange interactions [141].

\subsubsection{Fe-alloyed $\mathrm{Cs}_{2} \mathrm{AgInCl}_{6}$}

To tune the bandgap of the MHDPs, Yin et al. [142] demonstrated a new class of double perovskites by incorporation of $\mathrm{Fe}^{3+}$ in the parent structure of $\mathrm{Cs}_{2} \mathrm{AgInCl}_{6}$. This (a)

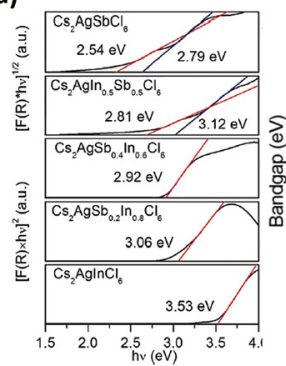

(e)

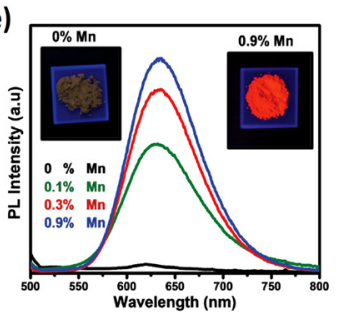

(i)

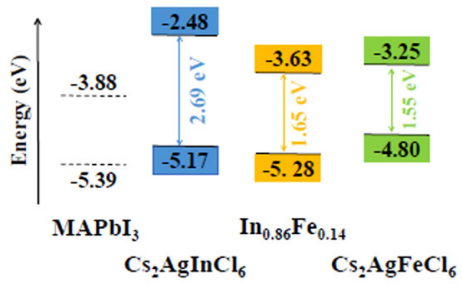

(b)
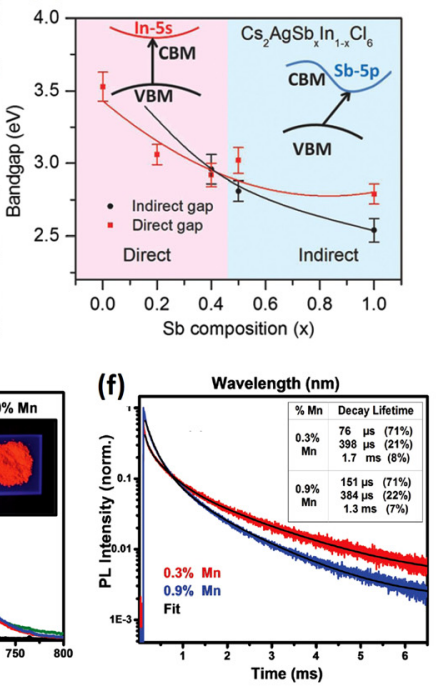

(j)

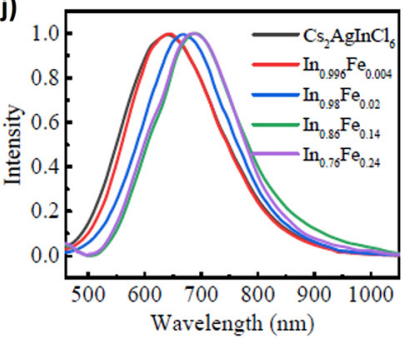

(d)

(c)
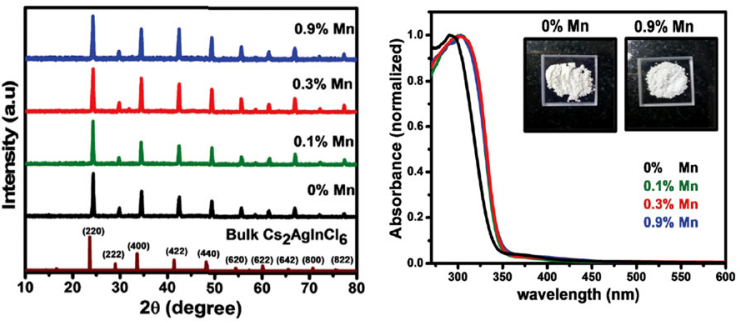

(g)
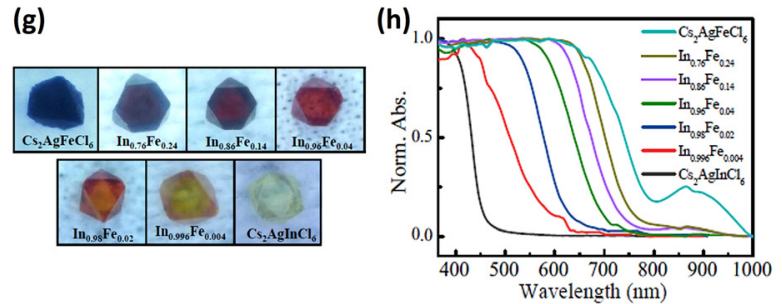

(k)

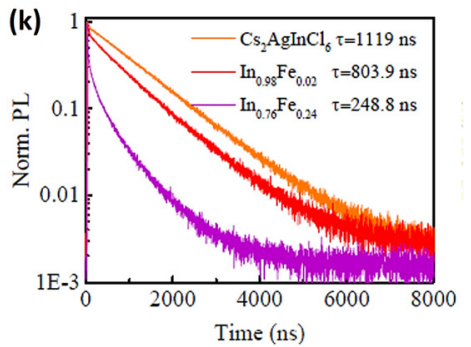

Figure 8: (a) Tauc plots for $\mathrm{CS}_{2} \mathrm{AgSb}_{x} \mathrm{In}_{1-x} \mathrm{Cl}_{6}(x=0,0.2,0.4,0.5,1)$ [92]. Copyright 2015, Royal Society of Chemistry. (b) Phase diagram for $\mathrm{Cs}_{2} \mathrm{AgSb}_{x} \mathrm{In}_{1-x} \mathrm{Cl}_{6}\left(x=0,0.2,0.4,0.5\right.$ and 1) [92]. Copyright 2015, Royal Society of Chemistry. (c) XRD patterns for $\mathrm{Mn}_{-}$doped $\mathrm{Cs}_{2} \mathrm{AgInCl}_{6}$ with

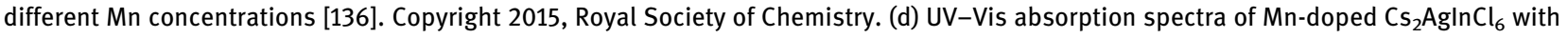
different $\mathrm{Mn}$ contents. Insets: the photographs of white colour powder samples under visible light [136]. Copyright 2015, Royal Society of Chemistry. (e) PL spectra of $\mathrm{Mn}$-doped $\mathrm{Cs}_{2} \mathrm{AgInCl}_{6}$ with different $\mathrm{Mn}$ contents. Insets: the photographs of luminescence from the powder samples under UV light [136]. Copyright 2015, Royal Society of Chemistry. (f) PL decay dynamics of 0.3 and $0.9 \% \mathrm{Mn}_{-}-\mathrm{doped} \mathrm{Cs}_{2} \mathrm{AgInCl}_{6}$ [136]. Copyright 2015, Royal Society of Chemistry. (g) Morphology of as-prepared $\mathrm{Cs}_{2} \mathrm{AgIn}_{x} \mathrm{Fe}_{1-x} \mathrm{Cl}_{6}(0 \leq x \leq 1)$ double perovskite single-crystals with different $x$ values [142]. 2020 Wiley-VCH GmbH. (h) UV-Vis absorbance spectra of as-prepared $\mathrm{Cs}_{2} \mathrm{AgIn}_{x} \mathrm{Fe}_{1-x} \mathrm{Cl}_{6}(0 \leq x \leq 1)$ double perovskite single-crystals with different $x$ values [142]. 2020 Wiley-VCH GmbH. (i) Bandgap alignment of $\mathrm{Cs}_{2} \mathrm{AgIn}_{x} \mathrm{Fe}_{1-x} \mathrm{Cl}_{6}(0 \leq x \leq 1)$ double perovskites [142]. 2020 Wiley-VCH GmbH. (j) PL spectra of as-prepared $\mathrm{Cs}_{2} \mathrm{AgIn}_{x} \mathrm{Fe}_{1-x} \mathrm{Cl}_{6}(0 \leq x \leq 1)$ double perovskite single-crystals with different $x$ values. (k) TRPL spectra of $\mathrm{Cs}_{2} \mathrm{AgIn}_{x} \mathrm{Fe}_{1-x} \mathrm{Cl}_{6}(0 \leq x \leq 1)$ double perovskite [142]. 2020 Wiley-VCH GmbH. 
triggered the successful development of a group of materials with the formula of $\mathrm{Cs}_{2} \mathrm{AgIn}_{x} \mathrm{Fe}_{1-x} \mathrm{Cl}_{6}(0 \leq x \leq 1)$ (Figure 8g). UV-Vis absorbance demonstrated a significant red-shift from 450 to $800 \mathrm{~nm}$ by increasing $\mathrm{Fe}^{3+}$ into the lattice (Figure 8h). This significant bandgap tuneability boosted various applications for $\mathrm{Cs}_{2} \mathrm{AgIn}_{x} \mathrm{Fe}_{1-x} \mathrm{Cl}_{6}(0 \leq x \leq 1)$ materials in optoelectronic and photovoltaic fields. Ultraviolet photoelectron spectroscopy (UPS) confirmed the evolution of the compound's band position, in which absolute replacement of $\mathrm{In}^{3+}$ with $\mathrm{Fe}^{3+}$ drives up the VBM from -5.39 to $-4.80 \mathrm{eV}$, while at the same time shifts the CBM down from -2.48 to $-3.25 \mathrm{eV}$ (Figure $8 \mathrm{i}$ ).

$\mathrm{Fe}^{3+}$ doping also resulted in the red-shift of PL spectra in $\mathrm{Cs}_{2} \mathrm{AgIn}_{x} \mathrm{Fe}_{1-x} \mathrm{Cl}_{6}(0 \leq x \leq 1)$ perovskite single-crystals. However, PL shifts did not show a consistent wavelength shift with the absorbance edge. In the case of $\mathrm{Cs}_{2} \mathrm{AgInCl}_{6}$ $(x=0)$, the spectrum peaked at $620 \mathrm{~nm}$ was attributed to the emission via self-trapped exciton recombination (Figure 8j). TRPL measurements revealed that the PL lifetime significantly decreased with increasing $\mathrm{Fe}^{3+}$-doping, suggesting the variation of the PL mechanism in $\mathrm{Cs}_{2} \mathrm{AgIn}_{x} \mathrm{Fe}_{1-x} \mathrm{Cl}_{6}$ $(0 \leq x \leq 1)$ perovskite family (Figure $8 \mathrm{k}$ ). The shorter lifetime of the $\mathrm{Cs}_{2} \mathrm{AgIn}_{x} \mathrm{Fe}_{1-x} \mathrm{Cl}_{6}(0 \leq x \leq 1)$ compounds with more $\mathrm{Fe}^{3+}$ most likely was due to the fast dissociation of the trapped excitons to generate free electrons and holes. The broad solar absorption and efficient exciton dissociation suggested the great potential applications of the proposed structures for photovoltaics and photocatalysis.

\section{Layered MHDPs}

The creation of elpasolite-type MHDPs was a remarkable breakthrough due to: (i) the 3D framework of the metal halide octahedral, and (ii) the all-inorganic composition that is expected to preserve high stability. However, large indirect bandgaps hamper their implementation in photovoltaics. Kentsch et al. [143], by studying the exciton mechanism of this family of materials, reported the existence of a very high exciton binding energy and also a strong electron-phonon coupling similar to $\mathrm{Cs}_{3} \mathrm{Bi}_{2} \mathrm{Br}_{9}$ and $\mathrm{BiBr}_{3}$. It is known that these features induced undesirable electron-hole recombination that severely barricaded efficient carrier transport. Dimensional reduction or structural conversion entailed a dramatic shift in the compound's photophysical properties [144]. For instance, upon chemical exfoliation of $\mathrm{MoS}_{2}$ from the bulk structure to a monolayer, an indirect to direct transition occurs in the material's bandgap $[145,146]$. Analogously, dimensional reduction in the inorganic block of organic-inorganic hybrids affords material's electronic confinement, well represented by
Pb-halide perovskites [123, 147]. Double perovskites with a neat configuration of two different metal cations, can host various metals with different oxidation states. Although halide double perovskites have been studied back to the 1930s [148], their 2D compounds are still rare. Therefore, their photophysical and electronic changes induced by the reduction of structural dimension have remained fairly underexplored. This section presents the progress achieved to date in the layered MHDPs.

\section{$5.1 \mathrm{Rb}_{4} \mathrm{Ag}_{2} \mathrm{BiBr}_{9}$}

Recently, Sharma et al. [149] indicated the formation of large single-crystals of a new all-inorganic non-toxic Bibased semiconductor, $\mathrm{Rb}_{4} \mathrm{Ag}_{2} \mathrm{BiBr}_{9}$, as the first-discovered composition in the quaternary $\mathrm{Rb}-\mathrm{Ag}-\mathrm{Bi}-\mathrm{Br}$ phase diagram. Different from elpasolite-type MHDPs, this material crystallizes in the centrosymmetric space group of Pnnm in which $\left(\mathrm{BiBr}_{6}\right)^{3-}$ octahedra and $\left(\mathrm{AgBr}_{5}\right)^{4-}$ square pyramids connected through edges and corners to complete a nonperovskite 2D layered structure. In this configuration, alternating polyanionic $\left[\mathrm{Ag}_{2} \mathrm{BiBr}_{9}\right]^{4-}$ layers are composed of alternating $\left[\mathrm{BiBr}_{4}\right]^{-}$and $\left[\mathrm{Ag}_{2} \mathrm{Br}_{5}\right]^{3-}$ sheets. In the $\left[\mathrm{Ag}_{2} \mathrm{Br}_{5}\right]^{3-}$ slab, $\left(\mathrm{AgBr}_{5}\right)^{4-}$ square pyramids form an edge- and cornershared network. These slabs are attached to $\left(\mathrm{BiBr}_{6}\right)^{3-}$ octahedral by a corner-shared connection that ultimately yields the polyanionic $\left[\mathrm{Ag}_{2} \mathrm{BiBr}_{9}\right]^{4-}$ layers separated by $\mathrm{Rb}^{+}$cations (Figure 9a and b).

To investigate the photophysical properties of the newly designed material, UV-Vis reflection measurement indicated the well-defined absorptions at 2.82 and $3.23 \mathrm{eV}$ (Figure 9c). One fact that could be deduced from the shape of the plot, whose tail gradually went off to the lower energies, was the existence of high defect concentration, similar to the case of most all-inorganic halide double perovskite [48, 49, 85, 150]. From the Tauc plots and adopting the indirect and direct fitting scenarios, bandgap energies of 2.38 (indirect) and $2.57 \mathrm{eV}$ (direct) were elicited fall within the observed range of other MHDPs such as $\mathrm{Cs}_{2} \mathrm{AgBiX}_{6}\left(\mathrm{X}=\mathrm{Cl}^{-}\right.$or $\left.\mathrm{Br}^{-}\right)$[48, 49, 85, 150]. Room-temperature PL spectrum of $\mathrm{Rb}_{4} \mathrm{Ag}_{2} \mathrm{BiBr}_{9}$ (Figure 9d) specified two emission bands, one positioned at $2.36 \mathrm{eV}$ featuring a weak and visible broadband emission (marked as P1), and a relatively intense one. The second narrow infrared emission comprising several peaks of P2, P3 and $\mathrm{P} 4$ settled at 1.52, 1.44 and $1.28 \mathrm{eV}$, respectively (Figure 9d). P1 emission agreed well with an indirect transition or trap emission, similar to the previous reports [48, $49,85,150]$. Measuring the photoluminescence excitation (PLE) spectra at different emission energies of 2.36 and $1.55 \mathrm{eV}$ (Figure 9d) showed a broad peak at $3.34 \mathrm{eV}$ for the 
(a)

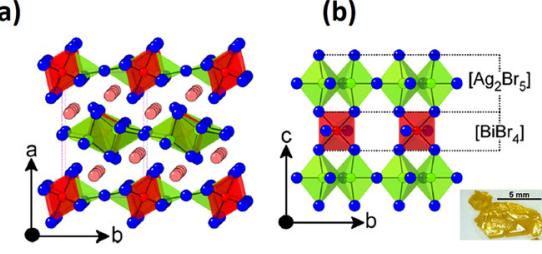

(f)

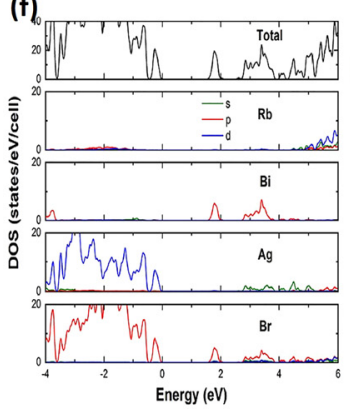

(j)

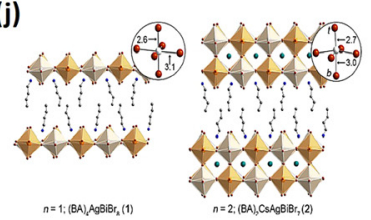

(g)

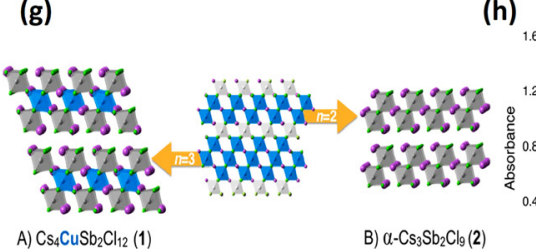

(h)
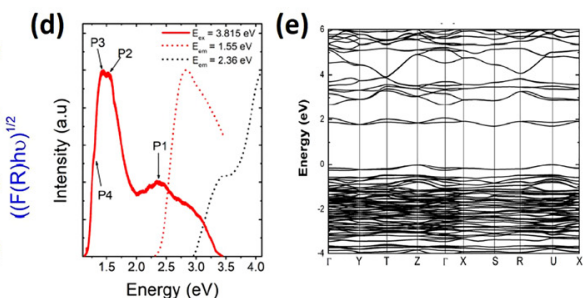

(i)

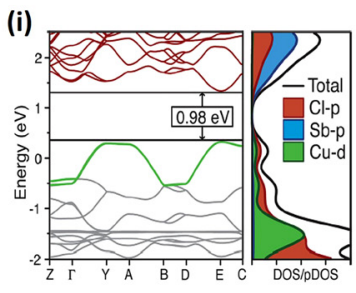

(k)

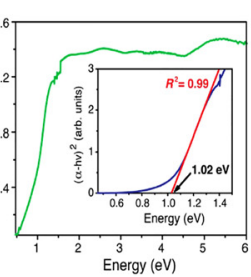

(I)

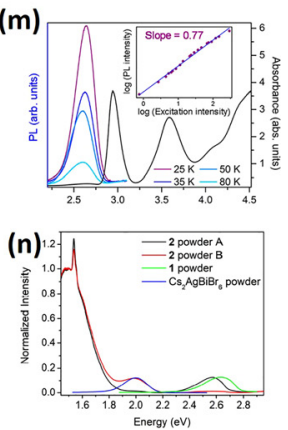

Figure 9: (a) A polyhedral representation of the crystal structure of $\mathrm{Rb}_{4} \mathrm{Ag}_{2} \mathrm{BiBr}_{9}$ [149]. Copyright 2019, American Chemical Society. (b) A top view of a segment of a $\left[\mathrm{Ag}_{2} \mathrm{BiBr}_{9}\right]^{4-}$ layer [149]. Copyright 2019, American Chemical Society. (c) Tauc plots of $\mathrm{Rb}_{4} \mathrm{Ag}_{2} \mathrm{BiBr}_{9}$. The inset: the absorption spectrum of $\mathrm{Rb}_{4} \mathrm{Ag}_{2} \mathrm{BiBr}_{9}$ [149]. Copyright 2019, American Chemical Society. (d) Room temperature PL spectrum (red solid line) and photoluminescence excitation (PLE) spectra of $\mathrm{Rb}_{4} \mathrm{Ag}_{2} \mathrm{BiBr}_{9}$ single-crystals [149]. Copyright 2019, American Chemical Society. (e) Electronic band structures and (f) PDOS of $\mathrm{Rb}_{4} \mathrm{Ag}_{2} \mathrm{BiBr}_{9}$ [149]. Copyright 2019, American Chemical Society. (g) Crystal structures of $\mathrm{Cs}_{4} \mathrm{CuSb}_{2} \mathrm{Cl}_{12}$ and $\alpha-\mathrm{Cs}_{3} \mathrm{Sb}_{2} \mathrm{Cl}_{9}$ [152]. Copyright 2017, American Chemical Society. (h) Absorbance spectrum of $\mathrm{Cs}_{4} \mathrm{CuSb}_{2} \mathrm{Cl}_{12}$. Inset: Tauc plot of $\mathrm{Cs}_{4} \mathrm{CuSb}_{2} \mathrm{Cl}_{12}$ [152]. Copyright 2017, American Chemical Society. (i) Calculated band structure (left) and DOS/PDOS (right) of $\mathrm{Cs}_{4} \mathrm{CuSb}_{2} \mathrm{Cl}_{12}[152]$. Copyright

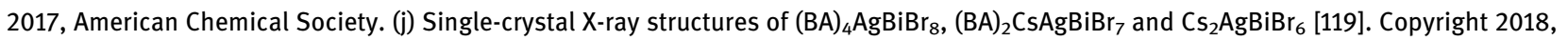
American Chemical Society. Band structures corresponding of $(\mathrm{k})(\mathrm{BA})_{2} \mathrm{CSAgBiBr}_{7}$ and $(\mathrm{l})(\mathrm{BA})_{4} \mathrm{AgBiBr}{ }_{8}[119]$. Copyright 2018, American Chemical Society. $(\mathrm{m})$ Low-temperature PL spectra and $7 \mathrm{~K}$ absorption spectrum of a film of $(\mathrm{BA})_{4} \mathrm{AgBiBr}_{8}$. Inset: Excitation power (mW/ $\left.\mathrm{cm}^{2}\right)$ dependence of the emission intensity [119]. Copyright 2018, American Chemical Society. (n) The $14 \mathrm{~K} \mathrm{PL} \mathrm{spectra} \mathrm{of} \mathrm{powders} \mathrm{of}(\mathrm{BA})_{2} \mathrm{CsAgBiBr}{ }_{7}$, $(\mathrm{BA})_{4} \mathrm{AgBiBr}_{8}$ and $\mathrm{Cs}_{2} \mathrm{AgBiBr}_{6}$ [119]. Copyright 2018, American Chemical Society.

former emission energy that was near the $3.23 \mathrm{eV}$ absorption peak depicted in Figure 9c. For the $1.55 \mathrm{eV}$ emission energy, PL spectra illustrated a peak at $2.82 \mathrm{eV}$, in excellent accordance with the low energy absorption peak in the absorption spectrum (Figure 9c). Given these, the 3.23 and $2.82 \mathrm{eV}$ absorption peaks were ascribed to excitonic absorption fundamentally from two different species of $\left(\mathrm{AgBr}_{5}\right)^{4-}$ and $\left(\mathrm{BiBr}_{6}\right)^{3-}$.

Electronic band structure calculations showed the valence and conduction band edges positioned at the $U$ - and $S$-points, respectively. This band configuration yielded an indirect bandgap of $1.69 \mathrm{eV}$ and slightly larger direct bandgap of $1.70 \mathrm{eV}$ (Figure 9e). Moreover, $\mathrm{Rb}_{4} \mathrm{Ag}_{2} \mathrm{BiBr}_{9}$ showed a similar band structure to that of $\mathrm{Cs}_{2} \mathrm{AgBiX}_{6}\left(\mathrm{X}=\mathrm{Cl}^{-}, \mathrm{Br}^{-}\right)$
[48, 49, 85, 150] and $\mathrm{Cs}_{2} \mathrm{AgTlX}_{6}$ [151]. PDOS calculation revealed that the CBM was a mixture of the strong contribution of Bi- $6 p$ and smaller contribution of $\mathrm{Br}-4 p$ orbitals, while the VBM consisted of antibonding Br- $4 p$ and Ag-4d orbitals (Figure 9f). Structurally, $\left(\mathrm{BiBr}_{6}\right)^{3-}$ octahedra were isolated; hence, the conduction band states were spatially localized in $\mathrm{Rb}_{4} \mathrm{Ag}_{2} \mathrm{BiBr}_{9}$ that caused a small dispersion in the conduction band. The wave function analysis of the compound's valence band showed a hybridization between the $\mathrm{Br}-4 p$ and Ag-4d states that was extensively confined within the $2 \mathrm{D}$ plane upright to the $a$-axis. This highlights the quasi2D nature of the $\mathrm{Rb}_{4} \mathrm{Ag}_{2} \mathrm{BiBr}_{9}$ electronic structure with both valence band and conduction band featuring flat bands. The localized electronic states on both $\left(\mathrm{BiBr}_{6}\right)^{3-}$ octahedra and 
$\left(\mathrm{AgBr}_{5}\right)^{4-}$ square pyramids must elevate exciton localization. Therefore, optical excitation may generate Ag- and $\mathrm{Bi}$ centred localized excitons [149].

\section{$5.2 \mathrm{Cs}_{4} \mathrm{CuSb}_{2} \mathrm{Cl}_{12}$}

Vargas et al. [152] reported the first combination of divalent $\mathrm{Cu}^{2+}$ and trivalent $\mathrm{Sb}^{3+}$ metal cations to synthesize $\mathrm{Cs}_{4} \mathrm{CuSb}_{2} \mathrm{Cl}_{12}$, with a triple-layered $(n=3)$ perovskite structure. $\mathrm{Cu}$ is the most reported transition metal to form 2D halide perovskites, some of which were used in solar cells, albeit with relatively low PCEs $(\leq 0.017 \%)$ [135]. Antimony $(\mathrm{Sb})$ has some advantages of relatively low toxicity and the capability to form versatile structures of corner-sharing $\left(\mathrm{SbX}_{6}\right)^{3-}(\mathrm{X}=\mathrm{Cl}, \mathrm{Br}, \mathrm{I})$ octahedral $[153,154]$ and halide perovskites $[41,123]$. Besides, $\mathrm{Sb}^{3+}$ is isoelectronic with $\mathrm{Sn}^{2+}$ so an orbital overlap with $\mathrm{Cu}$ was expected, as presented in $\mathrm{Cu}-\mathrm{Sb}$ chalcogenides with promising solar cell PCEs of up to 3.5\% [155]. Although computationally the potential of $\mathrm{Cu}^{+}-\mathrm{Sb}^{3+}$ 3D halide double perovskites of $\mathrm{Cs}_{2} \mathrm{CuSbX}_{6}(\mathrm{X}=\mathrm{Cl}, \mathrm{Br}$ and $\mathrm{I})$ have been examined and proposed [50], using traditional solution-process approaches, there has been no access to such compounds yet. The combination of $\mathrm{Cu}^{2+}-\mathrm{Sb}^{3+}$ can be an option, however not suitable for 3D structure, as the sort of the metals' electron configuration renders a layered perovskite. $\mathrm{Cs}_{4} \mathrm{CuSb}_{2} \mathrm{Cl}_{12}$ crystallizes in the monoclinic $\mathrm{C} / \mathrm{m}$ systems, in which alternating $\left(\mathrm{CuCl}_{6}\right)^{4-}$ and $\left(\mathrm{SbCl}_{6}\right)^{3-}$ octahedra attached through corner-sharing stack and $\mathrm{Cs}^{+}$atoms rested at the voids in between the octahedra to form a $\langle 111\rangle$-oriented triple-layered $(n=3)$ framework (Figure 9g). This structure can also be conceived as a defective 3D perovskite architecture with vacancies generated by $3+$ oxidation state of the $\mathrm{Sb}$ that administrated the structural breakage from 3D network to a 2D network.

Assessing the competency of $\mathrm{Cs}_{4} \mathrm{CuSb}_{2} \mathrm{Cl}_{12}$ for photovoltaics, the optical absorption measurement implicated the semiconducting nature of the material with an impressive direct bandgap of $1.00 \mathrm{eV}$ (Figure $9 \mathrm{~h}$ ). A semiconductor with this range of bandgap is well-fitted for single absorber solar cells, with a predicted PCE of 30.9\% according to the Shockley-Queisser limit [156] or as the bottom operation layer in an all-perovskite tandem solar cell. Remarkably, the bandgap of $\mathrm{Cs}_{4} \mathrm{CuSb}_{2} \mathrm{Cl}_{12}$ is $2.0 \mathrm{eV}$ smaller than $\mathrm{Cs}_{3} \mathrm{Sb}_{2} \mathrm{Cl}_{9}$ as the parent compound (3.00 eV), signifying a drastic bandgap reduction.

Electronic structure calculations of $\mathrm{Cs}_{4} \mathrm{CuSb}_{2} \mathrm{Cl}_{12}$ confirmed the direct characteristic of the bandgap by positioning both VBM and CBM near the $E$-point of the Brillouin zone (Figure 9i). Significant dispersion of the material's band structures in both directions of parallel and perpendicular to the layers acknowledged the material's capability for photovoltaics regardless of its layered structure $[41,123]$. PDOS calculations showed that CBM was predominantly made by $\mathrm{Sb}-5 p$ and $\mathrm{Cl}-3 p$ orbitals. However, $\mathrm{Cu}^{2+}$ contribution to the CBM was found to be negligible. Therefore the considerable bandgap shrinkage of $\mathrm{Cs}_{4} \mathrm{CuSb}_{2} \mathrm{Cl}_{12}$ should be mainly driven by the role of $\mathrm{Cu}^{2+}$ orbitals in the compound's VBM. It was found that the material's VMB was ran by $\mathrm{Cu}-3 d$ and $\mathrm{Cl}-3 p$ orbitals (Figure 9i). The appropriate orbitaloverlap between $\mathrm{Cu}-3 d$ and the $\mathrm{Cl}-3 p / \mathrm{Sb}-5 p$ orbitals broadened the VBM that ultimately reduced the bandgap. The presence of a $\mathrm{Cu}-3 d^{9}$ also raised partly occupied states at VBM that could generate further charge carriers. One of the key factors for solar cell performance is the charge carrier mobility of the absorbing layer that is closely related to the hole and electron effective masses of the material. The calculated hole and electron effective masses for $\mathrm{Cs}_{4} \mathrm{CuSb}_{2} \mathrm{Cl}_{12}$ were determined to be $0.16 \mathrm{~m}_{\mathrm{e}}$ and $0.32 \mathrm{~m}_{\mathrm{e}}$, respectively, comparable to those of $\mathrm{MAPbI}_{3}$ [157], and suggesting high carrier mobility of $\mathrm{Cs}_{4} \mathrm{CuSb}_{2} \mathrm{Cl}_{12}$.

\section{$5.3(\mathrm{BA})_{4} \mathrm{AgBiBr}_{8}$ and $(\mathrm{BA})_{2} \mathrm{CsAgBiBr}_{7}$}

The 3D lattice of halide perovskites $\left(\mathrm{A}^{+} \mathrm{B}^{2+} \mathrm{X}_{3}\right)$ accommodates corner-sharing $B-X$ octahedra, in which cuboctahedral cavities are engaged by small cations at the A-site [158]. Introducing larger organic cations to these cavities partitions the ordered 3D structure into the $2 \mathrm{D}$ structure of $\mathrm{A}_{2}^{+} \mathrm{B}^{2+} \mathrm{X}_{4}$, that is composed of corner-sharing $B-X$ octahedra in a single-sheet order $(n=1)$. These sheets are separated by regular arrays of large organic cations [159]. The thin inorganic sheets can be tuned to thicker ones by mixing small and large A-site cations that generate the general formula $\mathrm{A}^{\prime}{ }_{2} \mathrm{~A}_{n-1} \mathrm{~B}_{n} \mathrm{X}_{3 n+1}\left(\infty>n \geq 1 ; \mathrm{A}^{\prime}=\right.$ large organic cation, $\mathrm{A}=$ small inorganic cation) [160]. In this regard, Connor et al. [119] explored the viability of layered MHDPs by synthesizing (BA) ${ }_{4} \mathrm{AgBiBr}_{8}$ and $(\mathrm{BA})_{2} \mathrm{CsAgBiBr}_{7}\left(\mathrm{BA}=\mathrm{CH}_{3}\left(\mathrm{CH}_{2}\right)_{3} \mathrm{NH}_{3}{ }^{+}\right)$as the layered derivatives of $\mathrm{Cs}_{2} \mathrm{AgBiBr}_{6}$.

(BA) ${ }_{4} \mathrm{AgBiBr}_{8}$ showed a typical $n=1$ perovskite structure with the generic formula of $\mathrm{A}_{2}^{\prime} \mathrm{B}^{+}{ }_{0.5} \mathrm{~B}^{\prime 3+}{ }_{0.5} \mathrm{X}_{4} \times 2$ where $\mathrm{Ag}^{+}$and $\mathrm{Bi}^{3+}$ regularly occupy the $\mathrm{B}^{+}$and $\mathrm{B}^{\prime 3+}$ sites to form monolayer inorganic parts. By incorporating both inorganic cation of $\mathrm{Cs}^{+}$(A-site) and organic cation of $\mathrm{BA}^{+}$ ( $\mathrm{A}^{\prime}$-site), a product with the formula of $\mathrm{A}_{2}^{\prime} \mathrm{AB}^{+} \mathrm{B}^{\prime 3+} \mathrm{X}_{7}$ was attained, however, with heavy distortion particularly at the $\mathrm{Ag}^{+}$-site (Figure 9j). Similar to halide perovskites, this combination gave rise to the formation of thicker inorganic 
sheets with two inorganic layers of $\mathrm{Ag}^{+}$and $\mathrm{Bi}^{3+}$ octahedra arranged in all three dimensions $(n=2)$ (Figure $9 j)$. In this configuration, small $\mathrm{Cs}^{+}$cations resided in the cuboctahedra cavities of the lattice, whereas bilayers of the large organic cation $\left(\mathrm{BA}^{+}\right)$templated the inorganic slabs in a monoclinic lattice.

To explore the electronic consequences of the dimensional reduction in the proposed compounds, DFT calculations showed the band structure of $(\mathrm{BA})_{2} \mathrm{CsAgBiBr}_{7}$ (Figure 9k) was very similar to $\mathrm{Cs}_{2} \mathrm{AgBiBr}_{6}$. This indicated the orbital compositions of the VBM with Ag- $4 d, \mathrm{Br}-4 p$ and $\mathrm{Bi}-6$ s characteristics at the $A$-point and the CBM with an $\mathrm{Ag}$ $5 s, \mathrm{Br}-4 p$ and Bi- $6 p$ characteristics at the $B$-point resulting the indirect bandgap of $2.96 \mathrm{eV}$. Accordingly, the key band structure characteristics of $(\mathrm{BA})_{2} \mathrm{CsAgBiBr}_{7}$ directly came from $\mathrm{Cs}_{2} \mathrm{AgBiBr}_{6}$. In contrast, there was a great difference between the band structure of $(\mathrm{BA})_{4} \mathrm{AgBiBr}_{8}$ and $\mathrm{Cs}_{2} \mathrm{Ag}$ $\mathrm{BiBr}_{6}$. In (BA) ${ }_{4} \mathrm{AgBiBr}_{8}$ system, the $\mathrm{VBM}$ almost entirely came from the Ag- $4 d$ and $\mathrm{Br}-4 p$ states, while Bi-s orbitals showed very little contribution. The compound's CBM encompassed only $\mathrm{Bi}-6 p$ and $\mathrm{Br}-4 p$ orbitals with all Ag-5s orbitals sitting at higher energy levels. This concluded direct bandgap of $3.01 \mathrm{eV}$ for $(\mathrm{BA})_{4} \mathrm{AgBiBr}_{8}$ (Figure 9l). It was discussed that the simultaneous contribution of the $\mathrm{Ag}$ and Bi frontier orbitals in both the valence band and the conduction band manipulated the indirect bandgap in $\mathrm{Cs}_{2} \mathrm{AgBiBr}_{6}[47,49,132,161]$. Avoiding this hybridization in (BA) ${ }_{4} \mathrm{AgBiBr}_{8}$, a single-metal-orbital characteristic at the compound's band edges was observed. This indirect to direct transition due to dimensional reduction was reminiscent of the exfoliation impacts in transition-metal dichalcogenides $[145,146]$.

PL measurement of $(\mathrm{BA})_{4} \mathrm{AgBiBr}_{8}$ thin-film showed a weak and broad PL spectrum at $20 \mathrm{~K}$ that rapidly quenched at higher temperatures (Figure 9m). Unlike the excitonic PL from $\mathrm{Pb}-\mathrm{Br}$ halide perovskites that indicates superlinear behaviour [162, 163], the luminescence intensity of $(\mathrm{BA})_{4} \mathrm{AgBiBr}_{8}$ thin-film possessed a sub-linear dependence on the power density of the incident laser. This signified a defect-mediated radiative recombination source in the material. The PL measurement on $(\mathrm{BA})_{2} \mathrm{CsAgBiBr}_{7}$ demonstrated three broad luminescence characteristics, two of them strongly agreed the PL from (BA) ${ }_{4} \mathrm{AgBiBr}_{8}$ $(n=1)$ and $\mathrm{Cs}_{2} \mathrm{AgBiBr}_{6}(n=\infty)$ (Figure 9n). Similar to $\mathrm{Pb}-\mathrm{I}$ halide perovskite films with $n>1$, where PL displayed features from multiple " $n$ " values [164], this observation may come from the domination of $(\mathrm{BA})_{4} \operatorname{AgBiBr}_{8}(n=1)$ and $\mathrm{Cs}_{2} \mathrm{AgBiBr}_{6}(n=\infty)$ within the $(\mathrm{BA})_{2} \mathrm{CsAgBiBr}_{7}(n=2)$ structure or from similar defect-mediated emission in all these compounds.

\section{$5.4 \mathrm{Cs}_{3+n} \mathrm{M}^{2+}{ }_{n} \mathrm{Sb}_{2} \mathrm{X}_{9+3 n}\left(\mathrm{M}=\mathrm{Sn}^{2+}, \mathrm{Ge}^{2+}\right)$}

Although MHDPs have a 3D framework, they do not show high electronic dimensionality that is necessary for an efficient photovoltaic absorber [165]. Given this, Tang et al. computationally proposed a general approach to produce layered halide double perovskites with the formula of $\mathrm{Cs}_{3+n} \mathrm{M}^{2+}{ }_{n} \mathrm{Sb}_{2} \mathrm{X}_{9+3 n}\left(\mathrm{M}^{2+}=\mathrm{Sn}, \mathrm{Ge}\right)$ as promising light absorbers with high electronic dimensionality (Figure 10a) [166]. The parent material in this study was $\mathrm{Cs}_{3} \mathrm{Sb}_{2} \mathrm{I}_{9}$. Appraising different cations for $\mathrm{M}^{2+}$ site of the proposed structure, $\mathrm{Sn}^{2+}$ and $\mathrm{Ge}^{2+}$ were first selected, because of their low toxicity and also their isoelectronic structure with $\mathrm{Sb}^{3+}$. Calculating the band structures of the hypothetical-layered MHDPs of $\mathrm{Cs}_{4} \mathrm{M}^{2+} \mathrm{Sb}_{2} \mathrm{I}_{12}\left(\mathrm{M}^{2+}=\mathrm{Cu}, \mathrm{Sn}, \mathrm{Ge}\right)$ and hosting material of $\mathrm{Cs}_{3} \mathrm{Sb}_{2} \mathrm{I}_{9}$ revealed that for $\mathrm{Cs}_{3} \mathrm{Sb}_{2} \mathrm{I}_{9}$, the VBM mainly comprised antibonding Sb-5s and I-5p states, and the CBM mostly came from Sb-5p states (Figure 10b). For the case of hypothetical $\mathrm{Cs}_{4} \mathrm{CuSb}_{2} \mathrm{X}_{12}$, since $\mathrm{Cu}$ has $a+2$ oxidation state with the $3 d^{9}$ outer electron configuration, a hybridization occurred between the partially vacant $\mathrm{Cu}-3 d$ and I- $5 p$ states. This created a localized conduction band below the Sb- $5 p$ orbitals that generated considerably large electron effective mass (i.e. $m_{\text {electron }}=6.97 m_{e}, m_{\text {hole }}=1.09 m_{e}$ for $\mathrm{Cs}_{4} \mathrm{CuSb}_{2} \mathrm{Cl}_{12}$ ). Therefore, although $\mathrm{Cs}_{4} \mathrm{CuSb}_{2} \mathrm{X}_{12}(\mathrm{X}=\mathrm{I}, \mathrm{Br}, \mathrm{Cl})$ layered double perovskites showed narrower bandgaps, they offered less promise for photovoltaics. Considering other divalent cations with $\mathrm{ns}^{2}$ electron configuration $\left(\mathrm{Sn}^{2+}, \mathrm{Ge}^{2+}\right)$ should be an advantageous approach to enhance the photovoltaic-relevant characteristics. The calculations confirmed that hypothetical $\mathrm{Cs}_{4} \mathrm{SnSb}_{2} \mathrm{I}_{12}$ and $\mathrm{Cs}_{4} \mathrm{GeSb}_{2} \mathrm{I}_{12}$ layered MHDPs owned direct bandgaps of 1.66 and $1.76 \mathrm{eV}$, respectively, that were notably smaller than the hosting compound of $\mathrm{Cs}_{3} \mathrm{Sb}_{2} \mathrm{I}_{9}$ (Figure 10c). Additionally, in contrary to $\mathrm{Cu}^{2+}$ analogue, these compounds presented rather dispersive CBMs largely drew out of $\mathrm{Sn}-5 p$ or Ge- $4 p$ and Sb-5p states (Figure 10b). This dispersive characteristic of conduction band yielded smaller electron effective masses for $\mathrm{Cs}_{4} \mathrm{GeSb}_{2} \mathrm{I}_{12}$ and $\mathrm{Cs}_{4} \mathrm{SnSb}_{2} \mathrm{I}_{12}$ than those of $\mathrm{Cs}_{3} \mathrm{Sb}_{2} \mathrm{I}_{9}$ and $\mathrm{Cs}_{4} \mathrm{CuSb}_{2} \mathrm{Cl}_{12}$ calculated in this work (Table 2). For the $\mathrm{Cs}_{3} \mathrm{Sb}_{2} \mathrm{I}_{9}$, the VBMs of $\mathrm{Cs}_{4} \mathrm{SnSb}_{2} \mathrm{I}_{12}$ and $\mathrm{Cs}_{4} \mathrm{GeSb}_{2} \mathrm{I}_{12}$ experienced a 0.44 and $0.19 \mathrm{eV}$ shift-up, respectively, that was due to the higher energy-lying Sn-5s and Ge-4s orbitals. Regarding the compounds CBM, in $\mathrm{Cs}_{4} \mathrm{SnSb}_{2} \mathrm{I}_{12}$, this band slightly went up by $0.07 \mathrm{eV}$, while the case for $\mathrm{Cs}_{4} \mathrm{GeSb}_{2} \mathrm{I}_{12}$ was a $0.08 \mathrm{eV}$ shift-down. Therefore, bandgap reduction of the new compounds was dominated by the higher energy level of Sn-5s and Ge-4s states in their VBMs. Figure 10c shows the great improvement of the compounds' optical absorption as compared to parent material by inserting $\left[\mathrm{SnI}_{6}\right]^{4-}$ or $\left[\mathrm{GeI}_{6}\right]^{4-}$ octahedra into the $\left[\mathrm{Sb}_{2} \mathrm{I}_{9}\right]^{3-}$ bilayers. Interestingly, although 
$\mathrm{Cs}_{4} \mathrm{CuSb}_{2} \mathrm{Cl}_{12}$ possesses a smaller bandgap, it shows low absorption ability in the range of 2.0-3.0 eV with a small peak above the bandgap that originates from the isolated and extremely localized conduction band of this composition. Controlling the chemical composition to form a family of $\mathrm{Cs}_{3+n} \mathrm{M}^{2+}{ }_{n} \mathrm{Sb}_{2} \mathrm{X}_{9+3 n}$ layered MHDPs, their corresponding photovoltaic properties can be successfully tuned.

Regarding the great interest in optoelectronic material exploration on MHDPs, Lin et al. has introduced a new 3D perovskite-type structure beyond the double perovskite $\left(\mathrm{A}_{2} \mathrm{BB}^{\prime} \mathrm{X}_{6}\right)$ as quadruple perovskite halides $\mathrm{A}_{4} \square \mathrm{B}^{2+} \mathrm{B}_{2}^{\prime} \mathrm{X}_{12}$ $\left(\square=\right.$ vacancy, $\mathrm{A}=\mathrm{Cs} ; \mathrm{B}^{2+}=\mathrm{Zn}, \mathrm{Cd} ; \mathrm{B}^{\prime}=\mathrm{Sb}, \mathrm{Bi} ; \mathrm{X}=\mathrm{Cl}$, Br and I) with a vacancy-ordered $3 \mathrm{D}$ crystal structure in $F d \overline{3} m$ space group $[167,168]$. In this structure, every two $\mathrm{B}^{+}$cation in $\mathrm{A}_{2} \mathrm{BB}^{\prime} \mathrm{X}_{6}$ double perovskite is replaced by a vacancy and $\mathrm{a} \mathrm{B}^{2+}$ cation. Among the calculated materials, $\mathrm{Cs}_{4} \mathrm{CdSb}_{2} \mathrm{Cl}_{12}$ and $\mathrm{Cs}_{4} \mathrm{CdBi}_{2} \mathrm{Cl}_{12}$ showed enough thermodynamic stability to form at room temperature. These newly designed materials showed direct bandgaps of 2.93 and $3.05 \mathrm{eV}$ with a 3D electronic structure. It is believed that these findings can provide a new perspective for optoelectronic material design and expanding the research on MHPDs.

A summary of all the highlighted information regarding the optoelectronic properties of MHDPs mentioned in this work can be found in Table 2 .

\section{Optoelectronic applications of MHDPs}

It has been predicted that MHDPs have a large potential for different applications including solar cells, laser, lighting, bio-imaging and detectors. However, on the contrary to $\mathrm{Pb}$ based halide perovskites, so far rare applications have been studied for this developing class of materials due to the poor knowledge of MHDPs. It is still in its infancy stage for the application of MHDPs. Only a limited number of MHDPs (e.g. $\mathrm{Cs}_{2} \mathrm{AgBiBr}_{6}$ and $\mathrm{Cs}_{2} \mathrm{AgInCl}_{6}$ ) have been implemented in diverse optoelectronic devices, such as solar cells, X-ray detectors, LEDs and photodetectors. Here, we summarize the state-of-the-art applications for the MHDPs considering their characteristic optoelectronic properties.

\subsection{Solar cells}

In the past few years, intensive efforts have been devoted to realize the photovoltaics of MHDPs and clarify some of their relevant characteristics namely optoelectronic properties and thin-film morphology [48]. Ning et al. reported the first demonstration of the $\mathrm{Cs}_{2} \mathrm{AgBiBr}_{6}$ solar cells with the device configuration of the indium tin oxide (ITO)/ Compact-TiO $_{2} \quad\left(\mathrm{C}-\mathrm{TiO}_{2}\right) / \mathrm{Cs}_{2} \mathrm{AgBiBr}_{6} / 2,2^{\prime}, 7,7^{\prime}$-Tetrakis $[N, N$ di(4-methoxyphenyl)amino]-9,9'-spirobifluorene (SpiroOMeTAD)/Au with a PCE of 1.11\% [57]. Upon light excitation, they found coexistence of the free carriers and excitons inside the operation layer of $\mathrm{Cs}_{2} \mathrm{AgBiBr}_{6}$ with an impressively long diffusion length of around $110 \mathrm{~nm}$.

Very recently, Igbari et al. [60] investigated the influence of vacuum sublimation and solution processing on the optoelectronic properties and the resulting photovoltaic performance of $\mathrm{Cs}_{2} \mathrm{AgBiBr}_{6}$ thin-films. That comparison confirmed the viability of the solution-based approach to producing $\mathrm{Cs}_{2} \mathrm{AgBiBr}_{6}$ thin-film with an inherently better crystallinity, moderately narrower bandgap, higher charge carriers mobility, and long carrier lifetime. These outcomes were attributed to the right composition stoichiometry of solution-processed $\mathrm{Cs}_{2} \mathrm{AgBiBr}_{6}$ thin-films that enabled corresponding solar cells to generate an encouraging PCE of $2.51 \%$. A summary of all the thus far reports on MHDP solar cells can be seen in Table 3. In some works, the material stability was also carefully examined, which showed satisfactory stability of MHDP solar cells for long-time storage in ambient conditions.

Despite these strenuous efforts, the PCE of MHDPs is still far behind those of Pb-based counterpart solar cells. Considering the bandgap range observed for most of these materials, they can be rated as a talented candidates for tandem solar cells [169]. As mentioned before, to narrow the bandgap of $\mathrm{Cs}_{2} \mathrm{AgBiBr}_{6}$, Liu et al. [131] introduced $\mathrm{Sb}^{3+}$ into the structure of the material up to $75 \%$, which caused shrinkage of $0.25 \mathrm{eV}$ in the material's bandgap value. Further fabrication of the solar cells with the architecture of fluorine-doped tin

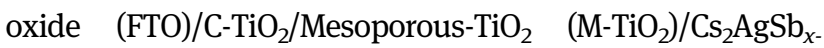
$\mathrm{Bi}_{1-x} \mathrm{Br}_{6} /$ spiro-MeOTAD/Au, an improvement of the PCE from $0.19 \%(x=0)$ to $0.25 \%(x=0.25)$ was observed. It was presented that $\mathrm{Cs}_{2} \mathrm{AgBiBr}_{6}$ solar cell devices can properly work under the temperature range of $50-70{ }^{\circ} \mathrm{C}$ at operational conditions, and also considerably higher temperatures during the device fabrication process $[48,170]$. So, in terms of thermal stability, $\mathrm{Cs}_{2} \mathrm{AgBiBr}_{6}$ material has superior tolerance related to traditional $\mathrm{Pb}$-based perovskites. To improve the PCE, Yang et al. reported a feasible strategy, in which a thin interlayer of di-tetrabutylammonium cis-bis(isothiocyanato) bis(2,2'-bipyridyl-4,4'-dicarboxylato)ruthenium(II) (N719) dye is deposited between the absorbing-layer and holetransporting layer (HTL). The roles of this thin interlayer were attributed to extending the absorption spectrum, accelerating the hole-transportation, reducing the charge carrier recombination, and adjusting the band alignment of 
(a)

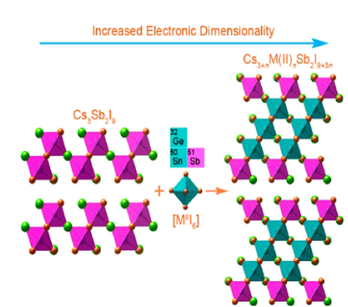

(e)

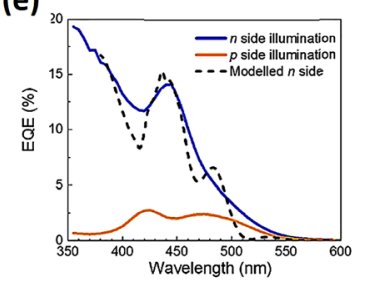

(i)

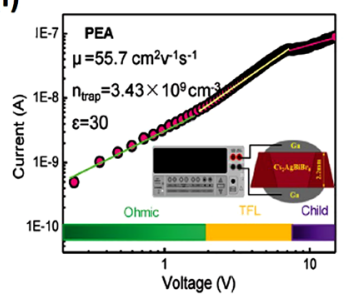

(m)

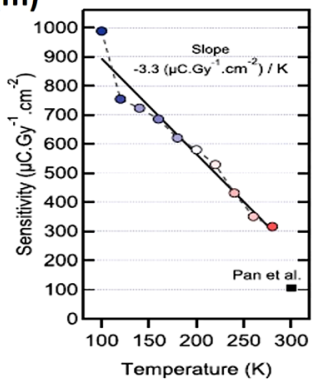

(b)

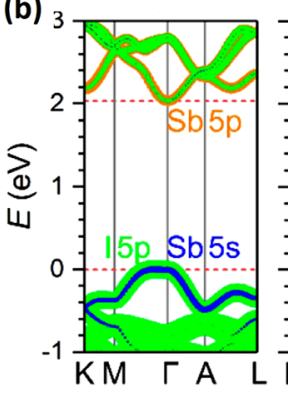

(f)

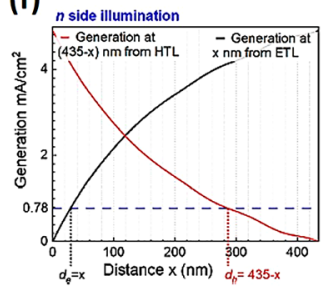

(j)

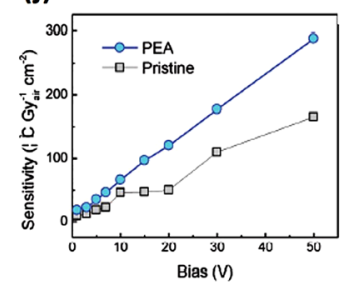

(n)

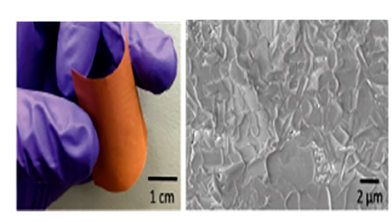

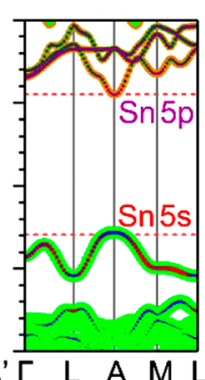

(g)

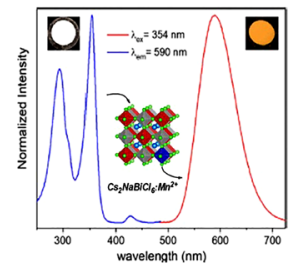

(k)

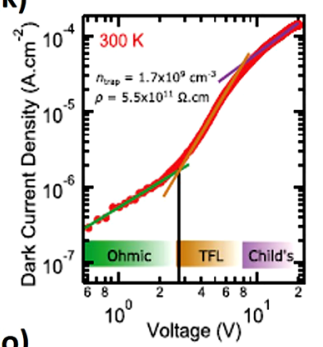

(o)

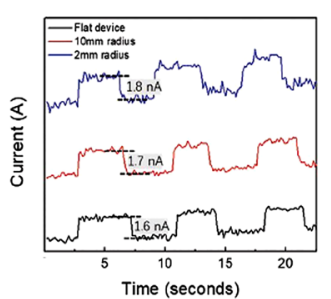

(c)

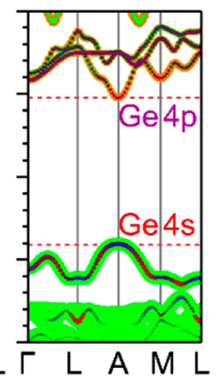

(d)
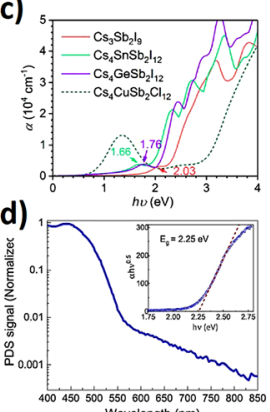

(h)

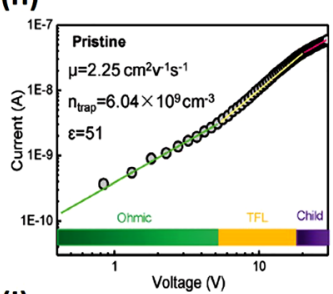

(I)

(p)
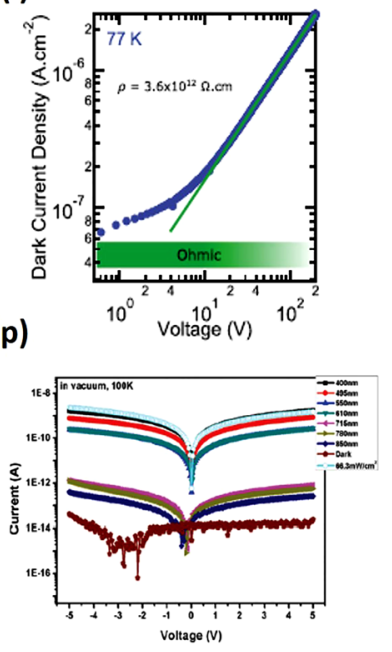

Figure 10: (a) General design principle for the layered halide double perovskites $\mathrm{Cs}_{3+n} \mathrm{M}^{2+}{ }_{n} \mathrm{Sb}_{2} \mathrm{X}_{9+3 n}(\mathrm{M}=\mathrm{Sn}, \mathrm{Ge})$ [166]. Copyright 2018, American Chemical Society. (b) Calculated band structures of $\mathrm{Cs}_{3} \mathrm{Sb}_{2} \mathrm{I}_{9}, \mathrm{Cs}_{4} \mathrm{CuSb}_{2} \mathrm{I}_{12}, \mathrm{Cs}_{4} \mathrm{SnSb}_{2} \mathrm{I}_{12}$ and $\mathrm{Cs}_{4} \mathrm{GeSb}_{2} \mathrm{I}_{12}$ from left to right [166]. Copyright 2018, American Chemical Society. (c) Calculated absorption spectra of $\mathrm{Cs}_{3} \mathrm{Sb}_{2} \mathrm{I}_{9}, \mathrm{Cs}_{4} \mathrm{SnSb}_{2} \mathrm{I}_{12}, \mathrm{Cs}_{4} \mathrm{GeSb}_{2} \mathrm{I}_{12}$ and $\mathrm{Cs}_{4} \mathrm{CuSb}_{2} \mathrm{Cl}_{12}[166]$. Copyright 2018, American Chemical Society. (d) Photothermal deflection optical absorption spectroscopy (PDS) spectrum of neat $\mathrm{Cs}_{2} \mathrm{AgBiBr}_{6}$ thin-film. Inset: Tauc plot with the calculated indirect band-gap reported [179]. Copyright 2020, American Chemical Society. (e) EQE measured with illumination from the ITO (blue curve), from the gold (orange curve) and the modelled $n$-EQE (black dashed curve) [179]. Copyright $\odot 2020$, American Chemical Society. (f) Current generation at a distance $x$ from the ETL (black curve) and a distance $435-x$ from the HTL (red curve) in the case of n-side illumination [179]. Copyright (c) 2020, American Chemical Society. (h) Excitation (blue) and emission (red) scans for

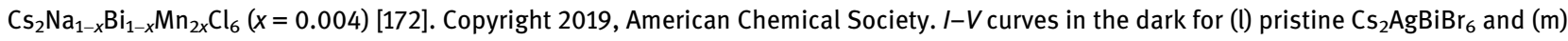
PEA-Cs ${ }_{2} \mathrm{AgBiBr}_{6}$ single-crystals [66]. 2019 WILEY-VCH Verlag GmbH \& Co. KGaA, Weinheim. (n) Obtained sensitivity under different bias of the corresponding $\mathrm{Cs}_{2} \mathrm{AgBiBr}_{6}$ and PEA-Cs${ }_{2} \mathrm{AgBiBr}_{6} \mathrm{X}$-ray detectors [66]. 2019 WILEY-VCH Verlag GmbH \& Co. KGaA, Weinheim. Dark I-V of singlecrystal $\mathrm{Cs}_{2} \mathrm{AgBiBr}_{6}$ photovoltaic device at (o) $300 \mathrm{~K}$ and (p) $77 \mathrm{~K}$ [207]. 2018 Wiley-VCH Verlag GmbH \& Co. KGaA, Weinheim. (q) Temperature dependence of $\mathrm{Cs}_{2} \mathrm{AgBiBr}_{6}$ detector sensitivity to X-rays [207]. 2018 Wiley-VCH Verlag GmbH \& Co. KGaA, Weinheim. (r) Optical photos of a $100 \mathrm{~mm}$-thick $\mathrm{Cs}_{2} \mathrm{AgBiBr}_{6} / \mathrm{PVA}$ (2:1 weight ratio) and SEM top images of the $\mathrm{CS}_{2} \mathrm{AgBiBr}_{6} / \mathrm{PVA}$ composite film [65]. Copyright 2015, Royal Society of Chemistry. (s) X-ray induced photocurrent responses of one detector at both flat and curved (10 and $2 \mathrm{~mm}$ bending radiuses) states [65]. Copyright 2015, Royal Society of Chemistry. (t) $I-V$ curves of $\mathrm{Cs}_{2} \mathrm{AgBiBr}_{6}$ single-crystals based on $\mathrm{Ag}$ electrodes at different wavelengths at 100 K [64]. Copyright 2015, Royal Society of Chemistry. 
Table 3: Summary of the photovoltaic parameters of the MHDP solar cells.

\begin{tabular}{|c|c|c|c|c|c|c|}
\hline $\mathbf{F F}$ & $\begin{array}{r}J_{\mathrm{sc}} \\
\left(\mathrm{mA} / \mathrm{cm}^{2}\right)\end{array}$ & $V_{\text {oc }}(V)$ & PCE \% & Device structure & Stability & Ref. \\
\hline 0.69 & 1.78 & 1.07 & 1.32 & $\mathrm{ITO} / \mathrm{SnO}_{2} / \mathrm{Cs}_{2} \mathrm{AgBiBr}_{6} / \mathrm{P}_{3} \mathrm{HT}^{1} / \mathrm{Au}$ & $\begin{array}{l}30 \text { days in ambient with } \\
\text { humidity } 40-60 \%\end{array}$ & [56] \\
\hline 0.69 & 1.51 & 1.07 & 1.11 & ITO $/ \mathrm{C}-\mathrm{TiO}_{2} / \mathrm{Cs}_{2} \mathrm{AgBiBr}_{6} /$ SpiroOMeTAD $/ \mathrm{Au}$ & Not reported & [57] \\
\hline 0.69 & 3.19 & 1.01 & 2.23 & $\mathrm{ITO} / \mathrm{Cu}-\mathrm{NiO} / \mathrm{Cs}_{2} \mathrm{AgBiBr}_{6} / \mathrm{C} 60 / \mathrm{BCP}^{2} / \mathrm{Ag}$ & $\begin{array}{l}30 \text { days in ambient with } \\
\text { humidity } 50 \%\end{array}$ & [59] \\
\hline 0.67 & 1.02 & 1.02 & 1.26 & $\mathrm{FTO} / \mathrm{C}-\mathrm{TiO}_{2} / \mathrm{Cs}_{2} \mathrm{AgBiBr}_{6} / \mathrm{PTAA}^{3} / \mathrm{Au}$ & Not reported & [61] \\
\hline 0.63 & 3.93 & 0.98 & 2.43 & $\mathrm{FTO} / \mathrm{C}-\mathrm{TiO}_{2} / \mathrm{M}-\mathrm{TiO}_{2} / \mathrm{Cs}_{2} \mathrm{AgBiBr}_{6} /$ Spiro-OMeTAD $/ \mathrm{Au}$ & 25 days in ambient & [58] \\
\hline 0.65 & 3.82 & 1.01 & 2.51 & ITO $/ \mathrm{C}-\mathrm{TiO}_{2} / \mathrm{Cs}_{2} \mathrm{AgBiBr}_{6} /$ Spiro-OMeTAD $/ \mathrm{MoO}_{3}{ }^{4} / \mathrm{Ag}$ & 15 days in ambient & [60] \\
\hline 0.68 & 1.1 & 1.1 & 1.37 & $\mathrm{FTO} / \mathrm{C}-\mathrm{TiO}_{2} / \mathrm{Cs}_{2} \mathrm{AgBiBr}_{6} / \mathrm{P} 3 \mathrm{HT} / \mathrm{Au}$ & $250 \mathrm{~h}$ in ambient & [235] \\
\hline 0.69 & 2.58 & 1.07 & 1.91 & $\mathrm{FTO} / \mathrm{C}-\mathrm{TiO}_{2} / \mathrm{Cs}_{2} \mathrm{AgBiBr}_{6} / \mathrm{P} 3 \mathrm{HT} / \mathrm{Cu}$ & $\begin{array}{l}68 \text { days in humidity of } \\
68 \pm 7 \%\end{array}$ & [62] \\
\hline 0.52 & 5.13 & 1.06 & 2.84 & $\mathrm{FTO} / \mathrm{C}-\mathrm{TiO}_{2} / \mathrm{M}-\mathrm{TiO}_{2} / \mathrm{Cs}_{2} \mathrm{AgBiBr}_{6} / \mathrm{N} 719 /$ Spiro-OMeTAD/Ag & $\begin{array}{l}16 \text { days in humidity of } \\
30-40 \%\end{array}$ & [171] \\
\hline 73.6 & 3.83 & 0.99 & 2.79 & ITO $/ \mathrm{SnO}_{2} / \mathrm{Cs}_{2} \mathrm{AgBiBr}_{6} /$ zinc chlorophyll derivative $(\mathrm{Zn}-\mathrm{Chl}) / \mathrm{Ag}$ & 50 days in ambient & [236] \\
\hline 0.70 & 1.33 & 1.10 & 1.03 & $\mathrm{FTO} / \mathrm{TiO}_{2} / \mathrm{Cs}_{2} \mathrm{AgBiBr}_{6} /$ Spiro-OMe-TAD $/ \mathrm{Ag}$ & Not reported & [179] \\
\hline
\end{tabular}

the active layer for the carrier collecting layers. That enabled a PCE of $2.84 \%$ with a simultaneous improvement in the stability of $\mathrm{Cs}_{2} \mathrm{AgBiBr}_{6}$ solar cells [171].

The problem with the potential MHDPs predicated by theoretical calculations as promising light absorber is mainly related to their big enthalpy formation, dissolubility of their precursors, poor thin-film quality [72, 165, 172]. In addition to these challenges, insufficient knowledge of the fundamental photophysics of MHDP thin-films has resulted in their low-performance in solar cells [173].

While most of the previous studies mainly focused on the photovoltaic performance of $\mathrm{C}_{2} \mathrm{AgBiBr}_{6} \mathrm{MHDP}$, comprehensive knowledge of its long-term stability and degradation mechanism is still scarce. Recently, we demonstrated the development of high-quality $\mathrm{Cs}_{2} \mathrm{AgBiBr}_{6}$ thin-film with a grain size in the range of $300-500 \mathrm{~nm}$ via a feasible solution method [62]. Implementing planar thinfilm solar cell could achieve a decent efficiency of $1.91 \%$. The stability of these $\mathrm{Cs}_{2} \mathrm{AgBiBr}_{6}$ photovoltaic devices was studied over long storage of 68 days in ambient conditions that helped to understand a dual-ion-migration phenomenon in $\mathrm{Cs}_{2} \mathrm{AgBiBr}_{6}$ double perovskite. Theoretical calculations consistently confirmed the low formation energy for $\mathrm{Ag}$ and $\mathrm{Br}$ vacancies, and small diffusive energy barriers that facilitated ion-migration effect. Given these, a mechanism of vacancy-mediated ion-migration was proposed to be responsible for this phenomenon. These key findings

1 Poly(3-hexylthiophene).

2 Bathocuproine.

3 Poly[bis(4-phenyl)(2,4,6-trimethylphenyl)amine.

4 Molybdenum trioxide. are of vital importance for MHDPs to outstretch their optoelectronic applications where mixed electronic, ionic and photonic properties are desired.

In general, the performance of the solar cells based on MHDPs is still far behind their Pb-based counterparts, suggesting some serious limitations that need to be carefully addressed. In the search for alternative $\mathrm{Pb}$-free perovskites, the absorber should have near-ideal optoelectronic properties (e.g. Direct bandgap preferably between 1 and $1.8 \mathrm{eV}$, long electron and hole diffusion length and low defect trap density) [126]. The best-reported PCE for MHDPs is $2.84 \%$ at a bandgap of around 2.25, with an open-circuit voltage $\left(V_{\text {oc }}\right)$ of $1.06 \mathrm{~V}$, short-circuit current $\left(U_{\mathrm{sc}}\right)$ of $5.13 \mathrm{~mA} / \mathrm{cm}^{2}$ and fill factor $(F F)$ of 0.52 [171]. Historically, a large voltage-deficit was obtained in photovoltaic technology, which however has been gradually improved due to technical progress in material processing and surface passivation [174]. On the other hand, the severely inhibited $J_{\mathrm{sc}}$ should be a major obstacle to high-performance solar cell devices [175]. To have an optimum absorption due to indirect bandgap of investigated MHDPs for solar cells, namely $\mathrm{Cs}_{2} \mathrm{AgBiBr}_{6}$, high thicknesses on the order of tens to hundreds of micrometres is necessary. This highlights the importance of long chargecarrier diffusion length in the absorbing layer to generate high short-circuit currents. To date, several different values have been reported for charge-carrier mobility and diffusion length of MHDPs mainly in the form of thin-film and singlecrystal [64, 173, 176-178]. Very recently, Longo et al. reported an evaluation of the carrier diffusion length of vapour-deposited $\mathrm{Cs}_{2} \mathrm{AgBiBr}_{6}$-based solar cells with the best PCE of $1.03 \%, J_{\mathrm{sc}}$ of $1.33 \mathrm{~mA} / \mathrm{cm}^{2}, V_{\text {oc }}$ of $1.10 \mathrm{eV}$ and $F F$ of 0.70 [179]. With the Shockley-Queisser assumptions at a 
bandgap of $2.25 \mathrm{eV}$, the thermodynamic limit should be $J_{\mathrm{sc}}$ of $9.79 \mathrm{~mA} / \mathrm{cm}^{2}, V_{\text {oc }}$ of $1.93 \mathrm{eV}$ and PCE of $17.6 \%$. Every $60 \mathrm{mV}$ loss in $V_{\mathrm{oc}}$ from this limit corresponds to a reduction of anorder-of-magnitude in the device's external radiative efficiency (ERE) [180-183]. Therefore, for a device with $V_{\text {oc }}$ of $1.10 \mathrm{eV}$, the loss was $\sim 800 \mathrm{mV}$, which declared a sufficiently low ERE of $\sim 10^{-13}$ for a $\mathrm{Cs}_{2} \mathrm{AgBiBr}_{6}$ solar cell device. As a comparison, this value is around 0.1 for the best organicinorganic $\mathrm{Pb}$-based perovskite solar cells. This indicated an intensely high rate of non-radiative recombination in $\mathrm{Cs}_{2} \mathrm{AgBiBr}_{6}$ device, which should originate from substantially large trap densities in the absorber and interfaces. Longo et al. discussed that a shallow absorption edge with an Urbach energy of $70 \mathrm{meV}$ (Figure 10d) [179] was a strong indicator of a large density of sub-bandgap states in $\mathrm{Cs}_{2} \mathrm{AgBiBr}_{6}$ thin-film. These states could severely facilitate fast charge-carrier trapping and the ulterior non-radiative recombination process [184]. This scenario was more problematic for wide bandgap light absorbers because the positions of VBM and CBM were far from the optimum energetic match that has been so far investigated for the promising charge extraction layers [183]. By an accurate examination of the external quantum efficiency (EQE) spectra of semi-transparent $\mathrm{Cs}_{2} \mathrm{AgBiBr}_{6}$ solar cells, they found an ineffective collection of electrons by the extraction layer when they had to pass through the entire active layer (Figure 10e). They also found that the strongly absorbed wavelengths could not reach the electron-transporting layer (ETL) (Figure 10e). These observations signified the short electron diffusion as the limiting factor for low short-circuit current of $\mathrm{Cs}_{2} \mathrm{AgBiBr}_{6}$ solar cells. It was shown that $\mathrm{Cs}_{2} \mathrm{Ag}$ $\mathrm{BiBr}_{6}$ double perovskite possesses a short electron diffusion length of $30 \mathrm{~nm}$ and a longer hole diffusion length of greater than $150 \mathrm{~nm}$ ascribed to a high density of electron traps in $\mathrm{Cs}_{2} \mathrm{AgBiBr}_{6}$ thin-film (Figure 10f) [179].

In general, the major challenges for high-efficiency MHDPs solar cells should be attributed to their short electron diffusion length, high defect trapping/low-quality light-absorbing and unsuitable ETL/HTL matches. Exhibiting these optoelectronic properties, another potential choice can be semi-transparent perovskite solar cells with a promising perspective for diverse applications of tandem devices, building-integrated photovoltaics and vehicleintegrated photovoltaics [185].

\subsection{Light-emitting diodes}

For lighting applications, white emission from a single emitter layer is of particular interest because significant advantages such as simple device structure, low self- absorption and good colour stability are commonly observed in mixed and multiple emitters [186]. Although hybrid $\mathrm{Pb}$-based perovskites with low-dimensional structures have attained tremendous attention as broadbandemission materials, they barely deliver high PL quantum yield [187]. Broadband and white emission normally are ascribed to the self-trapped excitons (STEs) that are typically observed in semiconductors with localized carriers and a soft lattice $[188,189]$. In 2018, Tang et al. demonstrated the stable and efficient white-light emission of doped $(0.04 \%$ $\left.\mathrm{Bi}^{3+}\right) \mathrm{Cs}_{2}\left(\mathrm{Ag}_{0.60} \mathrm{Na}_{0.40}\right) \mathrm{InCl}_{6}$ double perovskite with a broad spectrum (400-800 nm) that occurred through self-trapped excitons [190]. The origin of this ability was attributed to the Jahn-Teller distortion in $\left(\mathrm{AgCl}_{6}\right)^{5-}$ octahedron upon illumination in the excited state. As discussed before, $\mathrm{Cs}_{2} \mathrm{AgInCl}_{6}$ suffers from parity-forbidden transition. However, $\mathrm{Na}^{+}$ incorporation into the lattice was found to be beneficial to adjust the wave function's parity of the self-trapped excitons. This yielded an ultimate reduction into its electronic dimensionality [165]. Accordingly, an enhancement in PL efficiency (warm-white light efficiency of $86 \pm 5 \%$ and high stability of $\sim 1000 \mathrm{~h}$ ) was observed, which was three orders of magnitude of the one for pure $\mathrm{Cs}_{2} \mathrm{AgInCl}_{6}$ perovskite. It was proposed that this substantial stability originates from the nearly defect-free lattice of the material and strongly bound excitons that all together sufficiently inhibit PL quenching. This outstanding photometric performance emphasized the promise for white-phosphor applications. Regarding this point, MHDPs also have displayed promising potential for phosphor-converted light-emitting diode (pcLED) applications. In general, pc-LEDs are enabled to generate white light with a remarkable performance of almost double of the fluorescent lights and ten times of the incandescent lights [172]. Majher et al. [172] reported $\mathrm{Mn}^{2+}$ doped cubic double perovskite $\mathrm{Cs}_{2} \mathrm{NaBiCl}_{6}$, in which a strong absorption near-UV light was observed (Figure 10g). This was attributed to the localized excitations that are centred on $\mathrm{Bi}^{3+}$ sites in the parent lattice. Insertion of the strongly electropositive $\mathrm{Na}^{+}$cations into the octahedra of the lattice yielded a zero-dimensional electronic structure [191, 192]. Normally, localized electronic states are favourable for the formation of self-trapped and dopant-bound excitons [192]. Undoped host compound, $\mathrm{Cs}_{2} \mathrm{NaBiCl}_{6}$, showed a considerably weak PL, while intense orange-red photoluminescence was realized through $\mathrm{Mn}^{2+}$ doping. This trend was associated with the energy transfer from $\mathrm{Bi}^{3+}$ to $\mathrm{Mn}^{2+}[172]$. As discussed before, $\mathrm{Cs}_{2} \mathrm{AgInCl}_{6}$ was a wide bandgap semiconductor with a $3 \mathrm{D}$ electronic structure. Through illumination, $\mathrm{Mn}^{2+}$-doped $\mathrm{Cs}_{2} \mathrm{AgInCl}_{6}$ absorbed photons and generated electron-hole pairs. These photogenerated carriers were presumed to migrate through the 
lattice until they were trapped and recombined at the $\mathrm{Mn}^{2+}$ sites. In contrast, for the case of $\mathrm{Mn}^{2+}$-doped $\mathrm{Cs}_{2} \mathrm{NaBiCl}_{6}$, the light absorption occurred through localized excitations of $\left[\mathrm{BiCl}_{6}\right]^{3-}$ octahedral. Then their energy was transferred to the neighbouring $\mathrm{Mn}^{2+}$ sites that were assumed as the activators. The observed red-emission in $\mathrm{Mn}^{2+}$-doped $\mathrm{Cs}_{2} \mathrm{AgNaCl}_{6}$ spectrum particularly should be advantageous for some applications of tri-colour pc-LEDs employing red and green phosphors. However, fairly low quantum yield (3-5\%) and lack of absorbance at higher wavelengths than $350 \mathrm{~nm}$ were problematic. Besides, as an efficient phosphor for white lighting applications, a red-shift in the excitation wavelength would be beneficial because it provided a stronger overlap with the emission spectrum of $\mathrm{Ga}_{1-\chi} \mathrm{In}_{x} \mathrm{~N}$ LED sources. Tuning the bandgap of the material adopting other possible cations or halide anions should be a route to reach this goal. These findings encourage further investigation of white-light MTHDs emitters towards the next generation of lighting technologies.

\subsection{Photodetectors}

$\mathrm{X}$-ray detection is of great interest in a variety of applications including medical diagnostics, non-destructive product inspection and versatile scientific research [193,194]. A higher spatial resolution can achieve in direct route with simpler system configuration to convert $\mathrm{X}$-ray radiation into an electrical signal, while in indirect methods, $\mathrm{X}$-ray first is converted into the photons by scintillating phosphors following with detection by photodiodes [195]. Recently, solution-grown halide perovskites have exhibited exceptional properties of high X-ray attenuation coefficient, long carrier drift length per unit electric field (defined as $\mu \tau$ product, where $\mu$ is the carrier mobility and $\tau$ is the carrier lifetime), and facile integration with silicon-based electronics for imaging intentions [196]. So far X-ray detectors based on $\mathrm{Pb}$-halide perovskites have demonstrated an outstanding sensitivity of $2.1 \times 10^{4} \mu \mathrm{CGy}_{\text {air }}{ }^{-1} \mathrm{~cm}^{-2}$ [197, 198]. Despite this exceptional success, $\mathrm{Pb}$ toxicity is a barrier due to its fatal impacts on the human body [199]. Moreover, it is highly motivated for further optimization of the bestreported detection limit of $\mathrm{Pb}$-based halide perovskites, because a reduction in the radiation dose during medical tests can strikingly diminish the cancer risk [200]. A small detection limit is also necessary for $\mathrm{X}$-ray security screening systems [201]. Lowering this detection limit can enhance the spatial resolution of the images [202]. For these reasons, developing $\mathrm{Pb}$-free single-crystals with a low detection limit for X-ray detection applications is of great importance [203].
Although the indirect characteristics of the $\mathrm{Cs}_{2} \mathrm{AgBiBr}_{6}$ bandgap $(2.1 \mathrm{eV})$ relatively diminishes its potential for photovoltaics and lighting applications, it carries some promising features that enable its capability for X-ray detection applications as described here. (i) For an X-ray detector, the absorption coefficient $(\alpha)$ is a function of $\alpha \propto Z^{4} / E^{3}$ ( $Z=$ atomic number and $E=$ radiation energy), while in photovoltaics and LEDs, it is determined by the material's optical-transition type and bandgap value [204]. For the case of $\mathrm{Cs}_{2} \mathrm{AgBiBr}_{6}$, it preferably has the heaviest stable element (Bi) in its structure with an average $Z$ value of 53.1, higher than the $Z$ value of 48.9, 45.1 and 34.0 for $\mathrm{MAPbI}_{3}, \mathrm{MAPbBr}_{3}$ and $\alpha-\mathrm{Se}$, respectively. This implies more efficient X-ray attenuation and improved signal current. (ii) The $\mu \tau$ product indicates the carrier transportation per unit electric field before annihilation that pushes the charge extraction efficiency. The indirect characteristic of $\mathrm{Cs}_{2} \mathrm{AgBiBr}_{6}$ bandgap causes a long PL lifetime, which is remarkably higher than the reported magnitude for $\mathrm{MAPbBr}_{3}$ single-crystals ( $357 \mathrm{~ns}$ ), therefore a decent $\mu \tau$ product is predicted for $\mathrm{Cs}_{2} \mathrm{AgBiBr}_{6}[48$, 196, 205]. (iii) In an efficient $X$-ray detector, high resistivity is the key to mitigating dark current and consequently the noise current. This value is found to be $10^{9}-10^{11} \Omega \mathrm{cm}$ for $\mathrm{Cs}_{2} \mathrm{Ag}$ $\mathrm{BiBr}_{6}$, higher than those for $\mathrm{MAPbX}_{3}\left(\mathrm{X}=\mathrm{Cl}, \mathrm{Br}, \mathrm{I} ; 10^{7}\right.$ $10^{8} \Omega \mathrm{cm}$ ). (iv) In halide perovskites, severe halide migration widely plagues their detection limit [206]. In contrast, $\mathrm{Cs}_{2} \mathrm{AgBiBr}_{6}$ single-crystals have lower field-driven ionic migration that makes the material withstand a large external bias to improve the signal current and suppress a superlinear growth in the noise current. On the count of these features, fabricating X-ray detectors based on non-toxic stable $\mathrm{Cs}_{2} \mathrm{AgBiBr}_{6}$ single-crystals is highly promising. To this end, Tang et al. [196] successfully examined the application of $\mathrm{Cs}_{2} \mathrm{AgBiBr}_{6}$ single-crystals to fabricate X-ray detectors with high sensitivity and low detection limits. They presented an enhancement in the material's carrier transport by increasing the mobility from 3.17 to $11.81 \mathrm{~cm}^{2} \mathrm{v}^{-1} \mathrm{~s}^{-1}$ and a reduction in the surface trap densities from $4.54 \times 10^{9}$ to $1.74 \times 10^{9} \mathrm{~cm}^{-3}$ through thermal annealing and surface treatment. This came from a relief in the $\mathrm{Ag}^{+} / \mathrm{Bi}^{3+}$ disordering arrangement that adequately improved $\mathrm{Cs}_{2} \mathrm{AgBiBr}_{6}$ single-crystals' resistivity. As expected, $\mathrm{Cs}_{2} \mathrm{AgBiBr}_{6}$ single-crystals showed a suppressed field-driven ionic migration that permitted applying a large external bias to reduce the dark current. A promising sensitivity of $105 \mu \mathrm{CGy}_{\mathrm{air}}{ }^{-1} \mathrm{~cm}^{-2}$ and a low detection limit of $59.7 \mathrm{nGy}_{\text {air }}{ }^{-1} \mathrm{~s}^{-1}$ were found for the optimized $\mathrm{Cs}_{2} \mathrm{AgBiBr}_{6}$ $\mathrm{X}$-ray detector systems. All these characteristics benefit for $\mathrm{X}$-ray security screening systems and the applications of medical diagnostics. Nevertheless, the disordered arrangement of $\left[\mathrm{AgBr}_{6}\right]^{5-} /\left[\mathrm{BiBr}_{6}\right]^{3-}$ in the most explored case, 
$\mathrm{Cs}_{2} \mathrm{AgBiBr}_{6}$, usually causes some unexpected structural distortion that extensively influences the photoelectric properties. Yuan et al. [66] innovatively showed the ability of phenylethylamine bromide to in situ regulation of $\mathrm{Cs}_{2} \mathrm{Ag}$ $\mathrm{BiBr}_{6}$ order-disorder phase transition. In a combination of theoretical and experimental studies, they proved that modifying $\left[\mathrm{AgX}_{6}\right]^{5-}$ and $\left[\mathrm{BiX}_{6}\right]^{3-}$ octahedra ordering decreased the defect density in the structure and also suppressed the self-trapped exciton formation (Figure 10h and i). In accordance, this enhanced the material's charge carrier mobility. The as-fabricated X-ray detectors based on

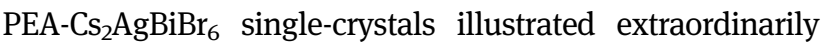
high sensitivity of $288.8 \mu \mathrm{CGy}_{\text {air }}{ }^{-1} \mathrm{~cm}^{-2}$ that is largely superior to those of their counterparts with less structural ordering (Figure 10j). In another work, Roeffaers et al. investigated the intrinsic photophysical pathways in $\mathrm{Cs}_{2} \mathrm{AgBiBr}_{6}$ singlecrystals at room and liquid-nitrogen temperatures. They showed deficient charge carrier dynamic for $\mathrm{Cs}_{2} \mathrm{AgBiBr}_{6}$ single-crystal X-ray detectors at room temperature [207]. A substantial enhancement of carrier lifetimes of $\mathrm{Cs}_{2} \mathrm{AgBiBr}_{6}$ single-crystals was notified from $700 \mathrm{~ns}$ at room temperature to over $1500 \mathrm{~ns}$ at liquid-nitrogen temperature. This caused a huge boost in devices' sensitivity from $316 \mu \mathrm{CGy}^{-1} \mathrm{~cm}^{-2}$ at room temperature to $988 \mu \mathrm{CGy}^{-1} \mathrm{~cm}^{-2}$ at liquid-nitrogen temperature (Figure 10k-m).

Flexible X-ray detectors are of significant interest due to their feasible adhesion to uneven surfaces, lightweight, transferable X-ray diagnostic instruments and potential capability in correcting image distortion in the cone-beam quantified tomography [208]. However, a tens-ofmicrometre thickness is required for halide perovskite devices to effectively absorb X-rays [209]. This will limit their flexibility due to crack formation and film delamination from the substrate. To overcome this, Li et al. [65] developed a new strategy by embedding composite films of $\mathrm{Cs}_{2} \mathrm{AgBiBr}_{6}$ in a polymer matrix. Polymers containing hydroxyl functional groups intensively modified $\mathrm{Cs}_{2} \mathrm{AgBiBr}_{6}$ dispersion in the composite that could deliver large-area dense films (Figure 10n). Fabricating X-ray detectors based on this composite film committed a promising sensitivity of $40 \mu \mathrm{CGyair}^{-1} \mathrm{~cm}^{-2}$. Flexing and bending the relevant detectors at a $2 \mathrm{~mm}$ radius (equivalent to a maximum 5\% tensile/compressive strain in the composite films), no degradation could be detected in the device's performance (Figure 10).

Single-crystals are considered as an ideal test platform to investigate the characteristics of double perovskites due to the absence of the grain boundaries and low densities of traps. Dang et al. surveyed the photodetectors based on centimetre-sized $\mathrm{Cs}_{2} \mathrm{AgBiBr}_{6}$ single-crystals, in which different metals of $\mathrm{Au}, \mathrm{Ag}$ and $\mathrm{Al}$ were applied as the contact electrode. An excellent photoresponse behaviour was found for Ag-based devices (Figure 10p) [64], which was attributed to the better ohmic contact between $\mathrm{Cs}_{2} \mathrm{AgBiBr}_{6}$ singlecrystals and Ag electrodes. Furthermore, a clear phase transition in $\mathrm{Cs}_{2} \mathrm{AgBiBr}_{6}$ single-crystals was notified that strongly affected the function of the corresponding devices. Carrying out the measurements at different applied voltages and wavelengths in a vacuum atmosphere at a low temperature of $100 \mathrm{~K}$, no ohmic-contact behaviour could be seen for $\mathrm{Cs}_{2} \mathrm{AgBiBr}_{6}$ single-crystals. This poor behaviour possibly originated from the variations in the crystal structure ordering induced by the material's phase transition [210]. Therefore, it is important to consider the consequence of this phase transition on the device performance and find the right approaches to manage it.

\subsection{Photocatalysts}

$\mathrm{CO}_{2}$ is considered as the main greenhouse gas causing global warming. However, it can also be advantageous to produce value-added chemicals and solar fuels (e.g. CO, $\left.\mathrm{HCOOH}, \mathrm{CH}_{3} \mathrm{OH}, \mathrm{CH}_{4}\right)$ by its reduction through photocatalytic strategies under light illumination. Recently, semiconductor quantum dots (QDs) have been classified as one of the promising candidates for initiating highly effcient artificial photosystems. This ongoing attention comes from some of the attracting characteristics of semiconductor QDs, including multiple exciton generation, abundant surface sites, excellent light-harvesting, feasible charge-carrier regulation and facile synthesis. Although $\mathrm{Pb}$-based halide perovskite QDs have indicated supreme optoelectronic abilities, the presence of toxic $\mathrm{Pb}$ and also limited intrinsic stability of this class of the materials to moisture hamper their widespread practical applications [211]. Very recently, Zhou et al. [212] for the first time reported the synthesis of pure cubic shape $\mathrm{Cs}_{2} \mathrm{AgBiBr}_{6}$ QDs, with a reasonably high optical absorption coefficient, through a simple hot-injection method (Figure 11a). It was shown that the high-crystalline $\mathrm{Cs}_{2} \mathrm{AgBiBr}_{6}$ QDs could preserve their structural stability in low polarity solutions for about three weeks. $\mathrm{Cs}_{2} \mathrm{AgBiBr}_{6}$ QDs also showed strong phase uniformity at different conditions of atmospheric humidity and light soaking time (Figure 11b), which all validate the material's striking stability against moisture, temperature and light, as crucial factors for the vast optoelectronic or photochemical applications. $\mathrm{Cs}_{2} \mathrm{AgBiBr}_{6}$ QDsbased photosystem exhibited high stability and selectivity to produce both $\mathrm{CO}$ and $\mathrm{CH}_{4}$ (Figure 11c). It is known that the ligands of QDs can affect the exchange of surface substances and excitons' transfer into the system, where 
the organic ligand blocks the efficient photogenerated charges transportation from photocatalysts to reactants. This promotes accumulation of the photoconversion products that intermediates in the ligand shell. This phenomenon yields catalyst poisoning diminishes activity, and finally dampens the photocatalytic performances [213]. On the other hand, low ligand density on QDs can enhance the photoconversion performance due to the effective carrier transport in the system. Considering these synthetic notes and optimization of the operation condition, $\mathrm{CO}$ and $\mathrm{CH}_{4}$ production rates of 14.1 and $9.6 \mu \mathrm{mol} \mathrm{g}^{-1}$ were found for the $\mathrm{Cs}_{2} \mathrm{AgBiBr}_{6}$ QDs photosystem. It was proposed that the proper position of the $\mathrm{Cs}_{2} \mathrm{AgBiBr}_{6} \mathrm{CBM}$ derived the $\mathrm{CO}_{2}$ reduction (Figure 11d). This observation triggered the great potential of non-toxic stable MHDPs for photocatalysts.

In another study by Zhang et al., an alcohol-based photocatalytic system was successfully implemented, in which $\mathrm{Cs}_{2} \mathrm{AgBiBr}_{6}$ was used as the light harvester to degrade different dyes [67]. Inspiringly, $\mathrm{Cs}_{2} \mathrm{AgBiBr}_{6}$ showed remarkable chemical stability in the presence of the ethanol during the whole photocatalytic processes. Likewise, ethanol solvent did not undergo any photocatalytic oxidation. Investigating the degradation process of four different dyes, a pseudo-zeroth-order reaction kinetics was revealed for $\mathrm{Cs}_{2} \mathrm{AgBiBr}_{6}$ (Figure 11e) that was in opposition to the pseudo-first-order reaction kinetics identified for CdS systems. In the studied systems in this work, dye molecules experienced a thorough mineralization process and the main active species were confirmed to be superoxide radical $\left(\mathrm{O}_{2}^{-}\right)$(Figure 11f). Additionally, it was shown that $\mathrm{Pt}$ and $\mathrm{Au}$ deposition facilitates the transformation of photogenerated electrons from $\mathrm{Cs}_{2} \mathrm{AgBiBr}_{6}$ to the metal electrodes. This design caused an impressive increase in the photocatalytic degradation rate, around two times, which surpassed CdS systems under the same reaction conditions. PL decay of the $\mathrm{Cs}_{2} \mathrm{AgBiBr}_{6}$ presented a fast initial drop due to multiple recombination centres in the $\mathrm{Cs}_{2} \mathrm{AgBiBr}_{6}$ powder followed by a slow decay that delivered an average lifetime of 3.18 ns. While Pt and $\mathrm{Au}$ deposition substantially decreased this average lifetime to 0.71 and $1.52 \mathrm{~ns}$, respectively (Figure 11g). This indicated the appearance of non-radiative centres, as well as interfacial charge transportation that all together demonstrate a promotion in the carrier separation after Pt or Au deposition. Applying five runs of the photocatalytic reaction confirmed the promising stability of the $\mathrm{Cs}_{2} \mathrm{AgBiBr}_{6}$ with no obvious decline in the photodegradation efficiency (Figure 11h). These results stimulate further efforts to expand the family of MHDPs for a broad range of possible applications in photocatalysis.

\subsection{Sensors}

One of the unique characteristics of $\mathrm{Cs}_{2} \mathrm{AgBiBr}_{6}$ is its remarkably high stability in the ambient environment $[48,214]$. Due to the great dependency of the $\mathrm{Cs}_{2} \mathrm{AgBiBr}_{6}$ electrical properties on the humidity, Weng et al. [63] devoted some effort to excavate its potential as a humidity sensor. The proposed structure for the $\mathrm{Cs}_{2} \mathrm{AgBiBr}_{6}$ thin-film humidity sensor can be seen in Figure 11i. For different applications namely weather forecast, medical tools and agriculture, humidity measurement is a pivotal demand [215]. For a well-performed humidity sensor, the commonly required features include high sensitivity, preferential linearity, the short response time $\left(t_{\text {res }}\right)$ and recovery time $\left(t_{\text {rec }}\right)$, good stability and reliability [216]. The humidity sensors based on stable $\mathrm{Cs}_{2} \mathrm{AgBiBr}_{6}$ thin-films showed a superfast response time of $1.78 \mathrm{~s}$ and a recovery time of $0.45 \mathrm{~s}$ in the operational condition with different relative humidity (RH) of $5-75 \%$ (Figure 11j) [63]. From this point of view, the performance of the $\mathrm{Cs}_{2} \mathrm{AgBiBr}_{6}$ thin-film humidity sensors was superior to that of other perovskite-based humidity sensors [217]. This outstanding sensing behaviour was presumed to be due to the plane structure of the $\mathrm{Cs}_{2} \mathrm{AgBiBr}_{6}$ thin-film that facilitated the volatilization of the water molecules during the desorption process. It is in contrary to the porous structure in ceramic humidity sensors, that traps the condensed water molecules in the pores, decelerates the volatilization process and finally causes much longer recovery times than the response times [218, 219]. Another possible reason for this high-performance sensing ability was related to the weaker bond between the surface of the $\mathrm{Cs}_{2} \mathrm{AgBiBr}_{6}$ thin-film and water molecules than the one in metal-oxide-ceramic humidity sensors, because the hydrogen bond $\mathrm{H}-\mathrm{Br}$ is weaker than $\mathrm{H}-\mathrm{O}$ bond. Therefore, the first-layer water molecules can feasibly volatilize from the $\mathrm{Cs}_{2} \mathrm{AgBiBr}_{6}$ surface. Moreover, the $\mathrm{Cs}_{2} \mathrm{AgBiBr}_{6}$ thin-film humidity sensors demonstrated an excellent sensitivity of 1162 in the $\mathrm{RH}$ range of $15-78 \%\left(25^{\circ} \mathrm{C}\right)$ (Figure 11k). In terms of long-term stability, the $\mathrm{Cs}_{2} \mathrm{AgBiBr}_{6}$ thin-film humidity sensors exhibit unchanged resistance after repeated measurement for 13 days under different $\mathrm{RH}$ values (Figure 11l). These observations validated the considerable tolerance and applicability of the $\mathrm{Cs}_{2} \mathrm{AgBiBr}_{6}$ thin-film humidity sensors for a daily life humidity measurement. Previous studies on the $\mathrm{Pb}$-based halide perovskites' electronic humidity sensors mainly focus on $\mathrm{MAPbI}_{3-x} \mathrm{Cl}_{x}$ perovskites. However, the moisture and thermal stability of this $\mathrm{Pb}$-halide perovskite poses serious concerns on their long-term operation [220, 221]. Therefore, considering excellent stability and superfast response and recovery speed, it is believed that 
(a)

(f)
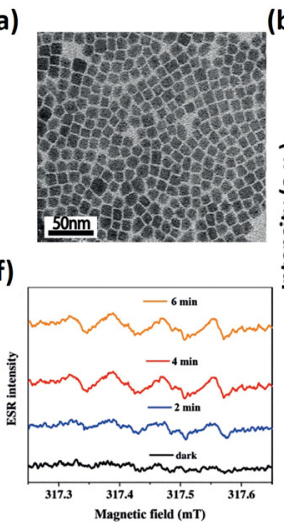

(j)

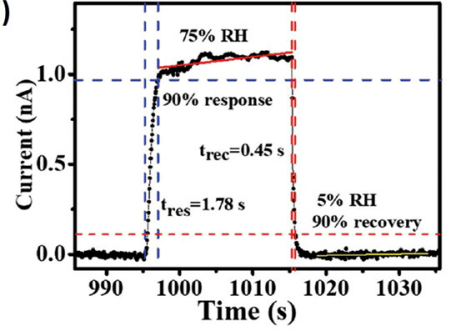

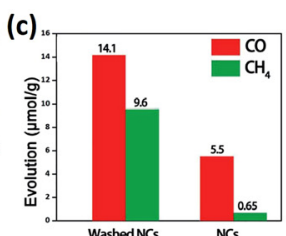

(g)

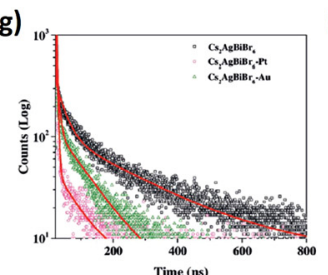

(k)

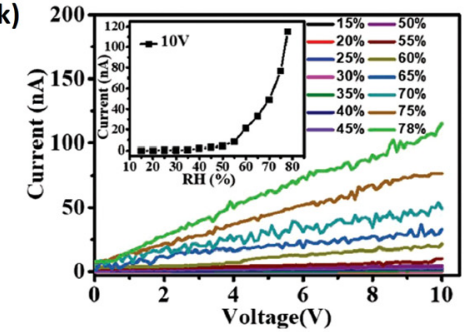

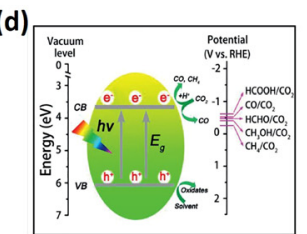

(h)

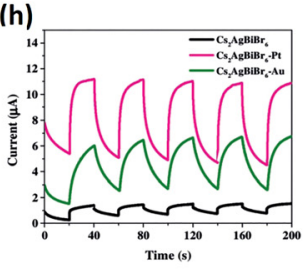

(I)

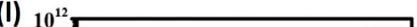

Figure 11: (a) TEM image of $\mathrm{Cs}_{2} \mathrm{AgBiBr}_{6}$ QDs [212]. (b) XRD patterns of absolute ethanol washed $\mathrm{Cs}_{2} \mathrm{AgBiBr}_{6}$ QDs stored in different environments [212]. (c) Comparison of photocatalytic $\mathrm{CO}_{2}$ reduction performance of the as-prepared $\mathrm{Cs}_{2} \mathrm{AgBiBr}_{6} \mathrm{QDs}$ and washed QDs [212]. (d) Schematic diagram of the photoreduction of $\mathrm{CO}_{2}$ on the surface of $\mathrm{Cs}_{2} \mathrm{AgBiBr}_{6}$ QDs [212]. (e) Kinetic curves of different dyes degradation [67]. 2019 Wiley-VCH Verlag GmbH \& Co. KGaA, Weinheim. (f) The DMPO spin-trapping ESR spectra of $\mathrm{Cs}_{2} \mathrm{AgBiBr}_{6}$ for $\mathrm{O}_{2}$ under different visiblelight irradiation time [67]. 2019 Wiley-VCH Verlag GmbH \& Co. KGaA, Weinheim. (g) TRPL of $\mathrm{Cs}_{2} \mathrm{AgBiBr}_{6}, \mathrm{Cs}_{2} \mathrm{AgBiBr}_{6}-\mathrm{Pt}_{\text {and }} \mathrm{Cs}_{2} \mathrm{AgBiBr}_{6}-\mathrm{Au}_{\text {[67] }}$. 2019 Wiley-VCH Verlag GmbH \& Co. KGaA, Weinheim. (h) Photocurrent response of $\mathrm{Cs}_{2} \mathrm{AgBiBr}_{6}, \mathrm{Cs}_{2} \mathrm{AgBiBr}_{6}-\mathrm{Pt}_{\text {and }} \mathrm{Cs}_{2} A g B i B r_{6}-\mathrm{Au}^{2}$ [67]. 2019 Wiley-VCH Verlag GmbH \& Co. KGaA, Weinheim. (i) The schematic device structure of the $\mathrm{Cs}_{2} \mathrm{AgBiBr}_{6}$ thin-film humidity sensor [63]. 2019 Wiley$\mathrm{VCH}$ Verlag $\mathrm{GmbH} \& \mathrm{Co} . \mathrm{KGaA}$, Weinheim. (j) The dynamic response and recovery characterization of $\mathrm{Cs}_{2} \mathrm{AgBiBr}_{6}$ thin-film humidity sensors [63]. 2019 Wiley-VCH Verlag GmbH \& Co. KGaA, Weinheim. (k) I-V curves of humidity sensor at different humidity. Inset: the current versus RH. (l) The long-term stability of the sensor (aged under the exposure of the ambient $\left(\approx 22^{\circ} \mathrm{C}, \approx 60 \% \mathrm{RH}\right)$ ) toward different RH values [63]. 2019 Wiley-VCH Verlag GmbH \& Co. KGaA, Weinheim.

$\mathrm{Cs}_{2} \mathrm{AgBiBr}_{6}$ double perovskites might be a good candidate for a high-performance real-time humidity sensing.

\subsection{Lasers}

The development of high-efficiency semiconductor laser diodes has raised great attention to the examination of new compounds with the ability to emit in the visible and nearinfrared range [222]. Some of the outstanding physicochemical attributes of $\mathrm{Pb}$-based perovskites (e.g. longranged ambipolar charge transport, low carrier effective mass, long carrier lifetimes and high photoluminescence quantum yields, accomplished by their feasible solutionprocess methods to fabricate large-scale product) highlight their great potential for laser materials [223-225]. Compared to the crystalline materials (e.g. ZnSe and organic semiconductors) that require grown at high operational temperatures, there are two distinct characteristics exclusive to perovskites that emphasize their promising function for laser applications: (i) Perovskites possess amplified spontaneous emission (ASE) that is one order of magnitude lower than that of organic materials [226]. In general, ASE is optically amplified light from the spontaneous emission and also is assumed as superluminescence [227]. (ii) Controlling perovskites composition and surface morphology, the emission colour of the compound can be easily tuned over a broad range of wavelengths from 350 to $800 \mathrm{~nm}$. Perovskite nanostructures, such as nanoplatelets and quantum dots, are much suitable for controlled lasing due to the observed optical cavities [228]. The capability of double perovskites for laser applications has been rarely researched so far. However, the abovementioned criteria shine the light on their functionality for this target application. Inspiringly in 1999, Fonseca et al. studied the doped- $\mathrm{Cr}^{3+} \mathrm{Cs}_{2} \mathrm{NaGaF}_{6}$ single-crystals [229] because transition-metal ions are considered as optically active ions due to their electronic transitions. They observed an intense luminescence for transition-metal ions-based laser diodes [230]. Similarly, 
MHDPs are supposed to be applicable in the laser applications with desired properties [231-234].

\section{Conclusions and outlook}

To accommodate a stable and non-toxic metal cation (e.g. $\left.\mathrm{Bi}^{3+}, \mathrm{Sb}^{3+}\right)$ in the perovskite structure with a 3D framework, one approach is to insert a monovalent metal cation into the lattice to form a double perovskite configuration with the generic formula of $\mathrm{A}_{2} \mathrm{BB}^{\prime} \mathrm{X}_{6}$, named elpasolite. This rich family involves more than 350 members, majority of them has 3D crystal structure. Versatile composition of these compounds offers a straightforward manipulation on their optoelectronic properties (e.g. bandgap and carrier transport, carrier effective mass and mobility). Moreover, the nanostructures of MHDPs, such as one-dimensional nanowire and 2D layered structures, provide the further method to control their optoelectronic properties for different applications. Initially motivated by providing an alternative light-absorber for $\mathrm{Pb}$-halide perovskites with high stability and low toxicity, to date significant progress has been made in $\mathrm{Pb}$-free double perovskites, from synthesis, fundamental understanding to the device fabrication and applications. The theoretical investigations have predicted that $\mathrm{Pb}$-free double perovskites could deliver intriguing optoelectronic properties, for example, transition from indirect to direct bandgap, and absorption bandgap tuning from UV to near infrared. Together with superior stability against heat and moisture as well as intrinsically environmentally friendly, MHDPs therefore are highly prospective for broad range of applications. However, comprehensive knowledge of their microstructure and their potential applications is still largely elusive. Therefore, to make sustainable progress, there remain plenty of underlying challenges. Here, we envisage some potential directions for further exploration of this family of materials: (i) One of the most crucial obstacles that MHDPs encounter is the wide-bandgap property that hampers the absorption of a great portion of the solar spectrum. The indirect characteristic of the bandgap is another barrier, in turn, it causes a relatively infeasible charge carrier generation. The material bandgap is predicted to originate from its particular electron configuration and the consequent orbital interaction of the contributed elements into the structure. One way to change this intrinsic property is to incorporate different and still yet to be explored types of metal cations to alter the authorized electron configuration. To attain this, similar to $\mathrm{Pb}$-based perovskites with the typical formula of $\mathrm{ABX}_{3}$, the structural stability of MHDPs is described by the proper tolerance factor and octahedral factor. Regulating these two factors utilizing composition engineering, the incorporation of various metal cations of $\mathrm{Mn}^{2+}, \mathrm{Co}^{2+}, \mathrm{Cu}^{2+}, \mathrm{Ni}^{2+}$ and $\mathrm{Fe}^{3+}$ can be assessed, which enables us to find structurally stable new members of this family with appropriate bandgap values. (ii) The localized defect states in the lattice and bulk of the double perovskites can detrimentally quench their function. Detailed studies on the charge carrier dynamic provide thoughtful concepts on understanding the mechanism of defect traps into the structure. More understanding on this part is assumed to be a definite way to discover the functional pathways towards long-lasting high-performance devices. (iii) Numerous works have discussed the critical role of light illumination in the defect curing and structural modification of Pb-based perovskites, while in the case of MHDPs, it has received poor attention. Hence, investigating the influence of light illumination on the materials' function either in the form of pure thin-film or in device structure is of great interest to deeply explore their photophysical and electronic characteristics. To this aim, the optical techniques, such as steady-state PL, micro-PL, TRPL, and transient absorption spectroscopy, can be powerful tools to understand the charge carrier and mobile ion dynamics in double perovskites. These spectroscopic techniques have been well developed to cover full timescales from femtoseconds to hours, to explore full ranges of carrier dynamic processes. Similar to halide perovskites, the dynamic recombination processes occurring in nanoseconds to microseconds have the most important interest because they are intimately correlated to the performance of the devices. Typically, the recombination processes include defect and surface trapping, exciton or free electron-hole recombination, Auger recombination, carrier diffusion and transfer/ extraction in the devices, etc. Moreover, combined with confocal microscopy and other microscopic techniques, the advanced micro-spectroscopic techniques provide superior capability with spatial and temporal resolution and therefore making comprehensive physical understanding assessable into the materials, interfaces and devices.

To date, various optoelectronic applications, including solar cells, LEDs and detectors have been primarily demonstrated for MHDPs. However, for photovoltaics the reported performances are still not comparable to that of $\mathrm{Pb}$-based perovskites. It is supposed that at this stage this class of perovskites cannot satisfactorily fulfil the requisitions of an ideal operation layer for photovoltaics due to their inferior photovoltaic properties (e.g. large and indirect bandgap, low absorption in the visible range, limited electronic dimensionality and formation of deep cation-on-cation antisite defects.). Nevertheless, the recent investigations have demonstrated the possibility to extend significantly the bandgap to an ideal energy of $1.5 \mathrm{eV}$ that secures a Shockley- 
Queisser limit of 32\% for single junction solar cell. Taking into account the large flexibility to tune the optoelectronic properties by changing their composites, crystalline and nanostructures, we can see there is a large space to improve the performance of photovoltaic devices. However, compared to the great success of halide perovskites in solar cells, one has to accept the fact that MHDPs may not be a competitive candidate for photovoltaics. Being highly luminescent materials due to the PL mechanism of self-trapped exciton, MHDPs have been demonstrated successfully in high performance LED and laser. The intrinsic broad band spectrum fully covered the visible and high luminescence quantum yield, MHDPs can be potentially used for tuneable laser source and white light display, together with their advantages of high stability and environment friendly nature. In addition, the properties of their nanostructures have not yet been deeply explored and understood. With quantum confinement the nanocrystals of MHDPS are expected to have large possibility to change and improve the optoelectronic properties. One prospective is the applications in bioimaging but not yet well demonstrated. The nanocrystals or quantum dots of MHDPs can be an excellent candidate because of high luminescence, and tuneable spectrum covering the visible and near infrared. Importantly, there are non-toxic and can be water soluble. It is believed that pushing pass the current developing stage by fundamental understanding of their photophysical properties and structural variation will certainly open new avenue towards their implementation.

Acknowledgements: B. J. and X.W. acknowledge support from the Australia Research Council through the Discovery Project scheme (Grant No. DP190103186, DP190103284). B.J. acknowledges the Industrial Transformation Training Centres scheme (Grant No. IC180100005).

Author contributions: All the authors have accepted responsibility for the entire content of this submitted manuscript and approved submission.

Conflict of interest statement: The authors declare no conflicts of interest regarding this article.

\section{References}

[1] A. Kojima, K. Teshima, Y. Shirai, T. Miyasaka, "Organometal halide perovskites as visible-light sensitizers for photovoltaic cells," J. Am. Chem. Soc., vol. 131, no. 17, pp. 6050-6051, 2009.

[2] H. S. Kim, C. R. Lee, J. H. Im, et al., "Lead iodide perovskite sensitized all-solid-state submicron thin film mesoscopic solar cell with efficiency exceeding 9\%," Sci. Rep., vol. 2, p. 591, 2012.

[3] M. Saliba, T. Matsui, K. Domanski, et al., "Incorporation of rubidium cations into perovskite solar cells improves photovoltaic performance," Science, vol. 354, no. 6309, pp. 206-209, 2016.
[4] Y. Shao, Y. Yuan, and J. Huang, "Correlation of energy disorder and open-circuit voltage in hybrid perovskite solar cells," Nature Energy, vol. 1, no. 1, pp. 1-6, 2016.

[5] B.R.C.E. NREL NREL, Best Research Cell Efficiencies, 2020 [cited 2020 Jan]; Available from: http://www.nrel.gov/ncpv/imaGes/ efficiency_chart.jpg.

[6] M. M. Lee, J. Teuscher, T. Miyasaka, T. N. Murakami, H. J. Snaith, "Efficient hybrid solar cells based on meso-superstructured organometal halide perovskites," Science, vol. 338, no. 6107, pp. 643-647, 2012.

[7] S. D. Stranks, G. E. Eperon, G. Grancini, et al., "Electron-hole diffusion lengths exceeding 1 micrometer in an organometal trihalide perovskite absorber," Science, vol. 342, no. 6156 , pp. 341-344, 2013.

[8] G. Xing, N. Mathews, S. Sun, et al., "Long-range balanced electron-and hole-transport lengths in organic-inorganic CH3NH3Pbl3," Science, vol. 342, no. 6156, pp. 344-347, 2013.

[9] W. S. Yang, B.-W. Park, E. H. Jung, et al., “lodide management in formamidinium-lead-halide-based perovskite layers for efficient solar cells," Science, vol. 356, no. 6345, pp. 1376-1379, 2017.

[10] F. Gabelloni, F. Biccari, N. Falsini, N. Calisi, S. Caporali, A. Vinattieri, "Long-living nonlinear behavior in $\mathrm{CsPbBr}_{3}$ carrier recombination dynamics," Nanophotonics, vol. 8, no. 9, p. 1447, 2019.

[11] S. D. Stranks and H. J. Snaith, "Metal-halide perovskites for photovoltaic and light-emitting devices," Nat. Nanotechnol., vol. 10, no. 5, p. 391, 2015.

[12] H. Cho, S.-H. Jeong, M.-H. Park, et al., "Overcoming the electroluminescence efficiency limitations of perovskite lightemitting diodes," Science, vol. 350, no. 6265, pp. 1222-1225, 2015.

[13] T. Erdem and H. V. Demir, "Colloidal nanocrystals for quality lighting and displays: milestones and recent developments," Nanophotonics, vol. 5, no. 1, p. 74, 2016.

[14] N. Li, Y. S. Lau, Y. Miao, F. Zhu, "Electroluminescence and photoresponse of inorganic halide perovskite bi-functional diodes," Nanophotonics, vol. 7, no. 12, p. 1981, 2018.

[15] Q. Chen, J. Wu, X. Ou, et al., "All-inorganic perovskite nanocrystal scintillators," Nature, vol. 561, no. 7721, pp. 88-93, 2018.

[16] F. Zhang, B. Yang, K. Zheng, and S. Yang, "Formamidinium lead bromide $\left(\mathrm{FAPbBr}_{3}\right)$ perovskite microcrystals for sensitive and fast photodetectors," Nano-Micro Lett., vol. 10, no. 3, p. 43, 2018.

[17] L. Chu, R. Hu, W. Liu, et al., "Screen printing large-area organometal halide perovskite thin films for efficient photodetectors," Mater. Res. Bull., vol. 98, pp. 322-327, 2018.

[18] H. Zhu, Y. Fu, F. Meng, et al., "Lead halide perovskite nanowire lasers with low lasing thresholds and high quality factors," Nat. Mater., vol. 14, no. 6, p. 636, 2015.

[19] A. Kostopoulou, K. Brintakis, N. K. Nasikas, E. Stratakis, "Perovskite nanocrystals for energy conversion and storage," Nanophotonics, vol. 8, no. 10, p. 1607, 2019.

[20] H. Luo, et al., "Efficient and air-stable planar perovskite solar cells formed on graphene-oxide-modified PEDOT: PSS hole transport layer," Nano-Micro Lett., vol. 9, no. 4, p. 39, 2017.

[21] J. Cheng, H. Zhang, S. Zhang, et al., "Highly efficient planar perovskite solar cells achieved by simultaneous defect engineering and formation kinetic control," J. Mater. Chem., vol. 6, no. 46, pp. 23865-23874, 2018. 
[22] J.-C. Hebig, I. Kühn, J. Flohre, T. Kirchartz, “Optoelectronic properties of $\left(\mathrm{CH}_{3} \mathrm{NH}_{3}\right)_{3} \mathrm{Sb}_{2} \mathrm{l}_{9}$ thin films for photovoltaic applications," ACS Energy Lett., vol. 1, no. 1, pp. 309-314, 2016.

[23] J. You, L. Meng, T.-B. Song, et al., “Improved air stability of perovskite solar cells via solution-processed metal oxide transport layers," Nat. Nanotechnol., vol. 11, no. 1, p. 75, 2016.

[24] W. Liao, D. Zhao, Y. Yu, et al., "Lead-free inverted planar formamidinium tin triiodide perovskite solar cells achieving power conversion efficiencies up to 6.22\%," Adv. Mater., vol. 28, no. 42, pp. 9333-9340, 2016.

[25] H. Tsai, W. Nie, J.-C. Blancon, et al., "High-efficiency twodimensional Ruddlesden-Popper perovskite solar cells," Nature, vol. 536, no. 7616, pp. 312-316, 2016.

[26] F. Matteocci, L. Cinà, E. Lamanna, et al., "Encapsulation for longterm stability enhancement of perovskite solar cells," Nano Energy, vol. 30, pp. 162-172, 2016.

[27] A. Mashreghi and M. Ghasemi, "Investigating the effect of molar ratio between $\mathrm{TiO}_{2}$ nanoparticles and titanium alkoxide in Pechini based $\mathrm{TiO}_{2}$ paste on photovoltaic performance of dyesensitized solar cells," Renew. Energy, vol. 75, pp. 481-488, 2015.

[28] G. Flora, D. Gupta, and A. Tiwari, “Toxicity of lead: a review with recent updates,” Interdiscipl. Toxicol., vol. 5, no. 2, pp. 47-58, 2012.

[29] L. Liang and P. Gao, "Lead-free hybrid perovskite absorbers for viable application: can we eat the cake and have it too?," Advanced Science, vol. 5, no. 2, p. 1700331, 2018.

[30] F. Hao, C. C. Stoumpos, R. P. H. Chang, M. G. Kanatzidis, "Anomalous band gap behavior in mixed $\mathrm{Sn}$ and $\mathrm{Pb}$ perovskites enables broadening of absorption spectrum in solar cells," J. Am. Chem. Soc., vol. 136, no. 22, pp. 8094-8099, 2014.

[31] T. Krishnamoorthy, H. Ding, C. Yan, et al., "Lead-free germanium iodide perovskite materials for photovoltaic applications," J. Mater. Chem., vol. 3, no. 47, pp. 23829-23832, 2015.

[32] E. T. Hoke, D. J. Slotcavage, E. R. Dohner, A. R. Bowring, H. I. Karunadasa, M. D. McGehee, "Reversible photo-induced trap formation in mixed-halide hybrid perovskites for photovoltaics," Chem. Sci., vol. 6, no. 1, pp. 613-617, 2015.

[33] B. Lee, C. C. Stoumpos, N. Zhou, et al., "Air-stable molecular semiconducting iodosalts for solar cell applications: $\mathrm{Cs}_{2} \mathrm{Snl}_{6}$ as a hole conductor," J. Am. Chem. Soc., vol. 136, no. 43, pp. 15379-15385, 2014.

[34] F. Hao, C. C. Stoumpos, D. H. Cao, R. P. H. Chang, M. G. Kanatzidis, "Lead-free solid-state organic-inorganic halide perovskite solar cells," Nat. Photonics, vol. 8, no. 6, p. 489, 2014.

[35] C. C. Stoumpos, L. Frazer, D. J. Clark, et al., "Hybrid germanium iodide perovskite semiconductors: active lone pairs, structural distortions, direct and indirect energy gaps, and strong nonlinear optical properties," J. Am. Chem. Soc., vol. 137, no. 21, pp. 6804-6819, 2015.

[36] S. A. Adonin, L. A. Frolova, M. N. Sokolov, et al., "Antimony (V) complex halides: lead-free perovskite-like materials for hybrid solar cells," Adv. Energy Mater., vol. 8, no. 6, p. 1701140 , 2018.

[37] M. Lyu, J.-H. Yun, M. Cai, et al., “Organic-inorganic bismuth (III)based material: a lead-free, air-stable and solution-processable light-absorber beyond organolead perovskites," Nano Res., vol. 9, no. 3, pp. 692-702, 2016.
[38] M. Ghasemi, M. Lyu, M. Roknuzzaman, et al., "Phenethylammonium bismuth halides: from single crystals to bulky-organic cation promoted thin-film deposition for potential optoelectronic applications," J. Mater. Chem., vol. 7, no. 36, pp. 20733-20741, 2019.

[39] B.-W. Park, B. Philippe, X. Zhang, H. Rensmo, G. Boschloo, E. M. J. Johansson, "Bismuth based hybrid perovskites $A_{3} B i_{2} I_{9}$ (A: methylammonium or cesium) for solar cell application," Adv. Mater., vol. 27, no. 43, pp. 6806-6813, 2015.

[40] K. M. Boopathi, P. Karuppuswamy, A. Singh, et al., "Solutionprocessable antimony-based light-absorbing materials beyond lead halide perovskites," J. Mater. Chem., vol. 5, no. 39, pp. 20843-20850, 2017.

[41] B. Saparov, F. Hong, J.-P. Sun, et al., "Thin-film preparation and characterization of $\mathrm{Cs}_{3} \mathrm{Sb}_{2} \mathrm{l}_{9}$ : a lead-free layered perovskite semiconductor," Chem. Mater., vol. 27, no. 16, pp. 5622-5632, 2015.

[42] T. Singh, A. Kulkarni, M. Ikegami, T. Miyasaka, “Effect of electron transporting layer on bismuth-based lead-free perovskite $\left(\mathrm{CH}_{3} \mathrm{NH}_{3}\right)_{3} \mathrm{Bi}_{2} \mathrm{l}_{9}$ for photovoltaic applications," ACS Appl. Mater. Interfaces, vol. 8, no. 23, pp. 14542-14547, 2016.

[43] H. Zhu, M. Pan, M. B. Johansson, E. M. J. Johansson, “High photon-to-current conversion in solar cells based on lightabsorbing silver bismuth iodide," Chem SusChem, vol.10, no. 12, pp. 2592-2596, 2017.

[44] K. Eckhardt, V. Bon, J. Getzschmann, J. Grothe, F. M. Wisser, S. Kaskel, “Crystallographic insights into $\left(\mathrm{CH}_{3} \mathrm{NH}_{3}\right)_{3}\left(\mathrm{Bi}_{2} \mathrm{l}_{9}\right)$ : a new lead-free hybrid organic-inorganic material as a potential absorber for photovoltaics," Chem. Commun., vol. 52, no. 14, pp. 3058-3060, 2016.

[45] X. Han, Y. Zheng, S. Chai, S. Chen, J. Xu, "2D organic-inorganic hybrid perovskite materials for nonlinear optics," Nanophotonics, vol. 9, no. 7, p. 1787, 2020.

[46] W. Li, J. Ma, H. Wang, C. Fang, H. Luo, D. Li, "Biexcitons in 2D (isoBA) $)_{2} \mathrm{Pbl}_{4}$ perovskite crystals," Nanophotonics, vol. 9, no. 7, p. 2001, 2020.

[47] M. R. Filip, S. Hillman, A. A. Haghighirad, H. J. Snaith, F. Giustino, "Band gaps of the lead-free halide double perovskites $\mathrm{Cs}_{2} \mathrm{BiAgCl}_{6}$ and $\mathrm{Cs}_{2} \mathrm{BiAgBr}_{6}$ from theory and experiment," J. Phys. Chem. Lett., vol. 7, no. 13, pp. 2579-2585, 2016.

[48] A. H. Slavney, T. Hu, A. M. Lindenberg, H. I. Karunadasa, “A bismuth-halide double perovskite with long carrier recombination lifetime for photovoltaic applications," J. Am. Chem. Soc., vol. 138, no. 7, pp. 2138-2141, 2016.

[49] E. T. McClure, M. R. Ball, W. Windl, P. M. Woodward, " $\mathrm{Cs}_{2} \mathrm{AgBiX}_{6}$ $(\mathrm{X}=\mathrm{Br}, \mathrm{Cl})$ : new visible light absorbing, lead-free halide perovskite semiconductors," Chem. Mater., vol. 28, no. 5, pp. 1348-1354, 2016.

[50] G. Volonakis, M. R. Filip, A. A. Haghighirad, et al., "Lead-free halide double perovskites via heterovalent substitution of noble metals," J. Phys. Chem. Lett., vol. 7, no. 7, pp. 1254-1259, 2016.

[51] E. V. D. Loef, P. Dorenbos, C. W. E. Eijk, K. W. Kr mer, H. U. G del, "Scintillation and spectroscopy of the pure and $\mathrm{Ce}^{3+}$-doped elpasolites: $\mathrm{Cs}_{2} \mathrm{LiYX}_{6}(\mathrm{X}=\mathrm{Cl}, \mathrm{Br})$," J. Phys. Condens. Matter, vol. 14, no. 36, p. 8481, 2002.

[52] S. Vasala and M. Karppinen, "A2B'B"O6 perovskites: a review," Prog. Solid State Chem., vol. 43, nos 1-2, pp. 1-36, 2015.

[53] K.-I. Kobayashi, T. Kimura, H. Sawada, K. Terakura, Y. Tokura, "Room-temperature magnetoresistance in an oxide material 
with an ordered double-perovskite structure," Nature, vol. 395, no. 6703, pp. 677-680, 1998.

[54] R. Nechache, C. Harnagea, S. Li, et al., "Bandgap tuning of multiferroic oxide solar cells,” Nat. Photonics, vol. 9, no. 1, p. 61, 2015.

[55] R. F. Berger and J. B. Neaton, "Computational design of lowband-gap double perovskites," Phys. Rev. B, vol. 86, no. 16, p. 165211, 2012.

[56] C. Wu, Q. Zhang, Y. Liu, et al., "The dawn of lead-free perovskite solar cell: highly stable double perovskite $\mathrm{Cs}_{2} \mathrm{AgBiBr}_{6}$ film," $A d v$. Sci., vol. 5, no. 3, p. 1700759, 2018.

[57] W. Ning, F. Wang, B. Wu, et al., "Long electron-hole diffusion length in high-quality lead-free double perovskite films," Adv. Mater., vol. 30, no. 20, p. 1706246, 2018.

[58] E. Greul, M. L. Petrus, A. Binek, P. Docampo, T. Bein, “Highly stable, phase pure $\mathrm{Cs}_{2} \mathrm{AgBiBr}_{6}$ double perovskite thin films for optoelectronic applications," J. Mater. Chem., vol. 5, no. 37, pp. 19972-19981, 2017.

[59] W. Gao, C. Ran, J. Xi, B. Jiao, W. Zhang, M. Wu, X. Hou, and Z. Wu, "High-quality $\mathrm{Cs}_{2} \mathrm{AgBiBr}_{6}$ double perovskite film for lead-free inverted planar heterojunction solar cells with $2.2 \%$ efficiency," ChemPhysChem, vol. 19, no. 14, pp. 1696-1700, 2018.

[60] F. Igbari, R. Wang, Z.-K. Wang, et al., "Composition stoichiometry of $\mathrm{Cs}_{2} \mathrm{AgBiBr}_{6}$ films for highly efficient lead-free perovskite solar cells," Nano Lett., vol. 19, no. 3, pp. 2066-2073, 2019.

[61] M. Pantaler, K. T. Cho, V. I. E. Queloz, et al., "Hysteresis-free lead-free double-perovskite solar cells by interface engineering," ACS Energy Lett., vol. 3, no. 8, pp. 1781-1786, 2018.

[62] M. Ghasemi, L. Zhang, J.-H. Yun, et al., "Dual-ion-diffusion induced degradation in lead-free $\mathrm{Cs}_{2} \mathrm{AgBiBr}_{6}$ double perovskite solar cells," Adv. Funct. Mater., vol. 30, p. 2002342.

[63] Z. Weng, J. Qin, A. A. Umar, et al., "Lead-free $\mathrm{Cs}_{2} \mathrm{BiAgBr}_{6}$ double perovskite-based humidity sensor with superfast recovery time," Adv. Funct. Mater., vol. 29, no. 24, p. 1902234, 2019

[64] Y. Dang, G. Tong, W. Song, et al., "Interface engineering strategies towards $\mathrm{Cs}_{2} \mathrm{AgBiBr}_{6}$ single-crystalline photodetectors with good Ohmic contact behaviours," J. Mater. Chem. C, vol. 8, no. 1, pp. 276-284, 2020.

[65] H. Li, X. Shan, J. N. Neu, et al., "Lead-free halide double perovskite-polymer composites for flexible X-ray imaging," J. Mater. Chem. C, vol. 6, no. 44, pp. 11961-11967, 2018.

[66] W. Yuan, G. Niu, Y. Xian, et al., "In situ regulating the orderdisorder phase transition in $\mathrm{Cs}_{2} \mathrm{AgBiBr}_{6}$ single crystal toward the application in an X-ray detector," Adv. Funct. Mater., vol. 29, no. 20, p. 1900234, 2019.

[67] Z. Zhang, Y. Liang, H. Huang, et al., "Stable and highly efficient photocatalysis with lead-free double-perovskite of $\mathrm{Cs}_{2} \mathrm{AgBiBr}_{6}$," Angew. Chem. Int. Ed., vol. 58, no. 22, pp. 7263-7267, 2019.

[68] H. L. Wu, X. B. Li, C. H. Tung, L. Z. Wu, "Semiconductor quantum dots: an emerging candidate for $\mathrm{CO}_{2}$ photoreduction," Adv. Mater., vol. 31, no. 36, p. 1900709, 2019.

[69] H. Yin, Y. Xian, Y. Zhang, W. Li, J. Fan, "Structurally stabilizing and environment friendly triggers: double-metallic lead-free perovskites," Solar RRL, vol. 3, no. 9, p. 1900148, 2019.

[70] L. Chu, W. Ahmad, W. Liu, et al., "Lead-free halide double perovskite materials: a new superstar toward green and stable optoelectronic applications," Nano-Micro Lett., vol. 11, no. 1 , p. 16, 2019.
[71] L. Lu, X. Pan, J. Luo, and Z. Sun, "Recent advances and optoelectronic applications of lead-free halide double perovskites," Chem. Eur. J., vol. 26, pp. 1-11, 2020.

[72] X.-G. Zhao, D. Yang, J.-C. Ren, Y. Sun, Z. Xiao, L. Zhang, "Rational design of halide double perovskites for optoelectronic applications," Joule, vol. 2, no. 9, pp. 1662-1673, 2018.

[73] D. Sánchez, J. A. Alonso, M. García-Hernández, M. J. MartínezLope, J. L. Martínez, and A. Mellergård, "Origin of neutron magnetic scattering in antisite-disordered $\mathrm{Sr}_{2} \mathrm{FeMoO}_{6}$ double perovskites," Phys. Rev. B, vol. 65, no. 10, p. 104426, 2002.

[74] L. Balcells, J. Navarro, M. Bibes, A. Roig, B. Martínez, J. Fontcuberta, "Cationic ordering control of magnetization in $\mathrm{Sr}_{2} \mathrm{FeMoO}_{6}$ double perovskite," Appl. Phys. Lett., vol. 78, no. 6, pp. 781-783, 2001

[75] P. D. Matthews, D. J. Lewis, and P. O'Brien, "Updating the road map to metal-halide perovskites for photovoltaics,"J. Mater. Chem., vol. 5, no. 33, pp. 17135-17150, 2017.

[76] P.-K. Kung, M.-H. Li, P.-Y. Lin, et al., "Lead-free double perovskites for perovskite solar cells," Solar RRL, vol. 4, no. 2, p. 1900306, 2020

[77] B. Philippe, B.-W. Park, R. Lindblad, et al., "Chemical and electronic structure characterization of lead halide perovskites and stability behavior under different exposures - a photoelectron spectroscopy investigation," Chem. Mater., vol. 27, no. 5, pp. 1720-1731, 2015.

[78] T. Umebayashi, K. Asai, T. Kondo, and A. Nakao, "Electronic structures of lead iodide based low-dimensional crystals," Phys. Rev. B, vol. 67, no. 15, p. 155405, 2003.

[79] W.-J. Yin, J.-H. Yang, J. Kang, Y. Yan, S.-H. Wei, “Halide perovskite materials for solar cells: a theoretical review," J. Mater. Chem., vol. 3, no. 17, pp. 8926-8942, 2015.

[80] M. H. Du, "Efficient carrier transport in halide perovskites: theoretical perspectives,"J. Mater. Chem., vol. 2, no. 24 , pp. 9091-9098, 2014

[81] R. Mohan, “Green bismuth," Nat. Chem., vol. 2, no. 4, pp. 336-336, 2010.

[82] L. A. Tillman, F. M. Drake, J. S. Dixon, J. R. Wood, "Safety of bismuth in the treatment of gastrointestinal diseases," Aliment. Pharmacol. Ther., vol. 10, no. 4, pp. 459-467, 1996.

[83] S. Khalfin and Y. Bekenstein, "Advances in lead-free double perovskite nanocrystals, engineering band-gaps and enhancing stability through composition tunability," Nanoscale, vol. 11, no. 18, pp. 8665-8679, 2019.

[84] Z. Xiao, W. Meng, J. Wang, and Y. Yan, "Thermodynamic stability and defect chemistry of bismuth-based lead-free double perovskite $\mathrm{Cs}_{2} \mathrm{AgBiBr}_{6}$," ChemSusChem, vol. 9, no. 18, 2628-2633, 2016.

[85] S. E. Creutz, E. N. Crites, M. C. De Siena, D. R. Gamelin, “Colloidal nanocrystals of lead-free double-perovskite (elpasolite) semiconductors: synthesis and anion exchange to access new materials," Nano Lett., vol. 18, no. 2, pp. 1118-1123, 2018.

[86] P. Cheng, T. Wu, Y. Li, L. Jiang, W. Deng, K. Han, “Combining theory and experiment in the design of a lead-free $\left(\left(\mathrm{CH}_{3} \mathrm{NH}_{3}\right)_{2} \mathrm{AgBi}_{6}\right)$ double perovskite," New J. Chem., vol. 41, no. 18, pp. 9598-9601, 2017.

[87] G. E. Eperon, G. M. Paternò, R. J. Sutton, et al., "Inorganic caesium lead iodide perovskite solar cells," J. Mater. Chem., vol. 3, no. 39, pp. 19688-19695, 2015. 
[88] F. Wei, Z. Deng, S. Sun, et al., "The synthesis, structure and electronic properties of a lead-free hybrid inorganic-organic double perovskite $(\mathrm{MA})_{2} \mathrm{KBiCl}_{6}$ ( $\mathrm{MA}=$ methylammonium)," Mater. Horizons, vol. 3, no. 4, pp. 328-332, 2016.

[89] A. Filippetti and A. Mattoni, "Hybrid perovskites for photovoltaics: insights from first principles," Phys. Rev. B, vol. 89, no. 12, p. 125203, 2014.

[90] F. Wei, Z. Deng, S. Sun, et al., "Synthesis and properties of a lead-free hybrid double perovskite: $\left(\mathrm{CH}_{3} \mathrm{NH}_{3}\right)_{2} \mathrm{AgBiBr}_{6}$," Chem. Mater., vol. 29, no. 3, pp. 1089-1094, 2017.

[91] J. Burschka, N. Pellet, S.-J. Moon et al., "Sequential deposition as a route to high-performance perovskite-sensitized solar cells," Nature, vol. 499, no. 7458, p. 316, 2013.

[92] T. T. Tran, J. R. Panella, J. R. Chamorro, J. R. Morey, T. M. McQueen, “Designing indirect-direct bandgap transitions in double perovskites," Mater. Horizons, vol. 4, no. 4, pp. 688-693, 2017.

[93] Z. Deng, F. Wei, S. Sun, G. Kieslich, A. K. Cheetham, P. D. Bristowe, "Exploring the properties of lead-free hybrid double perovskites using a combined computationalexperimental approach," J. Mater. Chem., vol. 4, no. 31, pp. 12025-12029, 2016.

[94] F. Wei, Z. Deng, S. Sun, et al., "Enhanced visible light absorption for lead-free double perovskite $\mathrm{Cs}_{2} \mathrm{AgSbBr}_{6}$," Chem. Commun., vol. 55, no. 26, pp. 3721-3724, 2019.

[95] N. Ashcroft and N. Mermin, Solid State Physics, Brooks Cole, 1976, p. 26, Cited on, 1993.

[96] Z. Xiao, K.-Z. Du, W. Meng, D. B. Mitzi, Y. Yan, “Chemical origin of the stability difference between copper (I)-and silver (I)Based halide double perovskites," Angew. Chem., vol. 129, no. 40, pp. 12275-12279, 2017.

[97] W. Zhou, P. Han, X. Zhang, et al., "Lead-free small-bandgap $\mathrm{Cs}_{2} \mathrm{CuSbCl}_{6}$ double perovskite nanocrystals," J. Phys. Chem. Lett., vol. 11, pp. 6463-6467, 2020.

[98] L. R. Morss, M. Siegal, L. Stenger, N. Edelstein, “Preparation of cubic chloro complex compounds of trivalent metals: $\mathrm{Cs}_{2} \mathrm{NaMCl}_{6}$," Inorg. Chem., vol. 9, no. 7, pp. 1771-1775, 1970.

[99] G. Meyer and H.-C. Gaebell, "Halogen-elpasolithe, IV [1]. Über brom-elpasolithe $\mathrm{Cs}_{2} \mathrm{BIMIIIBr}_{6} \mathrm{BI}=\mathrm{Li}, \mathrm{Na}$; $\mathrm{MIII}=\mathrm{Sc}, \mathrm{Y}, \mathrm{La}-\mathrm{Lu}$, in, $\mathrm{V}, \mathrm{Cr}$ )/Halo-Elpasolites, IV [1]. On bromo-elpasolites $\mathrm{Cs}_{2} \mathrm{BIMIIIBr}_{6}$ $\mathrm{BI}=\mathrm{Li}, \mathrm{Na}$; MIII = Sc, Y, La-Lu, in, V, Cr)," Z. Naturforsch. B Chem. Sci., vol. 33, no. 12, pp. 1476-1478, 1978.

[100] G. Volonakis, A. A. Haghighirad, R. L. Milot, et al., " $C \mathrm{C}_{2} \ln \mathrm{AgCl}_{6}$ : a new lead-free halide double perovskite with direct band gap," J. Phys. Chem. Lett., vol. 8, no. 4, pp. 772-778, 2017.

[101] F.-S. Zu, P. Amsalem, I. Salzmann, et al., "Impact of white light illumination on the electronic and chemical structures of mixed halide and single crystal perovskites," Adv. Opt. Mater., vol. 5, no. 9, p. 1700139, 2017.

[102] R. Gottesman and A. Zaban, "Perovskites for photovoltaics in the spotlight: photoinduced physical changes and their implications," Acc. Chem. Res., vol. 49, no. 2, pp. 320-329, 2016.

[103] W. Meng, X. Wang, Z. Xiao, J. Wang, D. B. Mitzi, Y. Yan, "Parityforbidden transitions and their impact on the optical absorption properties of lead-free metal halide perovskites and double perovskites,” J. Phys. Chem. Lett., vol. 8, no. 13, pp. 2999-3007, 2017.

[104] J. Dai, L. Ma, M. Ju, J. Huang, and X. C. Zeng, “In- and Ga-based inorganic double perovskites with direct bandgaps for photovoltaic application," Phys. Chem. Chem. Phys., vol. 19, 21691-21695, 2017.

[105] Y. Saeed, B. Amin, H. Khalil, et al., "Cs2NaGaBr6: a new leadfree and direct band gap halide double perovskite," RSC Adv., vol. 10, no. 30, pp. 17444-17451, 2020.

[106] X. Nie, S.-H. Wei, and S. Zhang, "Bipolar doping and band-gap anomalies in delafossite transparent conductive oxides," Phys. Rev. Lett., vol. 88, no. 6, p. 066405, 2002.

[107] A. B. Kehoe, D. O. Scanlon, and G. W. Watson, "Nature of the band gap of $\mathrm{Tl}_{2} \mathrm{O}_{3}$," Phys. Rev. B, vol. 83, no. 23, p. 233202, 2011.

[108] R. Summitt, J. A. Marley, and N. F. Borrelli, "The ultraviolet absorption edge of stannic oxide $\left(\mathrm{SnO}_{2}\right)$," J. Phys. Chem. Solid., vol. 25, no. 12, pp. 1465-1469, 1964.

[109] Walsh A., J. L. F. Da Silva, S.-H. Wei, et al., "Nature of the band gap of in ${ }^{2} \mathrm{O}_{3}$ revealed by first-principles calculations and X-ray spectroscopy," Phys. Rev. Lett., vol. 100, no. 16, p. 167402, 2008.

[110] A. H. Slavney, L. Leppert, A. Saldivar-Valdes, et al., "Smallband-gap halide double perovskites," Angew. Chem., vol. 130, no. 39, pp. 12947-12952, 2018.

[111] W.Cross and W.Hillebrand, "ART. XXX. - Communications from the US Geological Survey, Rocky Mountain division. IV. On minerals of the Cryolite group recently found in Colorado," Am. J. Sci., vol. 26, no. 154, p. 271.

[112] M. Retuerto, T. Emge, J. Hadermann, et al., "Synthesis and properties of charge-ordered thallium halide perovskites, $\mathrm{CsTl}^{+} 0.5 \mathrm{Tl}^{3+} 0.5 \mathrm{X}_{3}(\mathrm{X}=\mathrm{F}$ or $\mathrm{Cl})$ : theoretical precursors for superconductivity?," Chem. Mater., vol. 25, no. 20, pp. 4071-4079, 2013.

[113] S. J. Clark, C. D. Flint, and J. D. Donaldson, "Luminescence and electrical conductivity of $\mathrm{CsSnBr}_{3}$, and related phases,"J. Phys. Chem. Solid., vol. 42, no. 3, pp. 133-135, 1981.

[114] C. C. Stoumpos, C. D. Malliakas, J. A. Peters, et al., "Crystal growth of the perovskite semiconductor $\mathrm{CsPbBr}_{3}$ : a new material for high-energy radiation detection," Cryst. Growth Des., vol. 13, no. 7, pp. 2722-2727, 2013.

[115] M. Kulbak, D. Cahen, and G. Hodes, "How important is the organic part of lead halide perovskite photovoltaic cells? Efficient $\mathrm{CsPbBr}_{3}$ cells," J. Phys. Chem. Lett., vol. 6, no. 13, pp. 2452-2456, 2015.

[116] R. Prasanna, A. Gold-Parker, T. Leijtens, et al., “Band gap tuning via lattice contraction and octahedral tilting in perovskite materials for photovoltaics," J. Am. Chem. Soc., vol. 139, no. 32, pp. 11117-11124, 2017.

[117] C. C. Stoumpos, C. D. Malliakas, and M. G. Kanatzidis, "Semiconducting tin and lead iodide perovskites with organic cations: phase transitions, high mobilities, and near-infrared photoluminescent properties," Inorg. Chem., vol. 52, no. 15, pp. 9019-9038, 2013.

[118] A. E. Maughan, A. M. Ganose, M. M. Bordelon, E. M. Miller, D. O. Scanlon, J. R. Neilson, "Defect tolerance to intolerance in the vacancy-ordered double perovskite semiconductors $\mathrm{Cs}_{2} \mathrm{SnI}_{6}$ and $\mathrm{Cs}_{2} \mathrm{Tel}_{6}$," J. Am. Chem. Soc., vol. 138, no. 27, pp. 8453-8464, 2016.

[119] B. A. Connor, L. Leppert, M. D. Smith, J. B. Neaton, H. I. Karunadasa, "Layered halide double perovskites: dimensional reduction of $\mathrm{Cs}_{2} \mathrm{AgBiBr}_{6}$," J. Am. Chem. Soc., vol. 140 , no. 15 , pp. 5235-5240, 2018. 
[120] T. Baikie, N. S. Barrow, Y. Fang, et al., "A combined single crystal neutron/X-ray diffraction and solid-state nuclear magnetic resonance study of the hybrid perovskites $\mathrm{CH}_{3} \mathrm{NH}_{3} \mathrm{PbX}_{3}(\mathrm{X}=\mathrm{I}, \mathrm{Br}$ and $\mathrm{Cl})$," J. Mater. Chem., vol. 3, no. 17, pp. 9298-9307, 2015.

[121] H. B. Kim, I. Im, Y. Yoon, et al., "Enhancement of photovoltaic properties of $\mathrm{CH}_{3} \mathrm{NH}_{3} \mathrm{PbBr}_{3}$ heterojunction solar cells by modifying mesoporous $\mathrm{TiO}_{2}$ surfaces with carboxyl groups," J. Mater. Chem., vol. 3, no. 17, pp. 9264-9270, 2015.

[122] Z. Deng, F. Wei, F. Brivio, et al., "Synthesis and characterization of the rare-earth hybrid double perovskites: $\left(\mathrm{CH}_{3} \mathrm{NH}_{3}\right)_{2} \mathrm{KGdCl}_{6}$ and $\left(\mathrm{CH}_{3} \mathrm{NH}_{3}\right)_{2} \mathrm{KYCl}_{6}$," J. Phys. Chem. Lett., vol. 8, no. 20, pp. 5015-5020, 2017.

[123] B. Saparov and D. B. Mitzi, "Organic-inorganic perovskites: structural versatility for functional materials design," Chem. Rev., vol. 116, no. 7, pp. 4558-4596, 2016.

[124] G. Meyer, "The synthesis and structures of complex rare-earth halides," Prog. Solid State Chem., vol. 14, no. 3, pp. 141-219, 1982.

[125] J. L. Wu, G. Gundiah, and A. Cheetham, "Structure-property correlations in Ce-doped garnet phosphors for use in solid state lighting," Chem. Phys. Lett., vol. 441, nos 4-6, pp. 250-254, 2007.

[126] X.-G. Zhao, J.-H. Yang, Y. Fu, et al., "Design of lead-free inorganic halide perovskites for solar cells via cationtransmutation," J. Am. Chem. Soc., vol. 139, no. 7, pp. 2630-2638, 2017.

[127] Z. Xiao, K.-Z. Du, W. Meng, J. Wang, D. B. Mitzi, Y. Yan, “Intrinsic instability of $\mathrm{Cs}_{2} \ln (\mathrm{I}) \mathrm{M}(\mathrm{III}) \mathrm{X}_{6}(\mathrm{M}=\mathrm{Bi}, \mathrm{Sb} ; \mathrm{X}=$ halogen) double perovskites: a combined density functional theory and experimental study," J. Am. Chem. Soc., vol. 139, no. 17, pp. 6054-6057, 2017.

[128] F. Capasso, "Band-gap engineering: from physics and materials to new semiconductor devices," Science, vol. 235, no. 4785, pp. 172-176, 1987.

[129] M. Yuan, D. B. Mitzi, W. Liu, A. J. Kellock, S. J. Chey, V. R. Deline, "Optimization of CIGS-based PV device through antimony doping," Chem. Mater., vol. 22, no. 2, pp. 285-287, 2010.

[130] K.-Z. Du, W. Meng, X. Wang, Y. Yan D. B. Mitzi, "Bandgap engineering of lead-free double perovskite $\mathrm{Cs}_{2} \mathrm{AgBiBr}_{6}$ through trivalent metal alloying," Angew. Chem., vol. 129, no. 28, pp. 8270-8274, 2017.

[131] Y. Liu, L. Zhang, M. Wang, et al., "Bandgap-tunable doubleperovskite thin films by solution processing," Mater. Today, vol. 28, pp. 25-30, 2019.

[132] A. H. Slavney, L. Leppert, D. Bartesaghi, et al., "Defect-induced band-edge reconstruction of a bismuth-halide double perovskite for visible-light absorption," J. Am. Chem. Soc., vol. 139, no. 14, pp. 5015-5018, 2017.

[133] A. Karmakar, M. S. Dodd, S. Agnihotri, E. Ravera, V. K. Michaelis, " $\mathrm{Cu}$ (II)-doped $\mathrm{Cs}_{2} \mathrm{SbAgCl}_{6}$ double perovskite: a lead-free, low-bandgap material," Chem. Mater., vol. 30, no. 22, pp. 8280-8290, 2018.

[134] B. Vargas, R. Torres-Cadena, J. Rodríguez-Hernández, et al., "Optical, electronic, and magnetic engineering of $\langle 111\rangle$ layered halide perovskites," Chem. Mater., vol. 30, no. 15, pp. 5315-5321, 2018.

[135] D. Cortecchia, H. A. Dewi, J. Yin, et al., "Lead-free $\mathrm{MA}_{2} \mathrm{CuCl}_{x} \mathrm{Br}_{4-x}$ hybrid perovskites," Inorg. Chem., vol. 55, no. 3, pp. 1044-1052, 2016.
[136] A. Nag, "Synthesis and luminescence of $\mathrm{Mn}$-doped $\mathrm{Cs}_{2} \mathrm{AgInCl}_{6}$ double perovskites," Chem. Commun., vol. 54, no. 41, pp. 5205-5208, 2018.

[137] R. Beaulac, P. I. Archer, S. T. Ochsenbein, D. R. Gamelin, “ $\mathrm{Mn}^{2+}$ doped CdSe quantum dots: new inorganic materials for spinelectronics and spin-photonics," Adv. Funct. Mater., vol. 18, no. 24, pp. 3873-3891, 2008.

[138] N. Pradhan and D. D. Sarma, "Advances in light-emitting doped semiconductor nanocrystals," J. Phys. Chem. Lett., vol. 2, no. 21, pp. 2818-2826, 2011.

[139] N. Pradhan, S. Das Adhikari, A. Nag, D. D. Sarma, "Luminescence, plasmonic, and magnetic properties of doped semiconductor nanocrystals," Angew. Chem. Int. Ed., vol. 56, no. 25, pp. 7038-7054, 2017.

[140] K. P. Kadlag, M. J. Rao, and A. Nag, "Ligand-free, colloidal, and luminescent metal sulfide nanocrystals,” J. Phys. Chem. Lett., vol. 4, no. 10, pp. 1676-1681, 2013.

[141] A. Nag S. Chakraborty, and D. D. Sarma, "To dope $\mathrm{Mn}^{2+}$ in a semiconducting nanocrystal," J. Am. Chem. Soc., vol. 130, no. 32, pp. 10605-10611, 2008.

[142] H. Yin, Y. Xian, Y. Zhang, et al., "An emerging lead-free doubleperovskite $\mathrm{Cs}_{2} \mathrm{AgFeCl}_{6}$ : in single crystal," Adv. Funct. Mater., vol. 30, p. 2002225, 2020.

[143] R. Kentsch, M. Scholz, J. Horn, D. Schlettwein, K. Oum, T. Lenzer, "Exciton dynamics and electron-phonon coupling affect the photovoltaic performance of the $\mathrm{Cs}_{2} \mathrm{AgBiBr}_{6}$ double perovskite," J. Phys. Chem. C, vol. 122, no. 45, pp. 25940-25947, 2018.

[144] E. G. Tulsky and J. R. Long, "Dimensional reduction: a practical formalism for manipulating solid structures," Chem. Mater., vol. 13, no. 4, pp. 1149-1166, 2001.

[145] A. Splendiani, L. Sun, Y. Zhang, et al., "Emerging photoluminescence in monolayer $\mathrm{MoS}_{2}$," Nano Lett., vol. 10, no. 4, pp. 1271-1275, 2010.

[146] K. F. Mak, C. Lee, J. Hone, J. Shan, T. F. Heinz, "Atomically thin $\mathrm{MoS}_{2}$ : a new direct-gap semiconductor," Phys. Rev. Lett., vol. 105, no. 13, p. 136805, 2010

[147] L. Pedesseau, D. Sapori, B. Traore, et al., “Advances and promises of layered halide hybrid perovskite semiconductors," ACS Nano, vol. 10, no. 11, pp. 9776-9786, 2016.

[148] N. Elliott and L. Pauling, "The crystal structure of cesium aurous auric chloride, $\mathrm{Cs}_{2} \mathrm{AuAuCl}_{6}$, and cesium argentous auric chloride, $\mathrm{Cs}_{2} \mathrm{AgAuCl}_{6}$," J. Am. Chem. Soc., vol. 60, no. 8, pp. 1846-1851, 1938.

[149] M. Sharma, A. Yangui, V. R. Whiteside, et al., " $\mathrm{Rb}_{4} \mathrm{Ag}_{2} \mathrm{BiBr}_{9}$ : a lead-free visible light absorbing halide semiconductor with improved stability," Inorg. Chem., vol. 58, no. 7 , pp. 4446-4455, 2019.

[150] Y. Bekenstein, J. C. Dahl, J. Huang, et al., "The making and breaking of lead-free double perovskite nanocrystals of cesium silver-bismuth halide compositions," Nano Lett., vol. 18, no. 6, pp. 3502-3508, 2018.

[151] A. H. Slavney, L. Leppert, A. Saldivar-Valdes, et al., "Smallband-gap halide double perovskites," Angew. Chem., vol. 57, no. 39, pp. 12765-12770, 2018

[152] B. Vargas, E. Ramos, E. Pérez-Gutiérrez, J. C. Alonso, D. SolisIbarra, "A direct bandgap copper-antimony halide perovskite," J. Am. Chem. Soc., vol. 139, no. 27, pp. 9116-9119, 2017.

[153] T. Ben Rhaiem and H. Boughzala, "Crystal structure of a new hybrid antimony-halide-based compound for possible non- 
linear optical applications," Acta Crystallogr. E Crystallogr. Commun., vol. 71, no. 5, pp. 498-501, 2015.

[154] C. W. M. Timmermans, S. O. Cholakh, and G. Blasse, "The luminescence of $\mathrm{Cs}_{3} \mathrm{Bi}_{2} \mathrm{Cl}_{9}$ and $\mathrm{Cs}_{3} \mathrm{Sb}_{2} \mathrm{Cl}_{9}$," J. Solid State Chem., vol. 46, no. 2, pp. 222-233, 1983.

[155] A. W. Welch, L. L. Baranowski, P. Zawadzki, S. Lany, C. A. Wolden, and A. Zakutayev, " $\mathrm{CuSbSe}{ }_{2}$ photovoltaic devices with 3\% efficiency," Appl. Phys. Express, vol. 8, no. 8, p. 082301, 2015.

[156] S. Rühle, "Tabulated values of the Shockley-Queisser limit for single junction solar cells,” Sol. Energy, vol. 130, pp. 139-147, 2016.

[157] M. R. Filip, C. Verdi, and F. Giustino, "GW band structures and carrier effective masses of $\mathrm{CH}_{3} \mathrm{NH}_{3} \mathrm{Pbl}_{3}$ and hypothetical perovskites of the type $\mathrm{APbl}_{3}: \mathrm{A}=\mathrm{NH}_{4}, \mathrm{PH}_{4}, \mathrm{AsH}_{4}$, and $\mathrm{SbH}_{4}$," J. Phys. Chem. C, vol. 119, no. 45, pp. 25209-25219, 2015.

[158] L. Oesinghaus, J. Schlipf, N. Giesbrecht, et al., "Toward tailored film morphologies: the origin of crystal orientation in hybrid perovskite thin films," Adv. Mater. Interfaces, vol. 3, no. 19, p. 1600403, 2016.

[159] M. E. Kamminga, G. A. de Wijs, R. W. A. Havenith, G. R. Blake, T. T. M. Palstra, "Properties of organic-inorganic hybrids," Inorg. Chem., vol. 56, no. 14, pp. 8408-8414, 2017.

[160] J. Calabrese, N. L. Jones, R. L. Harlow, N. Herron D. L. Thorn, Y. Wang, "Preparation and characterization of layered lead halide compounds," J. Am. Chem. Soc., vol. 113, no. 6, pp. 2328-2330, 1991.

[161] C. N. Savory, A. Walsh, and D. O. Scanlon, "Can Pb-free halide double perovskites support high-efficiency solar cells?," ACS Energy Lett., vol. 1, no. 5, pp. 949-955, 2016.

[162] K. Gauthron, J.-S. Lauret, L. Doyennette, et al., “Optical spectroscopy of two-dimensional layered $\left(\mathrm{C}_{6} \mathrm{H}_{5} \mathrm{C}_{2} \mathrm{H}_{4}-\mathrm{NH}_{3}\right)_{2}-\mathrm{Pbl}_{4}$ perovskite," Opt. Express, vol. 18, no. 6, pp. 5912-5919, 2010.

[163] M. D. Smith, A. Jaffe, E. R. Dohner, A. M. Lindenberg, H. I. Karunadasa, "Structural origins of broadband emission from layered $\mathrm{Pb}-\mathrm{Br}$ hybrid perovskites," Chem. Sci., vol. 8, no. 6, pp. 4497-4504, 2017.

[164] I. C. Smith, E. T. Hoke, D. Solis-Ibarra, M. D. McGehee, H. I. Karunadasa, "A layered hybrid perovskite solar-cell absorber with enhanced moisture stability," Angew. Chem., vol. 126, no. 42, pp. 11414-11417, 2014.

[165] Z. Xiao, W. Meng, J. Wang, D. B. Mitzi, Y. Yan, “Searching for promising new perovskite-based photovoltaic absorbers: the importance of electronic dimensionality," Mater. Horizons, vol. 4, no. 2, pp. 206-216, 2017.

[166] G. Tang, Z. Xiao, H. Hosono, T. Kamiya, D. Fang, J. Hong, "Layered halide double perovskites $\mathrm{Cs}_{3+n} \mathrm{M}(\mathrm{II})_{n} \mathrm{Sb}_{2} \mathrm{X}_{9+3 n}$ ( $M=\mathrm{Sn}, \mathrm{Ge}$ ) for photovoltaic applications,"J. Phys. Chem. Lett., vol. 9, no. 1, pp. 43-48, 2018.

[167] Y.-P. Lin, S. Hu, B. Xia, et al., "Material design and optoelectronic properties of three-dimensional quadruple perovskite halides," J. Phys. Chem. Lett., vol. 10, no. 17, pp. 5219-5225, 2019.

[168] S. Hu, B. Xia Y. P. Lin, et al., " $p$-Type transparent quadruple perovskite halide conductors: fact or fiction?," Adv. Funct. Mater., vol. 30, p. 1909906, 2020.

[169] R. Sheng, A. W. Y. Ho-Baillie, S. Huang, et al., "Four-terminal tandem solar cells using $\mathrm{CH}_{3} \mathrm{NH}_{3} \mathrm{PbBr}_{3}$ by spectrum splitting," J. Phys. Chem. Lett., vol. 6, no. 19, pp. 3931-3934, 2015.
[170] N. Strevel, L. Trippel, and M. Gloeckler, "Performance characterization and superior energy yield of First Solar PV power plants in high-temperature conditions," Photovolt. Int., vol. 17, no. 3, pp. 148-154, 2012.

[171] X. Yang, Y. Chen, P. Liu, et al., "Simultaneous power conversion efficiency and stability enhancement of $\mathrm{Cs}_{2} \mathrm{AgBiBr}_{6}$ lead-free inorganic perovskite solar cell through adopting a multifunctional dye interlayer," Adv. Funct. Mater., vol. 30, no. 23, p. 2001557, 2020.

[172] J. D. Majher, M. B. Gray, T. A. Strom, P. M. Woodward, " $\mathrm{CS}_{2} \mathrm{NaBiCl}_{6}: \mathrm{Mn}^{2+}$-a new orange-red halide double perovskite phosphor," Chem. Mater., vol. 31, no. 5, pp. 1738-1744, 2019.

[173] D. Bartesaghi, A. H. Slavney, M. C. Gélvez-Rueda, et al., "Charge carrier dynamics in $\mathrm{Cs}_{2} \mathrm{AgBiBr}_{6}$ double perovskite," J. Phys. Chem. C, vol. 122, no. 9, pp. 4809-4816, 2018.

[174] P. K. Nayak, S. Mahesh, H. J. Snaith, D. Cahen, "Photovoltaic solar cell technologies: analysing the state of the art," Nat. Rev. Mater., vol. 4, no. 4, pp. 269-285, 2019.

[175] Y.-F. Li, Z.-L. Kou, J. Feng, H.-B. Sun, “Plasmon-enhanced organic and perovskite solar cells with metal nanoparticles," Nanophotonics, vol. 9, no. 10, p. 3111, 2020.

[176] R. L. Z. Hoye, L. Eyre, F. Wei, et al., "Fundamental carrier lifetime exceeding $1 \mu \mathrm{s}$ in $\mathrm{Cs}_{2} \mathrm{AgBiBr}_{6}$ double perovskite," Adv. Mater. Interfaces, vol. 5, no. 15, p. 1800464, 2018.

[177] E. M. Hutter, M. C. Gélvez-Rueda, D. Bartesaghi, F. C. Grozema, T. J. Savenije, "Band-like charge transport in $\mathrm{Cs}_{2} \mathrm{AgBiBr}_{6}$ and mixed antimony-bismuth $\mathrm{Cs}_{2} \mathrm{AgBi}_{1-x} \mathrm{Sb}_{x} \mathrm{Br} 6$ halide double perovskites," Omega Int. J. Manag. Sci., vol. 3, no. 9, pp. 11655-11662, 2018.

[178] M. Delor, A. H. Slavney, N. R. Wolf, et al., "Carrier diffusion lengths exceeding $1 \mu \mathrm{m}$ despite trap-limited transport in halide double perovskites," ACS Energy Lett., vol. 5, no. 5, pp. 1337-1345, 2020.

[179] Longo G., S. Mahesh, L. R. V. Buizza, et al., “Understanding the performance limiting factors of $\mathrm{Cs}_{2} \mathrm{AgBiBr}_{6}$ double-perovskite solar cells," ACS Energy Lett., 2020.

[180] W. Shockley and H. J. Queisser, "Detailed balance limit of efficiency of $p-n$ Junction solar cells,” J. Appl. Phys., vol. 32, no. 3, pp. 510-519, 1961.

[181] T. Kirchartz and U. Rau, "Detailed balance and reciprocity in solar cells," Phys. Status Solidi A, vol. 205, no. 12, pp. 2737-2751, 2008.

[182] Z. Liu, L. Krückemeier, B. Krogmeier, et al., "Open-circuit voltages exceeding $1.26 \mathrm{~V}$ in planar methylammonium lead iodide perovskite solar cells," ACS Energy Lett., vol. 4, no. 1, pp. 110-117, 2018.

[183] S. Mahesh, J. M. Ball, R. D. J. Oliver, et al., "Revealing the origin of voltage loss in mixed-halide perovskite solar cells," Energy Environ. Sci., vol. 13, 258-267, 2020.

[184] M. Stolterfoht, C. M. Wolff, J. A. Márquez, et al., "Visualization and suppression of interfacial recombination for highefficiency large-area pin perovskite solar cells," Nat. Energy, vol. 3, no. 10, pp. 847-854, 2018.

[185] M. Stolterfoht, C. M. Wolff, J. A. Márquez, et al., "Semitransparent perovskite solar cells with a cross-linked hole transport layer," Nano Energy, vol. 71, p. 104635, 2020.

[186] J. C. Yu, J. Sun, N. Chandrasekaran C. J. Dunn, A. S. R. Chesman, J. J. Jasieniak, "Self-assembly of broadband white-light 
emitters," J. Am. Chem. Soc., vol. 136, no. 5, pp. 1718-1721, 2014.

[187] E. R. Dohner, E. T. Hoke, and H. I. Karunadasa, "Luminescent zero-dimensional organic metal halide hybrids with near-unity quantum efficiency," Chem. Sci., vol. 9, no. 3, pp. 586-593, 2018.

[188] C. Zhou, H. Lin, Y. Tian, et al., "White-light emission from layered halide perovskites," Acc. Chem. Res., vol. 51, no. 3, pp. 619-627, 2018.

[189] H. Kanzaki, M. Ueta, and K. Kobayashi, Excitonic Processes in Solids, Berlin Heidelberg, New York, Tokyo, Springer-Verlag, 1986.

[190] M. D. Smith and H. I. Karunadasa, "Efficient and stable emission of warm-white light from lead-free halide double perovskites," Nature, vol. 563, no. 7732, pp. 541-545, 2018.

[191] J. Luo, X. Wang, S. Li, et al., "Optical properties of $\mathrm{Cs}_{2} \mathrm{NaBiCl}_{6}$," J. Lumin., vol. 17, no. 1, pp. 61-72, 1978.

[192] F. Pelle, B. Jacquier, J. P. Denis, B. Blanzat, “Discrete electronic bands in semiconductors and insulators: potential high-lightYield scintillators," Phys. Rev. Appl., vol. 3, no. 5, p. 054005 , 2015.

[193] H. Shi and M.-H. Du, "X-ray detectors for digital radiography," Phys. Med. Biol., vol. 42, no. 1, p. 1, 1997.

[194] M. J. Yaffe and J. A. Rowlands, "Amorphous and polycrystalline photoconductors for direct conversion flat panel X-ray image sensors," Sensors, vol. 11, no. 5, pp. 5112-5157, 2011.

[195] S. Kasap, J. B. Frey, G. Belev, et al., "X-ray imaging: perovskites target X-ray detection," Nat. Photonics, vol. 10, no. 5, p. 288, 2016.

[196] W. Heiss and C. Brabec, " $\mathrm{Cs}_{2} \mathrm{AgBiBr}_{6}$ single-crystal X-ray detectors with a low detection limit," Nat. Photonics, vol. 11, no. 11, pp. 726-732, 2017.

[197] W. Pan, H. Wu, J. Luo, et al., "Detection of X-ray photons by solution-processed lead halide perovskites," Nat. Photonics, vol. 9, no. 7, pp. 444-449, 2015.

[198] S. Yakunin, M. Sytnyk, D. Kriegner, et al., "Monolithic integration of hybrid perovskite single crystals with heterogenous substrate for highly sensitive X-ray imaging," Nat. Photonics, vol. 11, no. 5, p. 315, 2017.

[199] W. Wei, Y. Zhang, Q. Xu, et al., "Toxicity of organometal halide perovskite solar cells," Nat. Mater., vol. 15, no. 3, p. 247, 2016.

[200] A. Babayigit, A. Ethirajan, M. Muller, B. Conings, "Sensitive $\mathrm{X}$-ray detectors made of methylammonium lead tribromide perovskite single crystals," Nat. Photonics, vol. 10, no. 5, p. 333, 2016.

[201] Health Physics Society, HPS Development of American National Standards, 2020 [cited 2020 25th May].

[202] H. Wei, Y. Fang, P. Mulligan, et al., "Selenium direct-converter structure for static and dynamic X-ray detection in medical imaging applications," in Medical Imaging 1998: Physics of Medical Imaging, San Diego, California, International Society for Optics and Photonics, 1998.

[203] M. Thompson, S. L. R. Ellison, and R. Wood, "Harmonized guidelines for single-laboratory validation of methods of analysis (IUPAC Technical Report)," Pure Appl. Chem., vol. 74, no. 5, pp. 835-855, 2002.

[204] R. D. Evans and R. Evans, The Atomic Nucleus, New York, Toronto, London, McGRAW-HILL book company, 1955.

[205] M. Thompson, S. L. R. Ellison, and R. Wood, “Low trap-state density and long carrier diffusion in organolead trihalide perovskite single crystals," Science, vol. 347 , no. 6221 , pp. 519-522, 2015.

[206] R. D. Evans and R. Evans, "Ionic transport in hybrid lead iodide perovskite solar cells," Nat. Commun., vol. 6, p. 7497, 2015.

[207] D. Shi, V. Adinolfi, R. Comin, et al., "Perovskite-based devices: photophysical pathways in highly sensitive $\mathrm{Cs}_{2} \mathrm{AgBiBr}_{6}$ double-perovskite single-crystal X-ray detectors," Adv. Mater., vol. 30, no. 46, p. 1870353, 2018 (Adv. Mater. 46/2018).

[208] C. Eames, J. M. Frost, P. R. F. Barnes, B. C. O’Regan, A. Walsh, M. S. Islam, "Flexible X-ray imaging detector based on direct conversion in amorphous selenium," J. Vac. Sci. Technol. Vac. Surf. Films, vol. 32, no. 4, p. 041507, 2014.

[209] J. A. Steele, W. Pan, C. Martin, et al., "Printable organometallic perovskite enables large-area, low-dose X-ray imaging," Nature, vol. 550, p. 87, 2017.

[210] T.-T. Kuo, C.-M. Wu, H.-H. Lu, I. Chan, K. Wang, K.-C. Leou, "Temperature dependent energy levels of methylammonium lead iodide perovskite," Appl. Phys. Lett., vol. 106, no. 24, p. 243904, 2015.

[211] Y. C. Kim, K. H. Kim, D.-Y. Son, et al., "X-ray lithography on perovskite nanocrystals films: from patterning with anionexchange reactions to enhanced stability in air and water," $A C S$ Nano, vol. 10, no. 1, pp. 1224-1230, 2016.

[212] B. J. Foley, D. L. Marlowe, K. Sun, et al., "Synthesis and photocatalytic application of stable lead-free $\mathrm{Cs}_{2} \mathrm{AgBiBr}_{6}$ perovskite nanocrystals," Small, vol. 14, no. 11, p. 1703762 , 2018.

[213] F. Palazon, Q. A. Akkerman, M. Prato, L. Manna, "Photochemical reduction of $\mathrm{CO}_{2}$ using $\mathrm{TiO}_{2}$ : effects of organic adsorbates on $\mathrm{TiO}_{2}$ and deposition of Pd onto $\mathrm{TiO}_{2}$," ACS Appl. Mater. Interfaces, vol. 3, no. 7, pp. 2594-2600, 2011.

[214] L. Zhou, Y.-F. Xu, B.-X. Chen, D.-B. Kuang, C.-Y. Su, "Thermodynamic stability and defect chemistry of bismuthbased lead-free double perovskites," ChemSusChem, vol. 9, no. 18, pp. 2628-2633, 2016.

[215] T. Yui, A. Kan, C. Saitoh, K. Koike, T. Ibusuki, O. Ishitani, "Humidity sensors principle, mechanism, and fabrication technologies: a comprehensive review," Sensors, vol. 14, no. 5, pp. 7881-7939, 2014.

[216] Z. Xiao, W. Meng, J. Wang, Y. Yan, "Humidity sensors: a review of materials and mechanisms," Sens. Lett., vol. 3, no. 4, pp. 274-295, 2005.

[217] H. Farahani, R. Wagiran, and M. Hamidon, "Recent trends of ceramic humidity sensors development: a review," Sens. Actuat. B Chem., vol. 228, pp. 416-442, 2016.

[218] Z. Chen and C. Lu, "Highly sensitive humidity sensor based on amorphous $\mathrm{Al}_{2} \mathrm{O}_{3}$ nanotubes," J. Mater. Chem., vol. 21, no. 6, pp. 1907-1912, 2011.

[219] T. A. Blank, L. P. Eksperiandova, and K. N. Belikov, "Porous $\mathrm{ZnAl}_{2} \mathrm{O}_{4}$ spinel nanorods: high sensitivity humidity sensors," Ceram. Int., vol. 39, no. 7, pp. 7379-7386, 2013.

[220] B. Cheng, B. Tian, C. Xie, Y. Xiao, S. Lei, “Turning a disadvantage into an advantage: synthesizing high-quality organometallic halide perovskite nanosheet arrays for humidity sensors," J. Mater. Chem. C, vol. 5, no. 10, pp. 2504-2508, 2017.

[221] B. Cheng, Z. Ouyang, B. Tian, Y. Xiao, S. Lei, “Investigation of the interaction between perovskite films with moisture via 
in situ electrical resistance measurement," ACS Appl. Mater. Interfaces, vol. 7, no. 45, pp. 25113-25120, 2015.

[222] K. Ren, L. Huang, S. Yue, et al., "752 nm wing-pumped Cr: LiSrAlF/sub 6/laser,” IEEE J. Quant. Electron., vol. 28, no. 4, pp. 1188-1196, 1992.

[223] L. Hu, G. Shao, T. Jiang, et al., "Perovskites for laser and detector applications," Energy Environ. Mater., vol. 2, no. 2, pp. 146-153, 2019.

[224] S. A. Payne, W. F. Krupke, L. K. Smith, W. L. Kway, L. D. DeLoach, J. B. Tassano, "Advances in inorganic and hybrid perovskites for miniaturized lasers," Nanophotonics, vol. 9, no. 8, p. 2251, 2020.

[225] S. Das, S. Gholipour, and M. Saliba, "Perovskite nanowire lasers on low-refractive-index conductive substrate for high- $Q$ and low-threshold operation," Nanophotonics, vol. 9, no. 12, p. 3977, 2020.

[226] Z. Liu, S. Huang, J. Du, C. Wang, Y. Leng, “Low-threshold amplified spontaneous emission and lasing from colloidal nanocrystals of caesium lead halide perovskites," Nat. Commun., vol. 6, no. 1, pp. 1-9, 2015.

[227] D. I. Markina, A. P. Pushkarev, I. I. Shishkin, et al., "Highly efficient amplified stimulated emission from CdSe-CdS-ZnS quantum dot doped waveguides with two-photon infrared optical pumping," Adv. Mater., vol. 20, no. 1, pp. 69-73, 2008.

[228] S. Yakunin, L. Protesescu, F. Krieg, et al., "Advances in small perovskite-based lasers," Small Methods, vol. 1, no. 9, p. 1700163, 2017.
[229] J. J. Jasieniak, Fortunati I., Gardin S., et al., "Investigation of $\mathrm{Cr}^{3+}$ ions in $\mathrm{Cs}_{2} \mathrm{NaGaF}_{6}$ single crystals by optical spectroscopy," Solid State Commun., vol. 110, no. 9, pp. 519-524, 1999.

[230] G. A. Torchia, O. Martinez-Matos, N. M. Khaidukov, and J. O. Tocho, "Phonon coupling of $\mathrm{Cr}^{3+}$ ions in $\mathrm{Cs}_{2} \mathrm{NaAlF}_{6}$ crystals," Solid State Commun., vol. 130, nos 3-4, pp. 159-163, 2004.

[231] R. J. M. Da Fonseca, A. D. Tavares, P. S. Silva, T. Abritta, N. M. Khaidukov, "Highly efficient blue-light generation from a compact, diode-pumped femtosecond laser by use of a periodically poled KTP waveguide crystal," Opt. Lett., vol. 28, no. 20, pp. 1963-1965, 2003.

[232] G. A. Torchia, O. Martinez-Matos, N. M. Khaidukov, J. O. Tocho, "Recent developments in compact ultrafast lasers," Nature, vol. 424, no. 6950, pp. 831-838, 2003.

[233] B. Agate, E. U. Rafailov, W. Sibbett, et al., "Single-particle perovskite lasers: from material properties to cavity design," Nanophotonics, vol. 9, no. 3, p. 599, 2020.

[234] U. Keller, "Perovskite random lasers on fiber facet," Nanophotonics, vol. 9, no. 4, p. 935, 2020.

[235] A. S. Polushkin, E. Y. Tiguntseva, A. P. Pushkarev, S. V. Makarov, "High-quality sequential-vapor-deposited $\mathrm{CS}_{2} \mathrm{AgBiBr}_{6}$ thin films for lead-free perovskite solar cells," Solar RRL, vol. 2, no. 12, p. 1800217, 2018.

[236] B. Wang, L. Yang, C. Dall'Agnese, et al., "Photoactive Znchlorophyll hole transporter-sensitized lead-free $\mathrm{Cs}_{2} \mathrm{AgBiBr}_{6}$ perovskite solar cells," Solar RRL, vol. 4, pp. 1-7, 2020. 